\title{
Shear Behavior of High-strength Bolts at Elevated Temperatures: Testing and Formulation of Reduced-order Model
}

\author{
Mina Seif \\ Fire Research Division \\ Engineering Laboratory, NIST \\ Jonathan Weigand \\ Joseph Main \\ Materials and Structural Systems Division \\ Engineering Laboratory, NIST \\ Rafaela Peixoto \\ Luiz Vieira \\ Department of Structural Engineering \\ University of Campinas, Brazil
}

This publication is available free of charge from: https://doi.org/10.6028/NIST.TN.1978

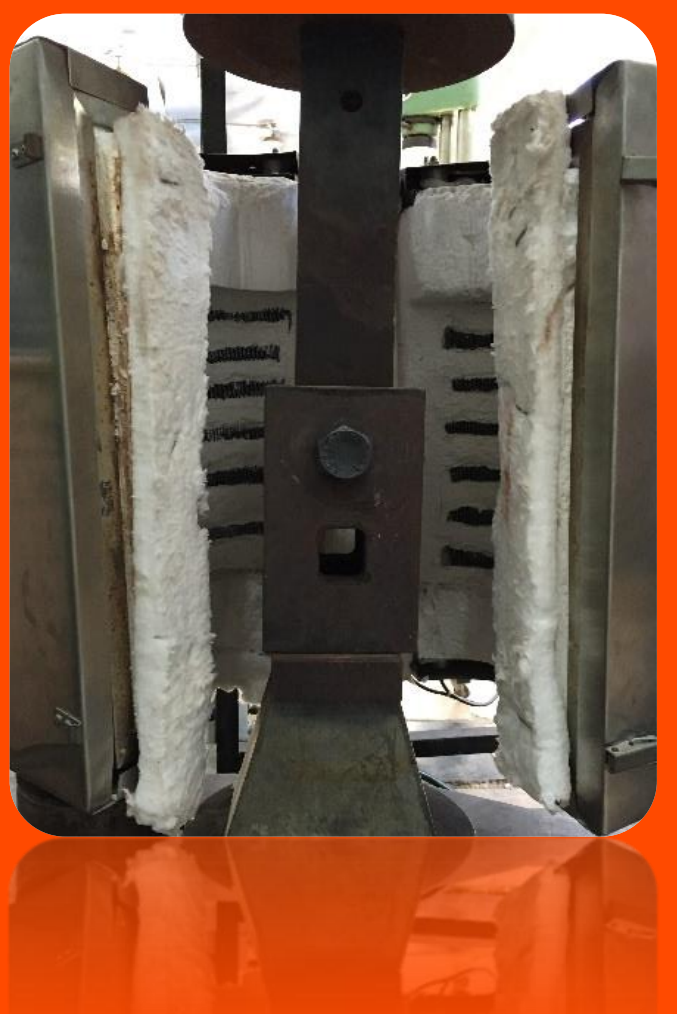

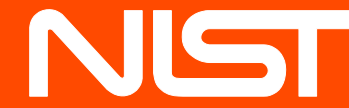

National Instifute of Standards and Technology U.S. Department of Commerce 



\title{
Shear Behavior of High-strength Bolts at Elevated Temperatures: Testing and Formulation of Reduced-order Model
}

\author{
Mina Seif \\ Fire Research Division \\ Engineering Laboratory, NIST \\ Jonathan Weigand \\ Joseph Main \\ Materials and Structural Systems Division \\ Engineering Laboratory, NIST \\ Rafaela Peixoto \\ Luiz Vieira \\ Department of Structural Engineering \\ University of Campinas, Brazil
}

This publication is available free of charge from:

https://doi.org/10.6028/NIST.TN.1978

September 2018

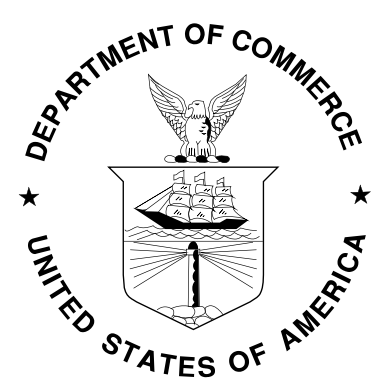

U.S. Department of Commerce Wilbur L. Ross, Jr., Secretary

National Institute of Standards and Technology Walter Copan, NIST Director and Undersecretary of Commerce for Standards and Technology 
The policy of the National Institute of Standards and Technology is to use metric units in all its published materials. Because this report is intended for the U.S. building construction industry, which uses inch-pound units, it is more practical and less confusing to use inch-pound units, in some cases, rather than metric units. However, in most cases, units are presented in both metric and the inch-pound system.

Certain commercial entities, equipment, products, or materials are identified in this document in order to describe a procedure or concept adequately. Such identification is not intended to imply recommendation or endorsement by the National Institute of

Standards and Technology, nor is it intended to imply that the entities, products, materials, or equipment are necessarily the best available for the purpose.

Another policy of the National Institute of Standards and Technology is to include statements of uncertainty with all NIST measurements. In this document, however, some measurements of authors outside of NIST are presented,

for which uncertainties were not reported and are unknown.

National Institute of Standards and Technology Technical Note 1978

Natl. Inst. Stand. Technol. Tech. Note 1978, 92 pages (September 2018)

CODEN: NTNOEF

This publication is available free of charge from: https://doi.org/10.6028/NIST.TN.1978 


\section{ABstRACt}

The behavior of high-strength structural steel bolts at elevated temperatures, especially under shear loading, is very limited in the literature. This report presents the test results, as well as a reduced order modeling approach of high-strength structural bolts subject to double-shear loading at elevated temperatures. First, it presents results from a recently conducted experimental study. The parameters varied between tests included the bolt grade, bolt diameter, and temperature. Bolt grades A325 and A490 were tested. For each bolt grade, three different diameters were tested (19 mm (3/4 in), $22 \mathrm{~mm}(7 / 8 \mathrm{in})$, and $25.4 \mathrm{~mm}(1 \mathrm{in}))$ at five different temperatures $\left(20^{\circ} \mathrm{C}, 200{ }^{\circ} \mathrm{C}\right.$, $400{ }^{\circ} \mathrm{C}, 500{ }^{\circ} \mathrm{C}$, and $600{ }^{\circ} \mathrm{C}$ ). At least three tests were conducted for each combination of parameters. Degradations in the mechanical and material properties including stiffness, strength, and deformation at fracture, are characterized and presented. The results from these experiments fill a critical knowledge gap currently present in the literature regarding the behavior of highstrength structural bolts under shear loading at elevated temperatures. These data will ultimately provide a thorough understanding of the overall behavior of structural steel systems under realistic fire loading by clarifying the (i) shear behavior of high-strength structural steel bolts at elevated temperatures, and (ii) degradation in the mechanical and material properties of high-strength steel bolts with increasing temperatures.

The report then describes the formulation of an empirical component-based model for shear behavior of high-strength bolts developed based on the data from the double-shear testing of highstrength bolts at elevated temperatures. Such component-based models are computationally efficient, facilitating large building-level analyses where high-fidelity modeling of the bolts would be infeasible. The component-based model is shown to accurately account for the temperaturedependent degradation of bolt shear strength and stiffness, while also providing the capability to model load reversal and bolt-shear rupture.

Keywords: Shear stress; stress-strain relationship; fire loading; high-strength structural bolts; retained yield; elevated temperatures; steel column; finite element; inelastic buckling; thermal strain; fracture; steel connection 
This page intentionally left blank. 


\section{Preface}

The division of responsibility for the work presented in this report has been as follows. The work initiated as a collaboration between Mina Seif at NIST and Luiz Vieira at UniCamp. Rafaela Peixoto, a graduate researcher at UniCamp, worked under the supervision of Luiz Vieira while in Brazil, and joined NIST as a guest researcher in 2016, where she worked under the supervision of Mina Seif. The tested bolts were purchased from the US, and shipped to Brazil for testing. Rafaela Peixoto and Luiz Vieira, along with the technicians at the Structures Laboratory at UNICAMP, Campinas, Brazil (LabDES) conducted the experiments, and authored Chapter 2 along with Mina Seif. William Luecke lead the chemical analysis of the bolts specimens presented in Chapter 2. Jonathan Weigand was primarily responsible for Chapter 3 where a cleaner version of the experimental results is presented after uncoupling the effects of plate bearing deformations. Jonathan Weigand also lead the development of the component-based (reduced-order) modeling approach presented in Chapter 4 with the help of Joseph Main, Mina Seif, and Rafaela Peixoto during her visit to NIST in 2016. Finally, Mina Seif served as the primary editor for this document, developing the overall outline and coordinating the contributions from the various co-authors.

The authors would like to thank the National Institute of Standards and Technology (NIST), the Coordination for the Improvement of Higher Education Personnel (CAPES), and the National Council for Scientific and Technological Development (CNPq) for providing testing materials and funding for this research. The authors would also like to thank the technicians in the Structures Laboratory at UNICAMP, Campinas, Brazil (LabDES), who contributed to the bolt double-shear testing. 
This page intentionally left blank. 


\section{TABLE OF CONTENTS}

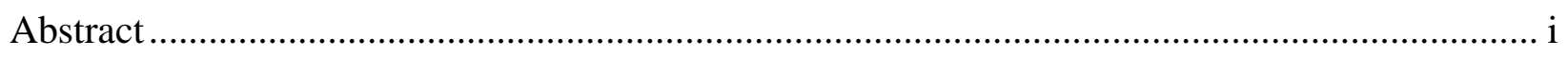

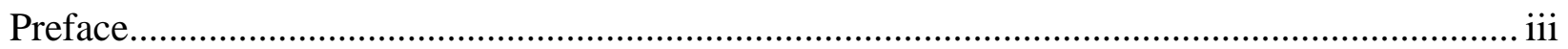

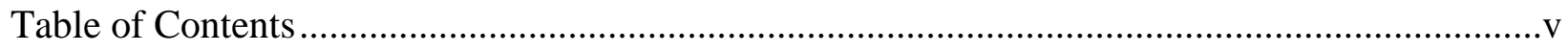

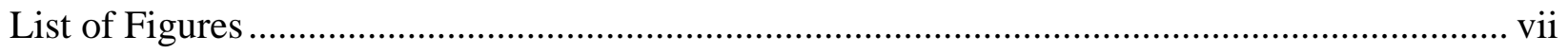

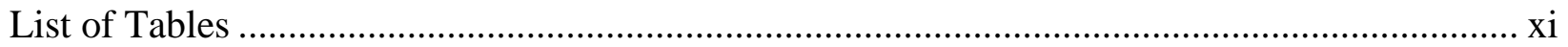

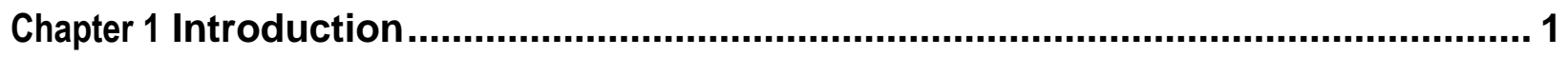

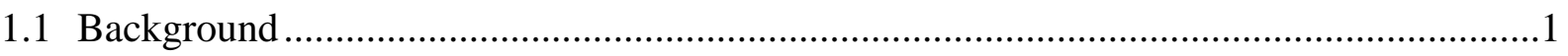

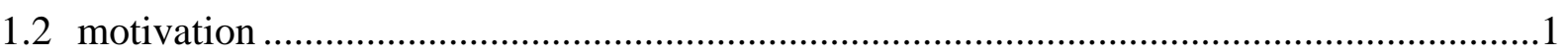

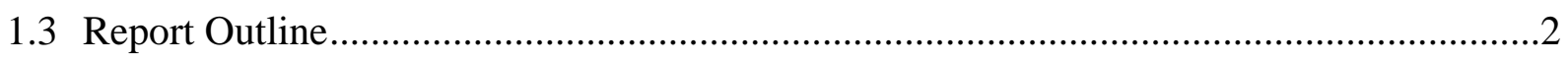

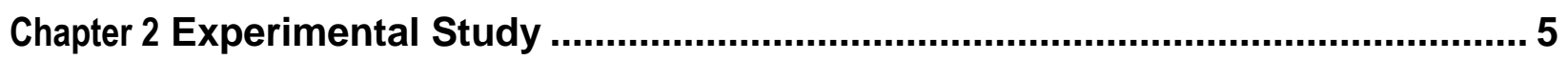

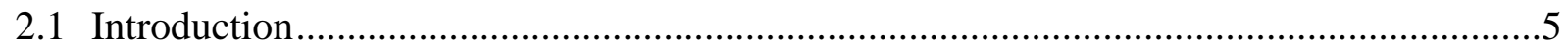

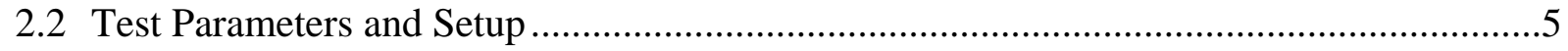

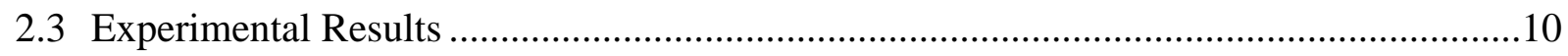

2.3.1 19 mm (3/4 in) Diameter Bolts............................................................ 11

2.3.2 $22 \mathrm{~mm}$ (7/8 in) Diameter Bolts..............................................................

2.3.3 $25 \mathrm{~mm}$ (1 in) Diameter Bolt .................................................................19

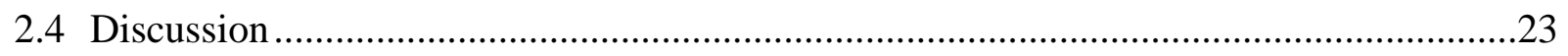

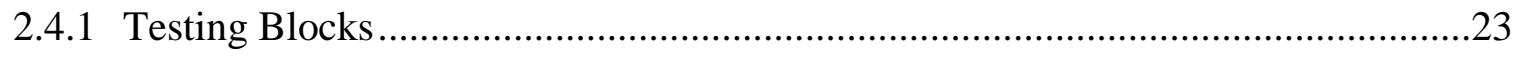

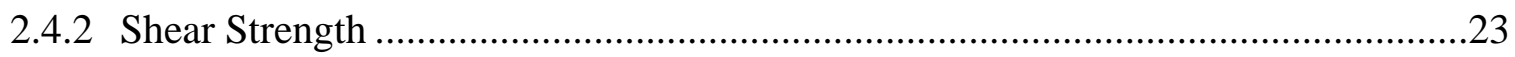

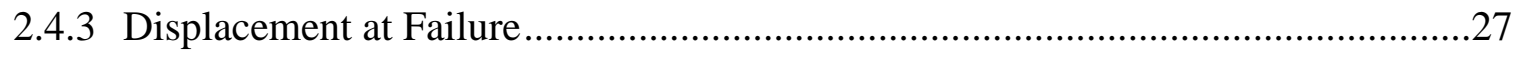

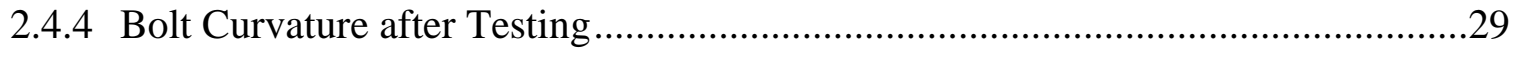

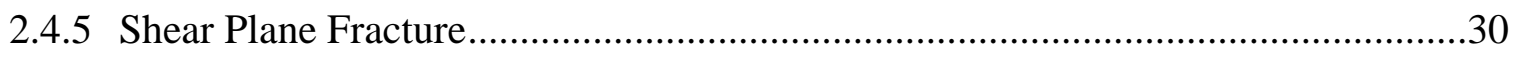




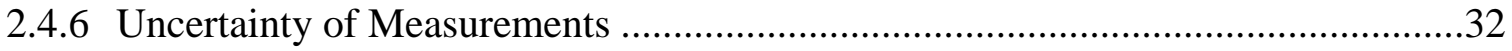

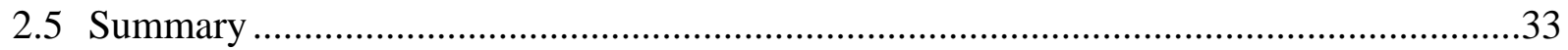

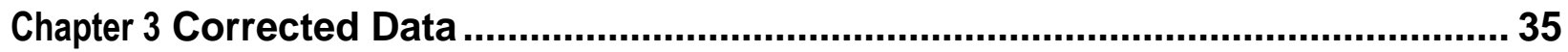

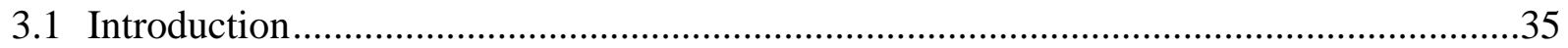

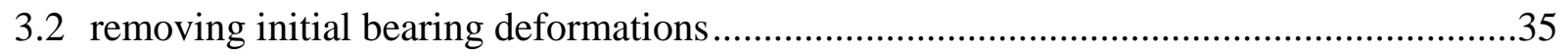

3.3 Summary, Conclusions, and Limitations ...........................................................44

Chapter 4 Component-Based Modelling Approach............................................... 45

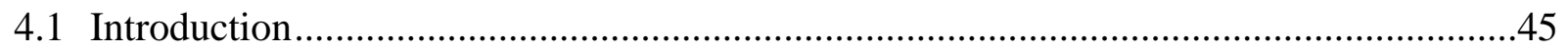

4.2 Calculation of Equation Parameters.....................................................................47

4.3 Calculation of Semi-Empirical Bolt Mechanical Properties.........................................52

4.4 Application of Modeling Approach to Smaller-Diameter Bolts .....................................58

4.5 Consolidation and Simplification of Component-Based Model ...................................62

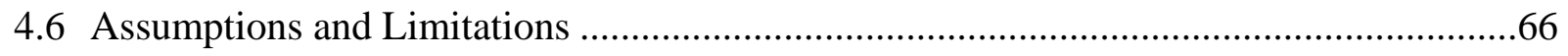

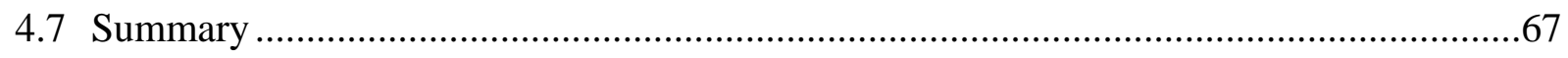

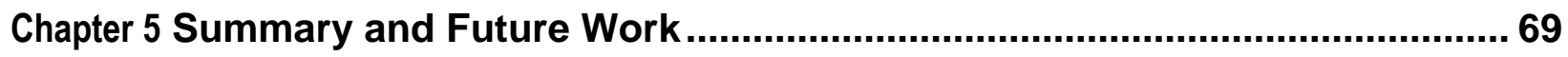

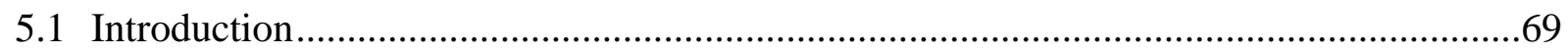

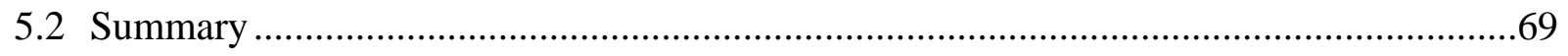

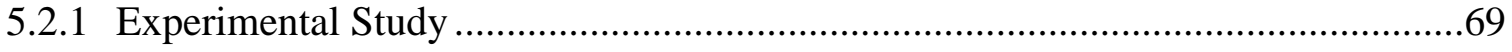

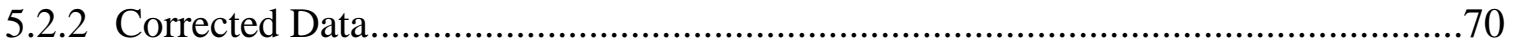

5.2.3 Component-Based Modeling Approach .................................................... 70

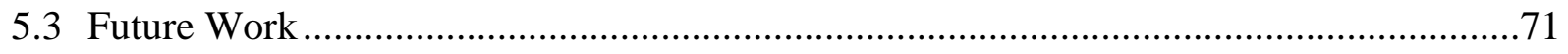

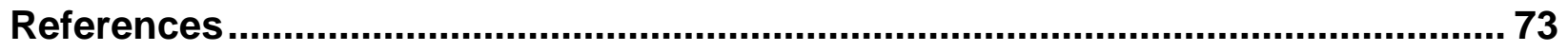




\section{LIST OF FIGURES}

Figure 2-1 Test block: (a) photo of actual setup, (b) and (c) dimensions ...................................... 6

Figure 2-2 Test setup: (a) load path, (b) furnace, (c) location of thermocouples, and (d) schematic location of thermocouples ............................................................................................ 8

Figure 2-3 Load versus displacement for the $19 \mathrm{~mm}$ (3/4 in) A325 bolts .................................... 12

Figure 2-4 Load versus displacement for the $19 \mathrm{~mm}$ (3/4 in) A490 bolts ..................................... 13

Figure 2-5 Load versus displacement for the $22 \mathrm{~mm}$ (7/8 in) A325 bolts .................................... 16

Figure 2-6 Load versus displacement for the $22 \mathrm{~mm}$ (7/8 in) A490 bolts ................................... 17

Figure 2-7 Load versus displacement for the $25 \mathrm{~mm}$ ( 1 in) A325 bolts ....................................... 20

Figure 2-8 Load versus displacement for the $25 \mathrm{~mm}$ (1 in) A490 bolts ...................................... 21

Figure 2-9 Failure load versus temperature for the A325 bolts ................................................... 24

Figure 2-10 Failure load versus temperature for the A490 bolts ................................................ 24

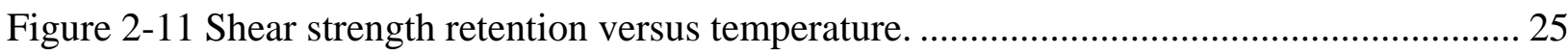

Figure 2-12 Comparison of different shear retention factors for (a) A325 bolts, and (b) A490 bolts.

Figure 2-13 Displacement at failure versus temperature for: (a) $19 \mathrm{~mm}$ (3/4 in) bolts, (b) $22 \mathrm{~mm}$

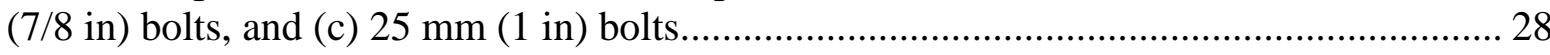

Figure 2-14 Curvature: (a) amplified deformed shape before complete bolt shear failure, (b) zoom in the bolt, and (c) photo showing bolt's curvature after testing................................ 29

Figure 2-15 Curvature versus order of each experiment in the sequence of experiments............ 30

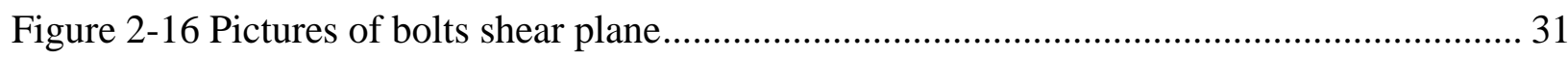

Figure 3-1: (a) Data from an individual bolt load-deformation response, (b) slope of bolt loaddeformation response, and (c) selected data to be used in fitting the parameters of the component-based model.

Figure 3-2: Data used in parameter fitting for $25 \mathrm{~mm}$ ( 1 in) diameter (a) A325 bolt specimens

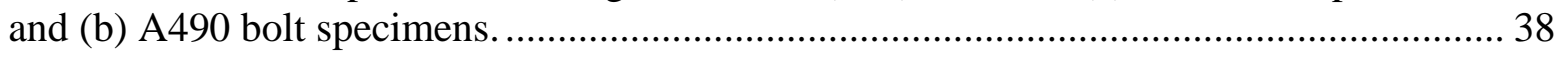


Figure 3-3: Portion of data lying above the linear regression line for $19 \mathrm{~mm}$ (3/4 in) diameter (a) A325 bolt specimens and (b) A490 bolt specimens.

Figure 3-4: Portion of data lying above the linear regression line for $22 \mathrm{~mm}$ (7/8 in) diameter (a) A325 bolt specimens and (b) A490 bolt specimens.

Figure 3-5: Experimental data (with initial bearing deformations removed) for $19 \mathrm{~mm}$ (3/4 in) diameter (a) A325 bolts and (b) A490 bolts.

Figure 3-6: Experimental data (with initial bearing deformations removed) for $22 \mathrm{~mm}$ (7/8 in) diameter (a) A325 bolts and (b) A490 bolts.

Figure 4-1: Schematic representation of spring assembly used to model bolt double-shear test assembly.

Figure 4-2: First-order approximation of Richard Equation parameters.

Figure 4-3: Values of fitted curve parameters for $25 \mathrm{~mm}$ (1 in) diameter A325 bolts as a function of temperature: (a) initial stiffness $\boldsymbol{k i T}$, (b) plastic stiffness $\boldsymbol{k p} \boldsymbol{T}$, (c) reference load $\boldsymbol{r n} \boldsymbol{T}$, and (d) shape parameter $\boldsymbol{n} \boldsymbol{T}$ (unitless)...

Figure 4-4: Values of fitted curve parameters for $25 \mathrm{~mm}$ (1 in) diameter A490 bolts as a function of temperature: (a) initial stiffness $\boldsymbol{k i} \boldsymbol{T}$, (b) plastic stiffness $\boldsymbol{k p} \boldsymbol{T}$, (c) reference load $\boldsymbol{r n} \boldsymbol{T}$, and (d) shape parameter $\boldsymbol{n T}$ (unitless).

Figure 4-5: Comparison between Eq. (4-1) using fitted curve parameters and experimental data for $25 \mathrm{~mm}$ (1 in) diameter (a) A325 bolts and (b) A490 bolts. 52

Figure 4-6: Ultimate tensile strength, fitted using Eq. (4-6), for $25 \mathrm{~mm}$ (1 in) diameter (a) A325 bolts and (b) A490 bolts. Hatched area corresponds to $95 \%$ confidence interval.

Figure 4-7: Modulus of elasticity, fitted using Eq. (4-14), for $25 \mathrm{~mm}$ (1 in) diameter (a) A325 bolts and (b) A490 bolts. Hatched area corresponds to $95 \%$ confidence interval............... 56

Figure 4-8: Fitted ratio of plastic stiffness to initial stiffness for $25 \mathrm{~mm}$ (1 in) diameter (a) A325 bolts and (b) A490 bolts. Hatched area corresponds to $95 \%$ confidence interval. 57

Figure 4-9: Fitted shape parameter for $25 \mathrm{~mm}$ (1 in) diameter (a) A325 bolts and (b) A490 bolts. Hatched area corresponds to $95 \%$ confidence interval. 57

Figure 4-10: Comparison of the component-based model predicted behavior to the experimental data for $25 \mathrm{~mm}$ ( 1 in) diameter (a) A325 bolts and (b) A490 bolts. 58

Figure 4-11: Effect of accumulated bearing deformations on $19 \mathrm{~mm}(3 / 4 \mathrm{in})$ diameter bolt tests. 
Figure 4-12: (a) comparison of individually fitted retained ultimate tensile strength curves for $25 \mathrm{~mm}$ (1 in) diameter grade A325 and A490 bolts and (b) aggregated ultimate tensile strength, fitted using Eq. (4-6).

Figure 4-13: (a) comparison of individually fitted retained modulus of elasticity curves for 25 mm (1 in) diameter grade A325 and A490 bolts and (b) aggregated modulus of elasticity, fitted using Eq. (4-14).

Figure 4-14: Aggregated 25 mm (1 in) diameter grade A325 and A490 bolt data for (a) shape parameter, and (b) ratio of plastic stiffness to initial stiffness..

Figure 4-15: Fitted shape parameter for $25 \mathrm{~mm}$ (1 in) diameter (a) A325 bolts and (b) A490 bolts. Hatched area corresponds to $95 \%$ confidence interval. 
This page intentionally left blank. 


\section{LIST OF TABLES}

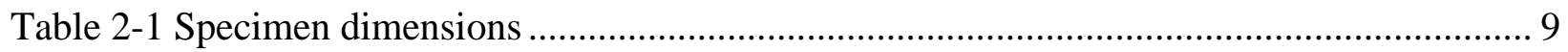

Table 2-2 Chemical Analysis of tested bolts samples* ................................................... 10

Table 2-3 Results for $19 \mathrm{~mm}$ (3/4 in) bolt diameter experiments........................................... 14

Table 2-4 Results for $22 \mathrm{~mm}$ (7/8 in) bolt diameter experiments ....................................... 18

Table 2-5 Results for $25 \mathrm{~mm}$ ( 1 in) bolt diameter experiments .............................................. 22

Table 2-6 Uncertainty in the experimental data measurements ......................................... 33

Table 4-1: Summary of measured and fitted curve parameters for bolt shear data. ................... 49

Table 4-2: Summary of fitted curve parameters for bolt mechanical properties...................... 54

Table 4-3: Summary of measured and predicted double-shear capacities for $19 \mathrm{~mm}$ (3/4 in) and

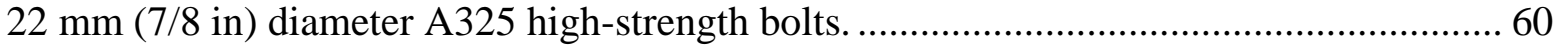

Table 4-4: Summary of measured and predicted double-shear capacities for $19 \mathrm{~mm} \mathrm{(3/4} \mathrm{in)} \mathrm{and}$ $22 \mathrm{~mm}(7 / 8 \mathrm{in})$ diameter A490 high-strength bolts. ................................................. 61 
This page intentionally left blank. 


\section{Chapter 1 \\ INTRODUCTION}

\section{$1.1 \quad$ BACKGROUND}

Structural fire safety has historically been accomplished through hourly fire endurance ratings specified by the applicable building codes, and evaluated via qualification testing on individual members or small assemblies. More recently, the National Institute of Standards and Technology (NIST) has recognized the need for performance-based approaches to structural fire safety, rather than the traditional prescriptive approach. Transitioning toward performance-based fire specifications is essential to modernizing building-code-based consideration of fire hazards, and would place fire hazards as a risk that structures are designed to resist. Similar performance-based methodologies have already proven effective in earthquake engineering, both as a means to design structures to achieve their target performance criteria given potential hazard levels and as an effective tool to facilitate communication between engineers and building owners regarding the cost-efficiency of designing more reliable structures.

While the recently commissioned structural portion of the National Fire Research Laboratory (NFRL) will support the development of performance-based design approaches through full-scale testing, the imminent availability of full-scale validation testing makes this a critical time for development of predictive modeling and analysis approaches. Finite-element or other analytical models require accurate constitutive models for the behavior of the steels in the beams, columns, and connections, rather than just the typical summary data such as yield and tensile strengths. These models should be based on validated data, and that data should be available for long-term review.

\subsection{MOTIVATION}

Fire effects on steel structures can produce failures of connections, including fracture of connection plates, shear rupture of bolts, and bolt tearout failure of beam webs or connection plates. Seif et al. (2013, 2016a) examined such failure modes for typical shear and moment connections at elevated temperatures, based on explicit high-fidelity finite element analyses. Whether such failures occur depends not only on the loads that can be sustained by the various components of a connection, but also on the deformations that can be accommodated prior to fracture, since fire-induced forces can result from the restraint of thermal expansion or contraction. 
The ductility of steel components plays an important role in the performance of connections at elevated temperatures. Sufficient ductility can potentially allow redistribution of loads after failure of one or more connection components.

Thus, a key issue in evaluating the response of structural systems to fire effects is the proper representation of material behavior, including fracture, at elevated temperatures. Temperature-dependent material behavior of structural plate materials (such as ASTM A36 (2014a), ASTM A572 (2013a), and ASTMA992(2011a)), has been studied both experimentally and numerically (e.g., Seif et al. (2016b, 2016c), and Hu et al. (2009)). However, the behavior of high-strength structural bolts at elevated temperatures, especially under shear loading, is not well established in the literature. The current available reliable experimental data is very limited, thus, has made proper characterization of the temperature-dependent material behavior of bolts very difficult, forcing researchers to use alternative approximations. Seif et al. (2016c) proposed a simple multi-linear representation of the temperature-dependent true stress-strain behavior for high-strength bolts.

Kodur et al. (2012) studied the influence of elevated temperatures on the thermal and mechanical properties of steel bolts, including a limited number of experiments on bolts under tensile loading at different temperatures. Yu (2006) studied the effect of high temperatures on bolted connections. His work included a few experiments on bolts under shear loading, and he noted that if a bolt is not heated to a temperature in excess of its tempering temperature, its shear resistance is not appreciably affected. However, these experiments were limited to a small set of data, with excessive bearing deformations embedded in the results. Thus, a more comprehensive set of test data was needed in order to provide a fuller understanding of the behavior of high-strength bolts under shear loading at elevated temperatures, which will ultimately lead to a fuller understanding of the overall behavior of structural steel systems under realistic fire loading. The following chapters describe the details of this experimental study along with the results, implementations, and discussions. They also describe how these results were used to formulate an empirical component-based model for high-strength bolts under double-shear loading at elevated temperatures.

\subsection{REPORT OUTLINE}

This report presents the behavior of high-strength structural bolts at elevated temperatures. It presents the experimental results of bolts with different strengths (types), and different diameters, tested at different elevated temperatures. It shows how the experimental results were used to 
develop component-based reduced-order computationally-efficient models that are capable capturing the bolts' behavior. The outline of the report is as follows:

- Chapter 2 presents the raw data from the experiments conducted on the high-strength bolts at elevated temperatures under double-shear loading. It describes in detail the test setup, along with the varied parameters, and the experimental results. It also presents a discussion on how the results compare to the design codes, and to other data available in the literature.

- Chapter 3 provides a "corrected set of data", where the bending effects due to the bearing deformations in the testing blocks are uncoupled from the overall behavior of the bolts. The resulting curves represent the pure shear load versus shear displacement of the different high-strength bolts at elevated temperatures.

- Chapter 4 shows how the data presented in Chapter 2 and Chapter 3 is used to develop a reduced-order component-based modeling approach that enables efficient and accurate modeling of high-strength bolts under fire conditions.

- Finally, Chapter 5 provides a summary and main conclusions of the work presented throughout the report. 
This page intentionally left blank. 


\section{Chapter 2 \\ EXPERIMENTAL STUDY}

\section{$2.1 \quad$ INTRODUCTION}

This chapter presents results of the experimental study conducted on high-strength structural steel bolts with different strengths, and different diameters, at elevated temperatures, while loaded in a double-shear setup. The test parameters and experimental setup are explained and the test results are presented and discussed. The experimental results presented in this chapter are the basis of the development of the reduced-order (component-based) models, which is presented in subsequent chapters.

\section{$2.2 \quad$ TEST PARAMETERS AND SETUP}

The parameters varied between tests included the bolt grade, bolt diameter, and temperature. Bolt grades ASTM A325 (2015) - specified nominal yield strength of $635 \mathrm{MPa}$ (92 ksi) and specified nominal ultimate strength of $825 \mathrm{MPa}(120 \mathrm{ksi})$ - and ASTM A490 ((2015) - specified nominal yield strength of $895 \mathrm{MPa}(130 \mathrm{ksi})$ and specified nominal ultimate strength of $1035 \mathrm{MPa}(150 \mathrm{ksi})$ - were tested. For each bolt grade, three different diameters were tested (19 mm (3/4 in), $22 \mathrm{~mm}$ (7/8 in), and $25.4 \mathrm{~mm}(1 \mathrm{in})$ ) at five different temperatures $\left(20^{\circ} \mathrm{C}, 200^{\circ} \mathrm{C}, 400{ }^{\circ} \mathrm{C}, 500{ }^{\circ} \mathrm{C}\right.$, and $600^{\circ} \mathrm{C}$ ). At least three tests were conducted for each combination of parameters. Degradations in the mechanical and material properties including stiffness, strength, and deformation at fracture, were documented and are presented in the following sections.

All specimens were tested in a specially manufactured testing blocks set, heated to the specified temperature, and then subjected to double-shear loading. The testing blocks were designed to resist loads much higher than the bolts' nominal shear capacity, and were reused for multiple tests. Two sets of testing blocks were manufactured: one set for the $19 \mathrm{~mm}(3 / 4 \mathrm{in})$ and $22 \mathrm{~mm}(7 / 8 \mathrm{in})$ diameter bolts, and one set for the $25 \mathrm{~mm}$ ( 1 in) diameter bolts. The first set was manufactured using ASTM A36 steel (2014a) - yield strength of $250 \mathrm{MPa}(36 \mathrm{ksi}$ ) and ultimate strength of 400 $\mathrm{MPa}(58 \mathrm{ksi}$ ), and the second was manufactured using the heat treated AISI/SAE 8640 alloy steel (2013b) - yield strength of $560 \mathrm{MPa}(81 \mathrm{ksi})$ and ultimate strength of $750 \mathrm{MPa}$ (109 ksi). For the $19 \mathrm{~mm}(3 / 4 \mathrm{in})$ and $22 \mathrm{~mm}$ (7/8 in) bolt diameter tests, the same set of testing blocks was used and only the hole necessary to pass the bolt was enlarged after all the $19 \mathrm{~mm}$ (3/4 in) bolts were tested. 
The configuration and dimensions of the testing blocks are shown in Fig. 2-1. Refer to Section 2.4.1 for further discussion on the blocks.

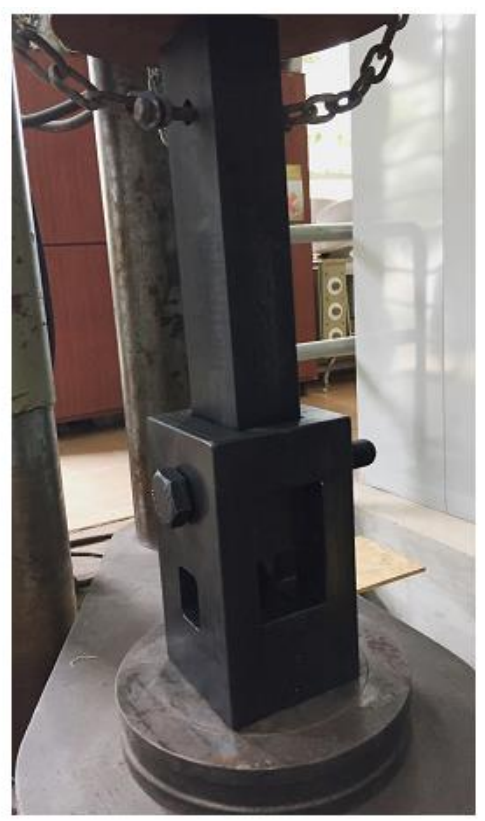

(a)

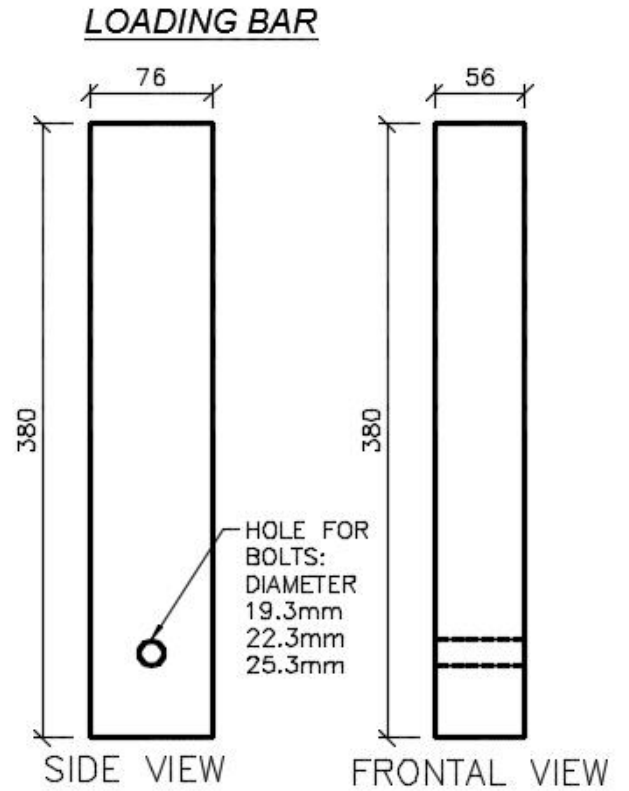

(b)
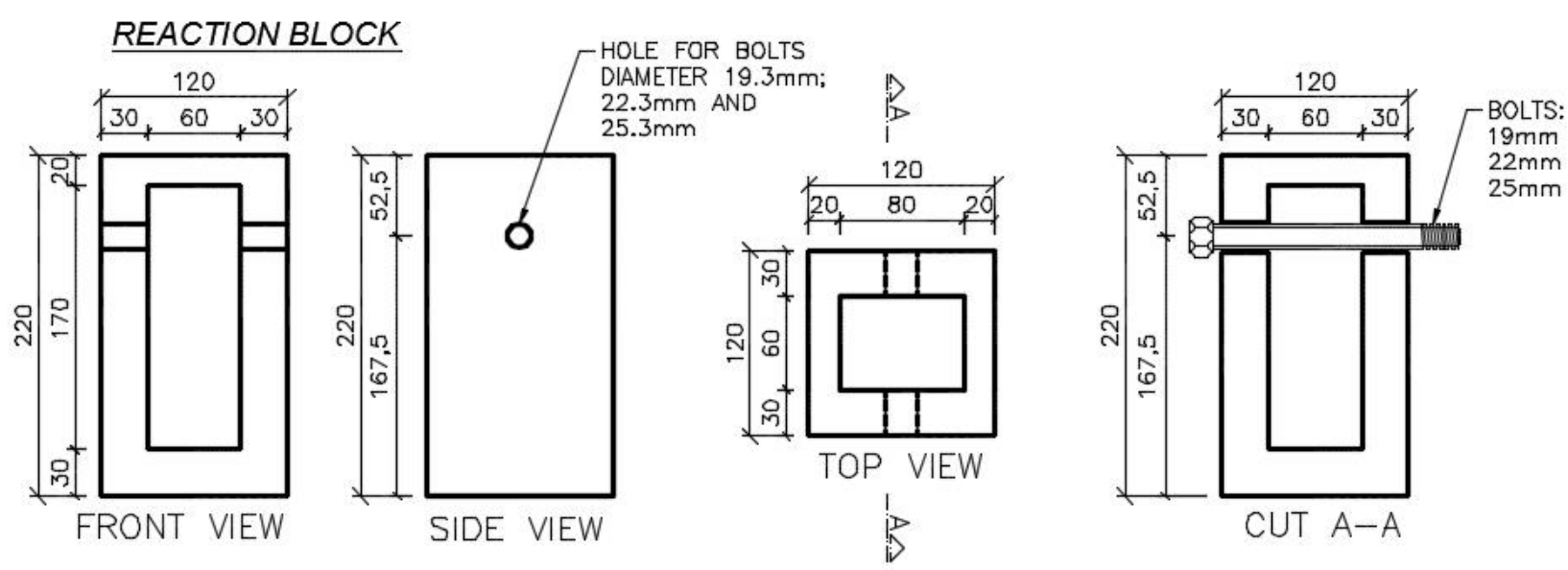

(c)

Figure 2-1 Test block: (a) photo of actual setup, (b) and (c) dimensions

All dimensions are in $\mathbf{~ m m ~}(1 \mathrm{in}=25.4 \mathrm{~mm})$

The specified temperature for each test was reached by placing the entire test setup in an electric furnace which was capable of achieving a maximum temperature of $1200^{\circ} \mathrm{C}$. A rate of temperature loading of $20^{\circ} \mathrm{C} / \mathrm{min}$ was used for all tests and the entire test setup was free to expand. One 
thermocouple type $\mathrm{K}$ was placed inside the furnace to control the furnace temperature and three additional thermocouples type $\mathrm{K}$ were strategically placed on the bolt specimens (touching the bolt surface) to ensure that the target temperature had been achieved in the bolt at the initiation of the shear loading. The shear loading on the bolt specimen was applied using a universal testing machine, which had a capacity of $980.7 \mathrm{kN}$ (220.5 kip). Compression loading was applied at a rate of approximately $60 \mathrm{kN} / \mathrm{min}$ (13.49 kip/min) throughout the entire test. The loading was continued until the bolt ruptured in double-shear. The displacement of the universal testing machine was monitored using an external linear variable displacement transducer (LVDT), which had a range of $100 \mathrm{~mm}$ (3.94 in) and a precision of 1/1000 mm. Double-shear was achieved by applying the load through the middle block, shearing the bolt through two shear-planes, as shown in Fig. 2-2(a). Fig. 2-2(b) shows the furnace enclosing the test setup. Fig. 2-2(c) shows the location of the three additional thermocouples: one in the bottom, and one on each side of the tested bolt. All the three thermocouples were touching the bolt surface until shear failure of the bolt occurred. Throughout each test, temperature, force and displacement were recorded. The results are presented in the following section. 


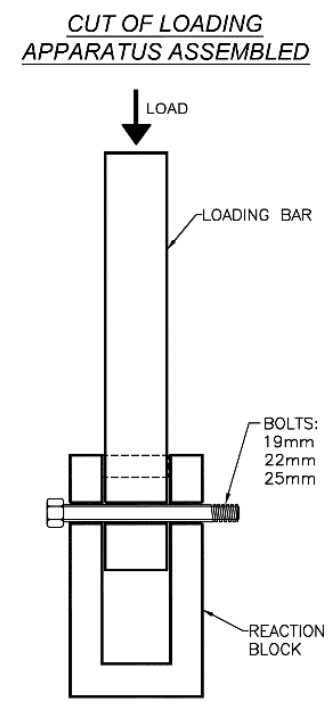

(a)

(b)

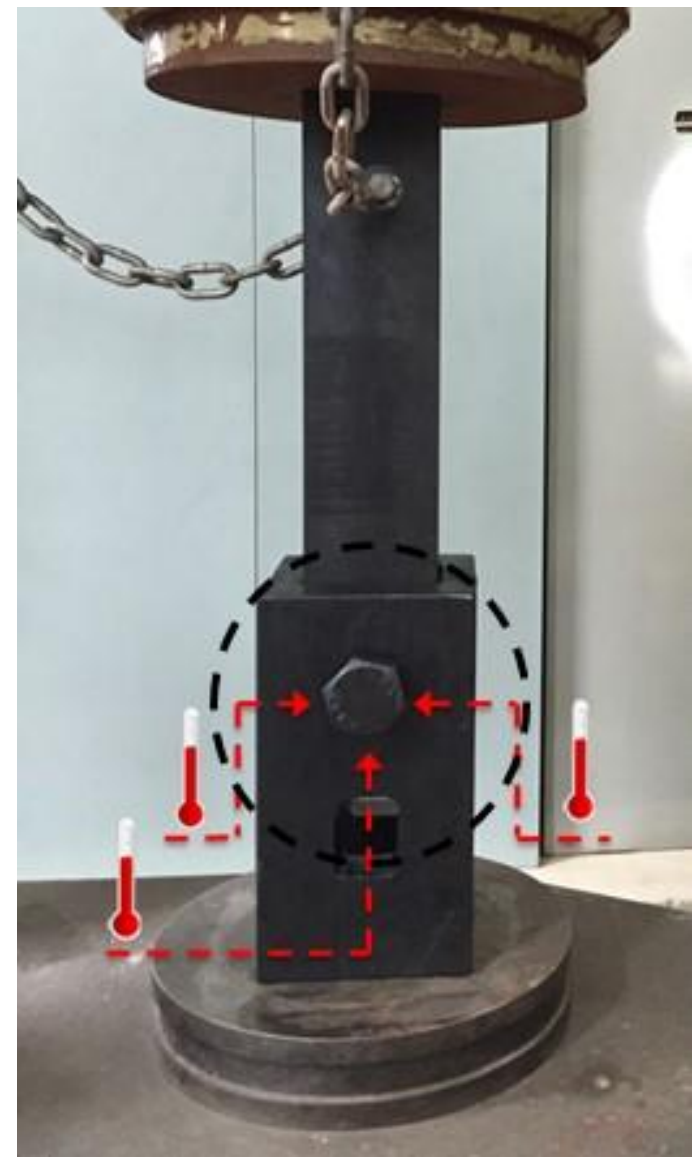

(c)

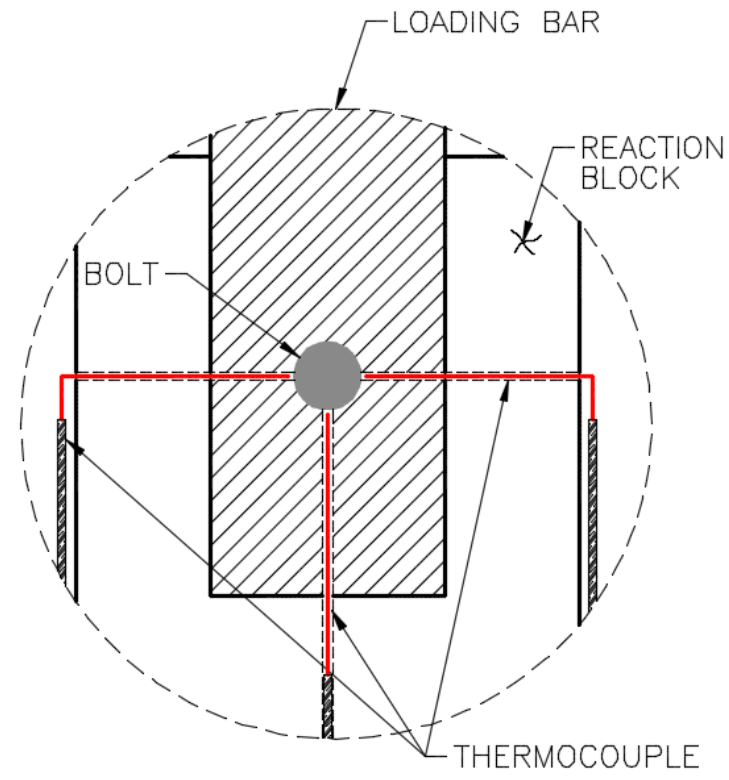

(d)

Figure 2-2 Test setup: (a) load path, (b) furnace, (c) location of thermocouples, and (d) schematic location of thermocouples 
For the ambient temperature tests, when the furnace was not required, the bolts were tested at their entire length. The dimensions of the tested bolts are given in Table 2-1. For the elevated temperature tests, due to the limited space within the furnace, only a $165 \mathrm{~mm}$ (6.5 in) length of the bolt was tested, and the excess length of the bolt was cut off. For all tests, both shear planes (within the $120 \mathrm{~mm}$ (4.7 in) width of block set) passed through the unthreaded portion of the bolt, and no thread-effect was tested or considered in this study. It is common practice to have the load path on bolts in connections pass through only unthreaded portions of the bolt.

Table 2-1 Specimen dimensions

\begin{tabular}{llc}
\hline $\begin{array}{c}\text { Steel } \\
\text { Grade }\end{array}$ & $\begin{array}{c}\text { Diameter } \\
\text { mm (in) }\end{array}$ & $\begin{array}{c}\text { Length } \\
\text { mm (in) }\end{array}$ \\
\hline \multirow{2}{*}{ A325 } & $19(3 / 4)$ & $203.2(8.0)$ \\
& $22(7 / 8)$ & $165.1(6.5)$ \\
& $25(1.0)$ & $203.2(8.0)$ \\
A490 & $19(3 / 4)$ & $215.9(8.5)$ \\
& $22(7 / 8)$ & $165.1(6.5)$ \\
\hline
\end{tabular}

Each test was assigned a unique name. The nomenclature includes the bolt, diameter, type, test temperature, and specimen number. For example, test "19A325T20-1". The first two digits represent the bolt diameter (19 $\mathrm{mm}(3 / 4 \mathrm{in}), 22 \mathrm{~mm}$ (7/8 in), or $25.4 \mathrm{~mm}(1 \mathrm{in}))$, the next four characters represent the bolt type (A325 or A490), followed by the letter $\mathrm{T}$ and the temperature at which that bolt was tested $\left(\mathrm{T} 20=20^{\circ} \mathrm{C}\right.$ (Ambient Temperature); $\mathrm{T} 200=200{ }^{\circ} \mathrm{C}$; $\mathrm{T} 400=400{ }^{\circ} \mathrm{C}$; $\mathrm{T} 500=500^{\circ} \mathrm{C} ; \mathrm{T} 600=600^{\circ} \mathrm{C}$ ), and lastly, the number of the specimen.

A commercial laboratory analyzed the chemical composition of three of the A325 (one of each bolt diameter size) and three of the A490 bolts (one of each bolt diameter size) using the ASTM E1019 (2011b) and ASTM E415 (2017) standard testing methods. Table 2-2 summarizes both the specified and as-analyzed chemistry. The chemistry of both sets of bolts corresponds to Type 1 . 
Table 2-2 Chemical Analysis of tested bolts samples*

\begin{tabular}{|c|c|c|c|c|c|c|c|c|}
\hline Type & \multicolumn{3}{|c|}{ A325 } & \multicolumn{3}{|c|}{ A490 } & \multirow{2}{*}{$\begin{array}{l}\text { A325 Type } 1 \\
\text { Specification }\end{array}$} & \multirow{2}{*}{$\begin{array}{l}\text { A490 Type } 1 \\
\text { Specification }\end{array}$} \\
\hline $\begin{array}{c}D(\mathrm{~mm} \\
\text { (in) })\end{array}$ & $25(1)$ & $22(7 / 8)$ & $19(3 / 4)$ & $25(1)$ & $22(7 / 8)$ & $19(3 / 4)$ & & \\
\hline Element & \multicolumn{8}{|c|}{ Mass fraction } \\
\hline $\mathbf{C}$ & 0.0042 & 0.0044 & 0.0038 & 0.0033 & 0.0031 & 0.004 & 0.0030 to 0.0052 & 0.0030 to 0.0048 \\
\hline Mn & 0.0098 & 0.0096 & 0.0084 & 0.0087 & 0.009 & 0.0092 & $0.0060 \mathrm{~min}$ & $0.0060 \mathrm{~min}$ \\
\hline $\mathbf{P}$ & 0.00008 & 0.00008 & 0.00012 & 0.0001 & 0.00011 & 0.00008 & $0.00035 \mathrm{max}$ & $0.00035 \mathrm{max}$ \\
\hline $\mathbf{S}$ & 0.00008 & 0.00008 & 0.00018 & 0.00006 & 0.00012 & 0.0001 & $0.0004 \max$ & $0.0004 \max$ \\
\hline $\mathbf{S i}$ & 0.0023 & 0.0024 & 0.0023 & 0.002 & 0.0022 & 0.0021 & 0.0015 to 0.0030 & $\mathrm{~ns}$ \\
\hline $\mathbf{N i}$ & 0.0005 & 0.0006 & 0.0006 & 0.0005 & 0.0008 & 0.0009 & $\mathrm{~ns}$ & $\mathrm{~ns}$ \\
\hline $\mathbf{C r}$ & 0.0031 & 0.0035 & 0.0037 & 0.0017 & 0.0023 & 0.0031 & $\mathrm{~ns}$ & $\mathrm{~ns}$ \\
\hline $\mathbf{V}$ & $<0.00005$ & $<0.00005$ & $<0.00005$ & $<0.00005$ & $<0.00005$ & $<0.00005$ & $\mathrm{~ns}$ & $\mathrm{~ns}$ \\
\hline Mo & 0.0022 & 0.0021 & 0.0003 & 0.0009 & 0.0009 & 0.002 & ns & $\mathrm{ns}$ \\
\hline $\mathbf{C u}$ & 0.0008 & 0.0008 & 0.0012 & 0.0007 & 0.001 & 0.0008 & $\mathrm{~ns}$ & $\mathrm{~ns}$ \\
\hline Al & 0.0002 & 0.0002 & $<0.00005$ & 0.0002 & 0.0003 & 0.0002 & $\mathrm{~ns}$ & $\mathrm{~ns}$ \\
\hline $\mathbf{N b}$ & $<0.00005$ & 0.0001 & $<0.00005$ & $<0.00005$ & 0.0001 & $<0.00005$ & $\mathrm{~ns}$ & $\mathrm{~ns}$ \\
\hline $\mathbf{T i}$ & $<0.00005$ & $<0.00005$ & $<0.00005$ & 0.0002 & 0.0002 & $<0.00005$ & $\mathrm{~ns}$ & $\mathrm{~ns}$ \\
\hline B & $<0.00005$ & $<0.00005$ & $<0.00005$ & 0 & 0 & $<0.00005$ & $0.00003 \mathrm{max}$ & $0.00003 \mathrm{max}$ \\
\hline
\end{tabular}

$*$ ns $=$ not specified

\section{$2.3 \quad$ EXPERIMENTAL RESULTS}

This section presents the experimental results for all of the ninety-one bolts tested under double-shear loading. Fig. 2-3 through Fig. 2-8 show the load versus displacement curves for all the experiments. Each figure contains six plots, each for the load versus displacement curves for a specific bolt diameter and steel grade for the individual different testing temperatures: $20^{\circ} \mathrm{C}$, $200{ }^{\circ} \mathrm{C}, 400{ }^{\circ} \mathrm{C}, 500{ }^{\circ} \mathrm{C}$, and $600^{\circ} \mathrm{C}$; the last plot shows all load versus displacement together. The variable "Load" plotted in the y-axis represents the total load applied by the universal testing machine to the testing apparatus and, it should be noted that only half of this value is applied to each shear plane in the bolt. The universal testing machine is operated through load control and thus after peak load has been reached the failure is abrupt and the degradation could not be captured.

There is a similar trend in most of these experiments; a temperature increase leads to a loss of shear strength and to an increase in the shear deformation at failure load, both observations are more pronounced at higher temperatures. At $200{ }^{\circ} \mathrm{C}$, however, the shear strength is similar to that at ambient temperature, but the shear deformation is still higher. The load-displacement curves also have similar characteristics throughout the experiments of $19 \mathrm{~mm}(3 / 4 \mathrm{in})$ and $22 \mathrm{~mm}$ (7/8 in) 
diameter bolts; at lower loads, there is a linear relationship between load and displacement. The load, however, reaches a certain level, second stage, and the displacement increases at a greater rate than the stage before. In a third stage, the load and displacement maintain a linear-like relationship with a rate similar to that of the first stage; until, the applied load reaches a level, fourth stage, in which load and displacement does not hold a linear relationship and failure is imminent. For a more thorough discussion on these stages, and their limitations, refer to Chapter 3 and Chapter 4 of this report, in which these relationships are used to develop component-based models for modelling shear behavior in high-strength bolts at elevated temperatures.

The raw experimental data presented in in this chapter is available for download from the following link: https://doi.org/10.18434/M33T0T.

\subsection{1 $19 \mathrm{~mm}(3 / 4 \mathrm{in})$ Diameter Bolts}

Fig. 2-3, Fig. 2-4, and Table 2-3 summarize the results presented in this section. Bolts made out of A490 (steel grade) at ambient temperature resists about $10 \% \pm 1.9 \%$ ( \pm represents the relative standard error) more shear loading than the A325 bolts. Bolts A325 heated to $200{ }^{\circ} \mathrm{C}$ had a slightly higher shear strength by about $2 \% \pm 1.4 \%$, when compared with ambient temperature experiments; A490 bolts, however, had a slightly lower shear strength by about $2 \% \pm 1.6 \%$, when compared with ambient temperature experiments. At $200{ }^{\circ} \mathrm{C}$, however, the temperature influenced the deformation at failure; the A325 bolts' deformation at failure increased by about $12 \% \pm 6.2 \%$ compared to the ambient temperature experiments, while the A490 bolts had an increase of about $19 \% \pm 8.7 \%$.

For temperatures between $200{ }^{\circ} \mathrm{C}$ and $600{ }^{\circ} \mathrm{C}$, both steel grades had significant degradation in their mechanical properties: shear strength decreased and shear deformation at failure load increased. Shear strength of bolts A325 reduces from about $82 \% \pm 1.3 \%$ at $400{ }^{\circ} \mathrm{C}$ when compared to experiments at ambient temperature to only $33 \% \pm 1.5 \%$ at $600{ }^{\circ} \mathrm{C}$; shear strength of the A490 bolts reduced from about $85 \% \pm 1.4 \%$ at $400{ }^{\circ} \mathrm{C}$ when compared to experiments at ambient temperature to $38 \% \pm 1.0 \%$ at $600{ }^{\circ} \mathrm{C}$. Thus, the shear strength of the A490 bolts degraded slightly less than that of the A325 bolts.

The deformation at failure of the A325 bolts increased from about $42 \% \pm 6.5 \%$ at $400{ }^{\circ} \mathrm{C}$ when compared to experiments at ambient temperature to $83 \% \pm 6.5 \%$ at $600{ }^{\circ} \mathrm{C}$; deformation at failure of the A490 bolts increased from about $40 \% \pm 8.9 \%$ at $400{ }^{\circ} \mathrm{C}$ when compared to experiments at ambient temperature to $113 \% \pm 9.7 \%$ at $600{ }^{\circ} \mathrm{C}$. Although, the $\mathrm{A} 490$ bolts deformation at failure 
was greater than that of the A325 bolts, note that the failure load was also greater than that of the A325 bolts.
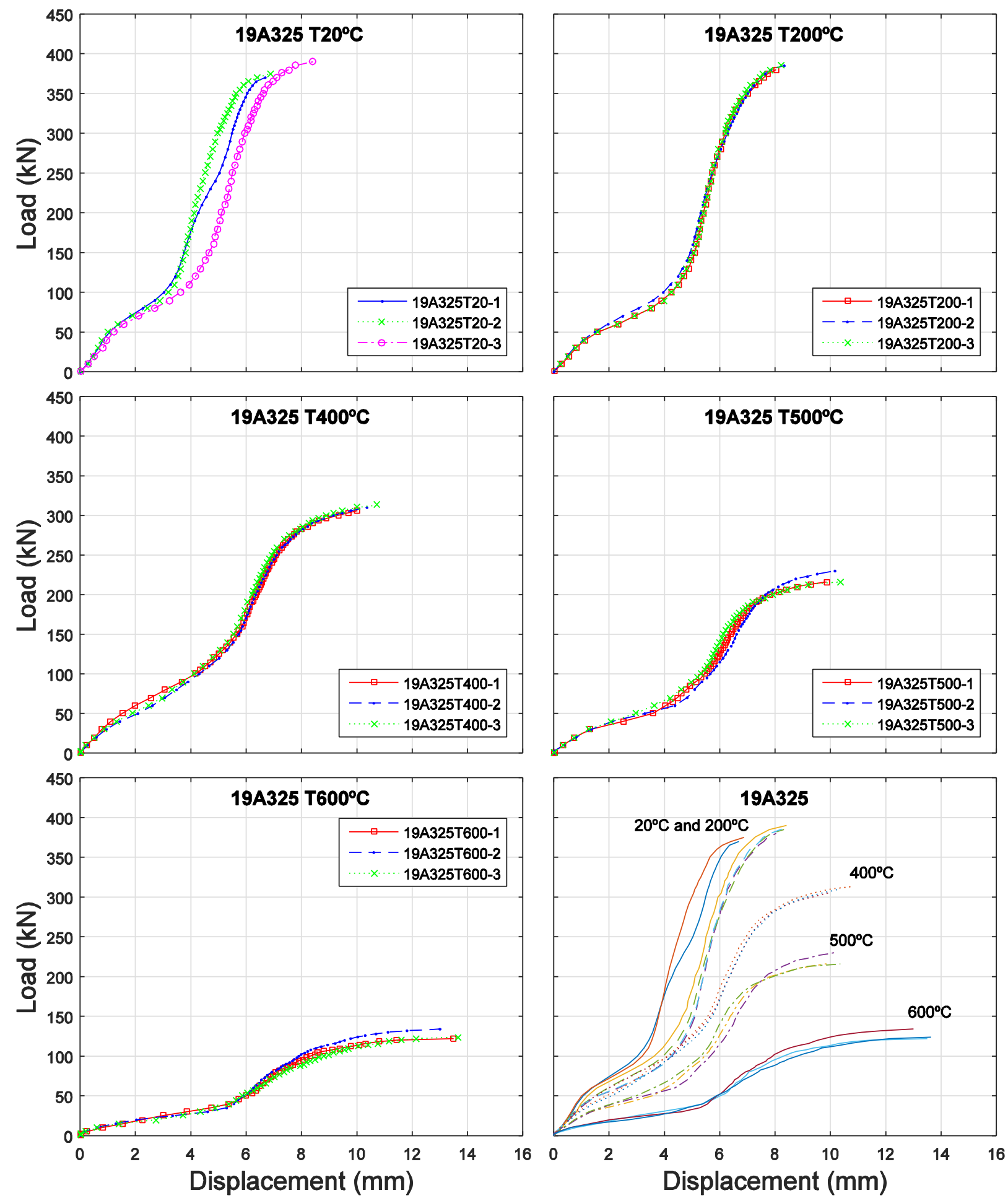

Figure 2-3 Load versus displacement for the $19 \mathrm{~mm}$ (3/4 in) A325 bolts 

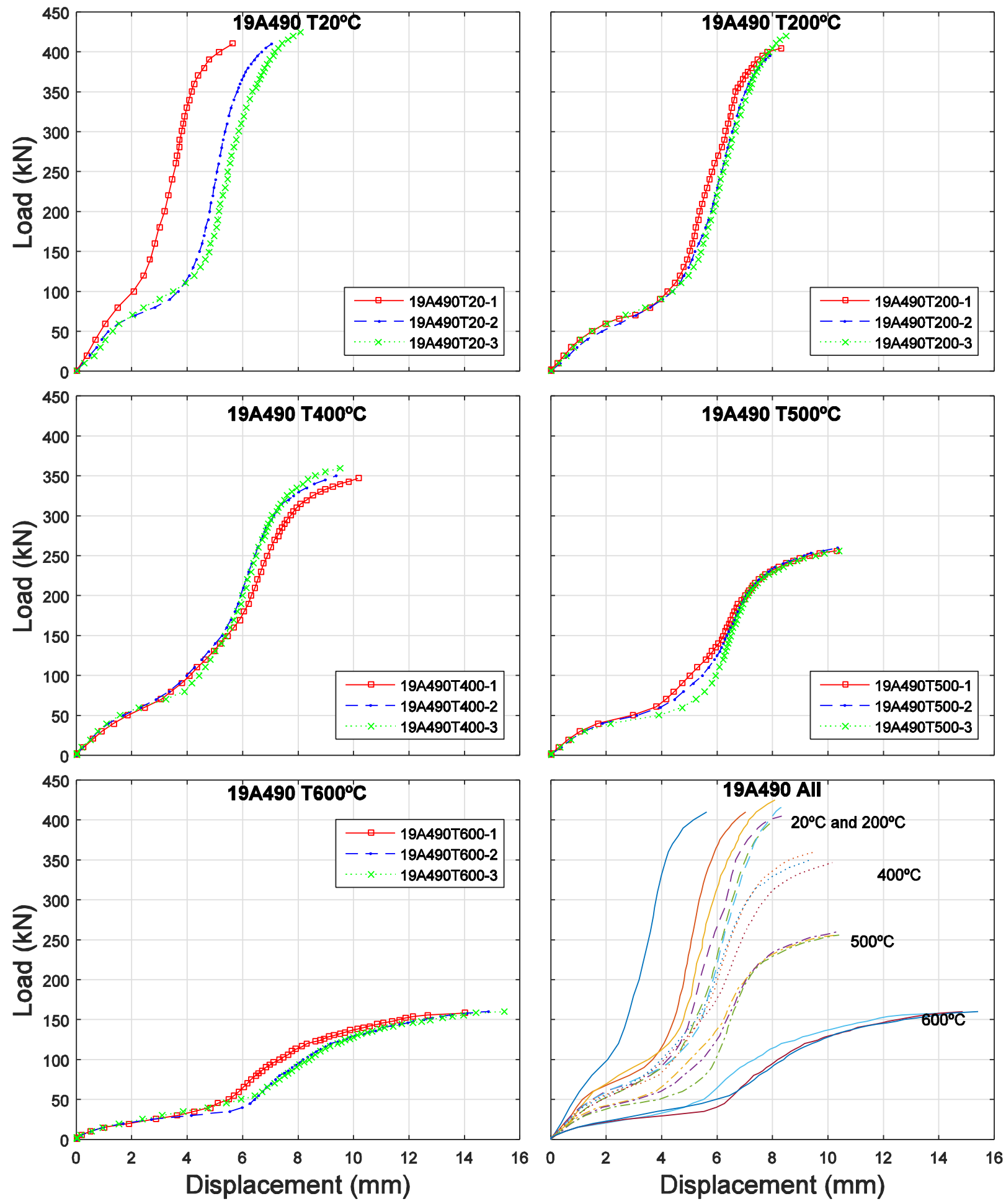

Figure 2-4 Load versus displacement for the $19 \mathrm{~mm}$ (3/4 in) A490 bolts 
Table 2-3 Results for 19 mm (3/4 in) bolt diameter experiments

\begin{tabular}{|c|c|c|c|c|}
\hline Specimen Name & Steel & $\begin{array}{c}\text { Temperature } \\
\left({ }^{\circ} \mathrm{C}\right)\end{array}$ & $\begin{array}{c}\text { Failure } \\
\text { Load kN } \\
\text { (kip) }\end{array}$ & $\begin{array}{l}\text { Displacement at } \\
\text { Failure mm (in) }\end{array}$ \\
\hline 19A325T20-1 & & & $372.0(83.7)$ & $6.69(0.263)$ \\
\hline 19A325T20-2 & & 20 & $375.0(84.4)$ & $6.88(0.270)$ \\
\hline 19A325T20-3 & & & $391.5(88.1)$ & $8.41(0.331)$ \\
\hline 19A325T200-1 & & & $383.9(86.4)$ & $8.03(0.316)$ \\
\hline 19A325T200-2 & & 200 & $392.0(88.2)$ & $8.33(0.327)$ \\
\hline 19A325T200-3 & & & $388.6(87.4)$ & $8.24(0.324)$ \\
\hline 19A325T400-1 & & & $309.8(69.7)$ & $10.02(0.394)$ \\
\hline 19A325T400-2 & A325 & 400 & $312.1(70.2)$ & $10.36(0.407)$ \\
\hline 19A325T400-3 & & & $314.0(70.7)$ & $10.74(0.422)$ \\
\hline 19A325T500-1 & & & $217.6(49.0)$ & $9.87(0.388)$ \\
\hline 19A325T500-2 & & 500 & $232.4(52.3)$ & $10.16(0.399)$ \\
\hline 19A325T500-3 & & & $216.3(48.7)$ & $10.36(0.407)$ \\
\hline 19A325T600-1 & & & $122.0(27.5)$ & $13.50(0.531)$ \\
\hline 19A325T600-2 & & 600 & $134.5(30.3)$ & $13.00(0.511)$ \\
\hline 19A325T600-3 & & & $124.0(27.9)$ & $13.64(0.536)$ \\
\hline 19A490T20-1 & & & $414.0(93.2)$ & $5.63(0.221)$ \\
\hline 19A490T20-2 & & 20 & $414.7(93.3)$ & $7.04(0.277)$ \\
\hline 19A490T20-3 & & & $429.1(96.5)$ & $8.09(0.318)$ \\
\hline 19A490T200-1 & & & $412.0(92.7)$ & $8.33(0.327)$ \\
\hline 19A490T200-2 & & 200 & $398.0(89.6)$ & $7.91(0.311)$ \\
\hline 19A490T200-3 & & & $420.1(94.5)$ & $8.50(0.334)$ \\
\hline 19A490T400-1 & & & $347.2(78.1)$ & $10.16(0.399)$ \\
\hline 19A490T400-2 & A490 & 400 & $354.6(79.8)$ & $9.37(0.368)$ \\
\hline 19A490T400-3 & & & $364.5(82.0)$ & $9.52(0.374)$ \\
\hline 19A490T500-1 & & & $258.0(58.1)$ & $10.32(0.406)$ \\
\hline 19A490T500-2 & & 500 & $262.7(59.1)$ & $10.34(0.406)$ \\
\hline 19A490T500-3 & & & $258.9(58.3)$ & $10.40(0.409)$ \\
\hline 19A490T600-1 & & & $158.4(35.6)$ & $14.03(0.551)$ \\
\hline 19A490T600-2 & & 600 & $163.7(36.8)$ & $14.86(0.584)$ \\
\hline 19A490T600-3 & & & $160.8(36.2)$ & $15.42(0.606)$ \\
\hline
\end{tabular}




\subsection{2 $22 \mathrm{~mm}(7 / 8 \mathrm{in})$ Diameter Bolts}

Fig. 2-5, Fig. 2-6, and Table 2-4 summarize the results presented in this section. There are many similar observations to what was discussed for the $19 \mathrm{~mm}$ (3/4 in) diameter bolts. A490 bolts at ambient temperature resisted about $8 \% \pm 1.1 \%$ more shear loading than the A325 bolts (four experiments, instead of the usual three, were carried out at ambient temperature). A325 bolts, when heated to $200{ }^{\circ} \mathrm{C}$, had a reduction in the shear strength of about $4 \% \pm 1.0 \%$ compared to ambient temperature experiments; A490 bolts reduced its shear strength by about $5 \% \pm 1.1 \%$ when compared to ambient temperature experiments. At $200^{\circ} \mathrm{C}$ the deformation at failure load was similar to that of the A325 bolts and it changed by only $1 \% \pm 2.9 \%$ when compared to ambient temperature experiments, while A490 bolts showed larger increases by about $11 \% \pm 2.0 \%$, of the deformation at failure. Thus, at $200{ }^{\circ} \mathrm{C}$ the shear strength reduction was about the same for both steel grades, but the deformation of the A490 bolts at failure was more sensitive to increasing temperature.

For temperatures between $200{ }^{\circ} \mathrm{C}$ and $600^{\circ} \mathrm{C}$ both steel grades, as observed for the $19 \mathrm{~mm}(3 / 4 \mathrm{in})$ bolt diameter, had significant degradation in their mechanical properties: shear strength decreased and shear deformation at failure load increased. Shear strength of A325 bolts reduced from about $85 \% \pm 1.3 \%$ at $400{ }^{\circ} \mathrm{C}$ when compared to experiments at ambient temperature to only $33 \% \pm$ $1.0 \%$ at $600{ }^{\circ} \mathrm{C}$; shear strength of the $\mathrm{A} 490$ bolts reduced from about $81 \% \pm 1.5 \%$ at $400{ }^{\circ} \mathrm{C}$ when compared to experiments at ambient temperature to $37 \% \pm 1.1 \%$ at $600{ }^{\circ} \mathrm{C}$. Thus, the A490 bolts shear strength degraded slightly less than that of the A325 bolts.

Deformation at failure of the A325 bolts increased from about $27 \% \pm 3.1 \%$ at $400{ }^{\circ} \mathrm{C}$ when compared to experiments at ambient temperature to $51 \% \pm 4.6 \%$ at $600{ }^{\circ} \mathrm{C}$; deformation at failure of the A490 bolts increased from about $34 \% \pm 3.3 \%$ at $400{ }^{\circ} \mathrm{C}$ when compared to experiments at ambient temperature to $95 \% \pm 4.7 \%$ at $600{ }^{\circ} \mathrm{C}$. 

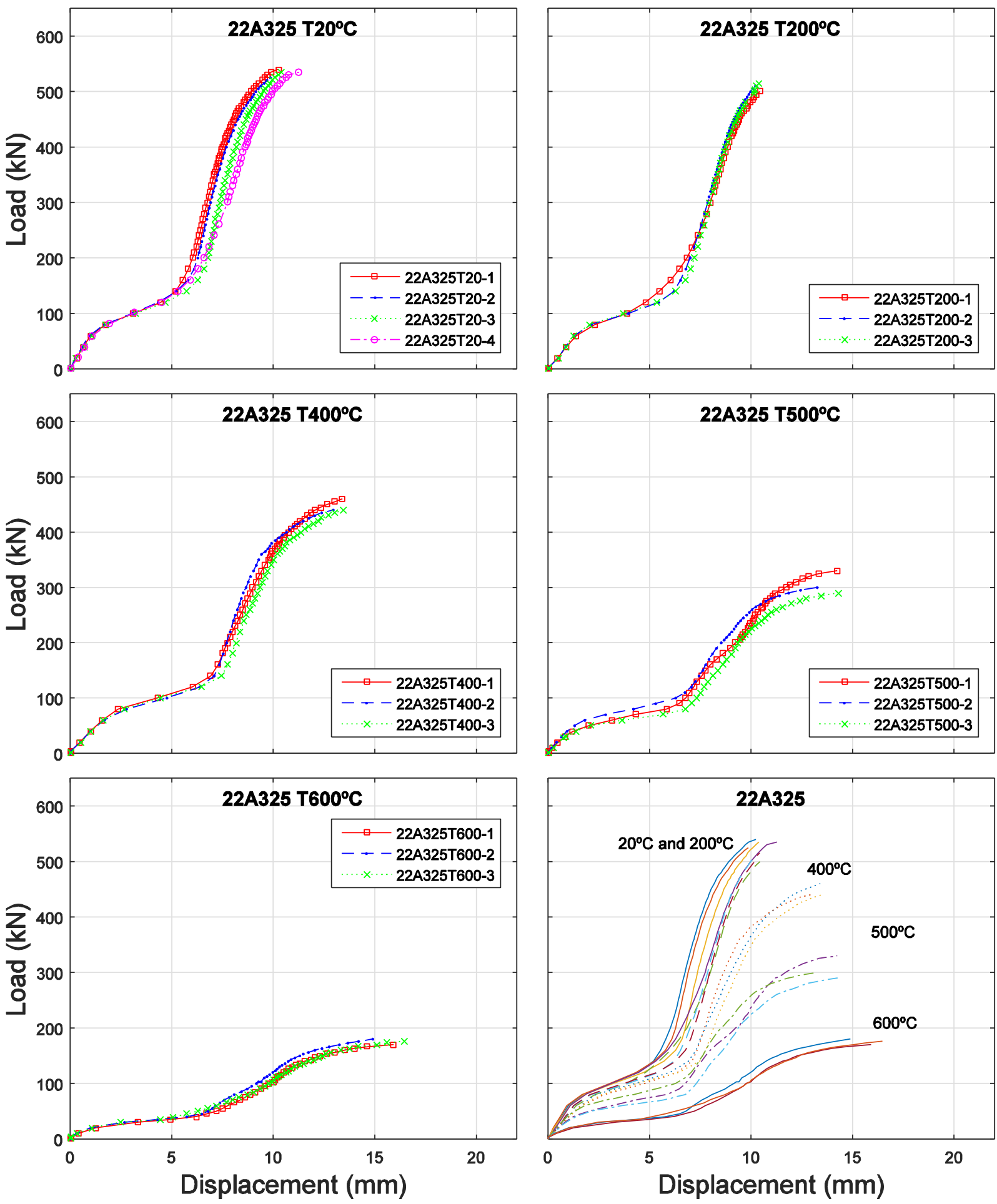

Figure 2-5 Load versus displacement for the $22 \mathrm{~mm}$ (7/8 in) A325 bolts 

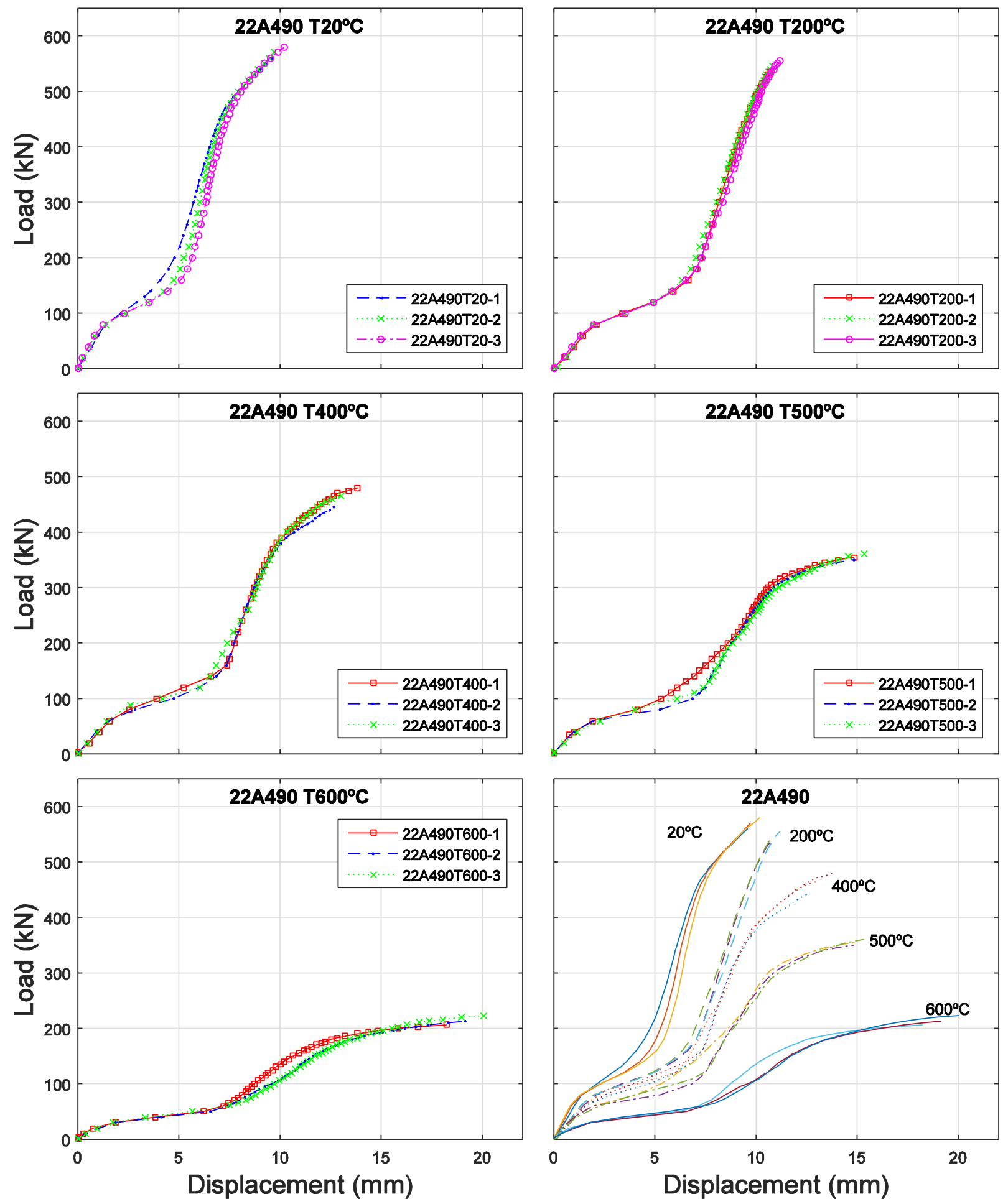

Figure 2-6 Load versus displacement for the $22 \mathrm{~mm}$ (7/8 in) A490 bolts 
Table 2-4 Results for 22 mm (7/8 in) bolt diameter experiments

\begin{tabular}{|c|c|c|c|c|}
\hline Specimen Name & Steel & $\begin{array}{c}\text { Temperature } \\
\left({ }^{\circ} \mathrm{C}\right)\end{array}$ & $\begin{array}{l}\text { Failure Load } \\
\qquad(\mathrm{kN})\end{array}$ & $\begin{array}{l}\text { Displacement } \\
\text { at Failure } \\
(\mathrm{mm})\end{array}$ \\
\hline 22A325T20-1 & \multirow{16}{*}{ A325 } & \multirow{4}{*}{20} & $540.0(121.5)$ & $10.24(0.402)$ \\
\hline 22A325T20-2 & & & $527.6(118.7)$ & $9.86(0.388)$ \\
\hline 22А 325 T20-3 & & & $539.9(121.5)$ & $10.38(0.408)$ \\
\hline 22A325T20-4 & & & $523.0(117.7)$ & $11.27(0.443)$ \\
\hline 22A325T200-1 & & \multirow{3}{*}{200} & $503.0(113.2)$ & $10.43(0.400)$ \\
\hline 22А 325 T200-2 & & & $513.8(115.6)$ & $10.21(0.401)$ \\
\hline 22А 325 T200-3 & & & $517.2(116.4)$ & $10.41(0.409)$ \\
\hline 22A325T400-1 & & \multirow{3}{*}{400} & $464.0(104.4)$ & $13.41(0.500)$ \\
\hline 22A325T400-2 & & & $442.5(99.6)$ & $12.94(0.500)$ \\
\hline 22A325T400-3 & & & 444.1 (99.9) & $13.48(0.530)$ \\
\hline 22A325T500-1 & & \multirow{3}{*}{500} & $332.3(74.8)$ & $14.25(0.560)$ \\
\hline 22A325T500-2 & & & $304.2(68.4)$ & $13.26(0.521)$ \\
\hline 22А $325 T 500-3$ & & & $294.3(66.2)$ & $14.30(0.562)$ \\
\hline 22A325T600-1 & & \multirow{3}{*}{600} & $171.8(38.7)$ & $15.92(0.626)$ \\
\hline 22А325T600-2 & & & $182.8(41.1)$ & $14.89(0.585)$ \\
\hline 22A325T600-3 & & & $178.9(40.3)$ & $16.47(0.647)$ \\
\hline 22A490T20-1 & \multirow{15}{*}{ A490 } & \multirow{3}{*}{20} & $568.0(127.8)$ & $9.59(0.377)$ \\
\hline 22A490T20-2 & & & $574.8(129.3)$ & $9.72(0.382)$ \\
\hline 22A490T20-3 & & & $587.7(132.2)$ & $10.20(0.401)$ \\
\hline 22А490T200-1 & & \multirow{3}{*}{200} & $537.2(120.9)$ & $10.69(0.420)$ \\
\hline 22A490T200-2 & & & $548.7(123.5)$ & $10.80(0.424)$ \\
\hline 22A490T200-3 & & & $555.2(124.9)$ & $11.19(0.440)$ \\
\hline 22A490T400-1 & & \multirow{3}{*}{400} & $480.3(108.1)$ & $13.85(0.544)$ \\
\hline 22А490T400-2 & & & $449.9(101.2)$ & $12.65(0.497)$ \\
\hline 22А490T400-3 & & & $466.3(104.9)$ & $13.04(0.512)$ \\
\hline 22А490T500-1 & & \multirow{3}{*}{500} & $356.8(80.3)$ & $14.86(0.584)$ \\
\hline 22A490T500-2 & & & $352.6(79.3)$ & $14.84(0.583)$ \\
\hline 22A490T500-3 & & & $362.7(81.6)$ & $15.33(0.602)$ \\
\hline 22А490T600-1 & & \multirow{3}{*}{600} & $206.4(46.4)$ & $18.23(0.716)$ \\
\hline 22А490T600-2 & & & $214.5(48.3)$ & $19.14(0.752)$ \\
\hline 22А490T600-3 & & & $224.0(50.4)$ & $20.07(0.789)$ \\
\hline
\end{tabular}




\subsection{3 $25 \mathrm{~mm}(1 \mathrm{in})$ Diameter Bolt}

Fig. 2-7, Fig. 2-8, and Table 2-5 summarize the results presented in this section. A490 bolts at ambient temperature resisted to about $13 \% \pm 0.4 \%$ more shear loading than the A325 bolts. A325 bolts when heated to $200{ }^{\circ} \mathrm{C}$ showed a reduction in the shear strength of about $4 \% \pm 0.7 \%$ when compared to ambient temperature experiments; A490 bolts, however, had a slightly lower shear strength, about $2 \% \pm 0.3 \%$, when compared to ambient temperature experiments. At $200{ }^{\circ} \mathrm{C}$, however, deformation of the A325 bolts at failure had a decrease of $11 \% \pm 7.8 \%$ when compared to ambient temperature experiments, while A490 bolts had an increase of about $16 \% \pm 5.5 \%$. Thus, although shear strength considerably changed for the A325 bolts, shear deformation slightly decreased; conversely, A490 bolts shear strength is about the same, while shear deformation was considerably higher.

For temperatures between $200{ }^{\circ} \mathrm{C}$ and $600{ }^{\circ} \mathrm{C}$, as showed for the $19 \mathrm{~mm}(3 / 4 \mathrm{in})$ and the $22 \mathrm{~mm}$ (7/8 in) bolts, both steel grades had significant degradation in their mechanical properties: shear strength decreased and shear deformation at failure load increased. Shear strength of the A325 bolts reduced from about $79 \% \pm 0.7 \%$ at $400{ }^{\circ} \mathrm{C}$ when compared to experiments at ambient temperature to about $33 \% \pm 0.6 \%$ at $600{ }^{\circ} \mathrm{C}$; shear strength of the $\mathrm{A} 490$ bolts reduced from about $81 \% \pm 0.6 \%$ at $400{ }^{\circ} \mathrm{C}$ when compared to experiments at ambient temperature to only $39 \% \pm$ $1.3 \%$ at $600{ }^{\circ} \mathrm{C}$. A490 bolts, however, were abruptly affected by raising the temperature from $500{ }^{\circ} \mathrm{C}$ to $600{ }^{\circ} \mathrm{C}$, while at $500{ }^{\circ} \mathrm{C}$ the shear strength reduction was about $60 \% \pm 0.3 \%$, at $600{ }^{\circ} \mathrm{C}$ the shear strength reduced to about $39 \% \pm 1.3 \%$ when compared to experiments at ambient temperature. The next section will discuss this observation in more detail.

Deformation at failure of the A325 bolts increased from about $43 \% \pm 12.1 \%$ at $400{ }^{\circ} \mathrm{C}$ when compared to experiments at ambient temperature to about $76 \% \pm 9.3 \%$ at $600{ }^{\circ} \mathrm{C}$; deformation at failure of the A490 bolts increased from about $44 \% \pm 7.6 \%$ at $400{ }^{\circ} \mathrm{C}$ when compared to experiments at ambient temperature to about $250 \% \pm 19.9 \%$ at $600{ }^{\circ} \mathrm{C}$. As discussed in the following section, it is not possible to directly compare displacement values at failure measured for the $25 \mathrm{~mm}(1 \mathrm{in})$ bolts to those for the $19 \mathrm{~mm}(3 / 4 \mathrm{in})$ and $22 \mathrm{~mm}$ (7/8 in) bolts, since the material of the loading blocks was changed. 

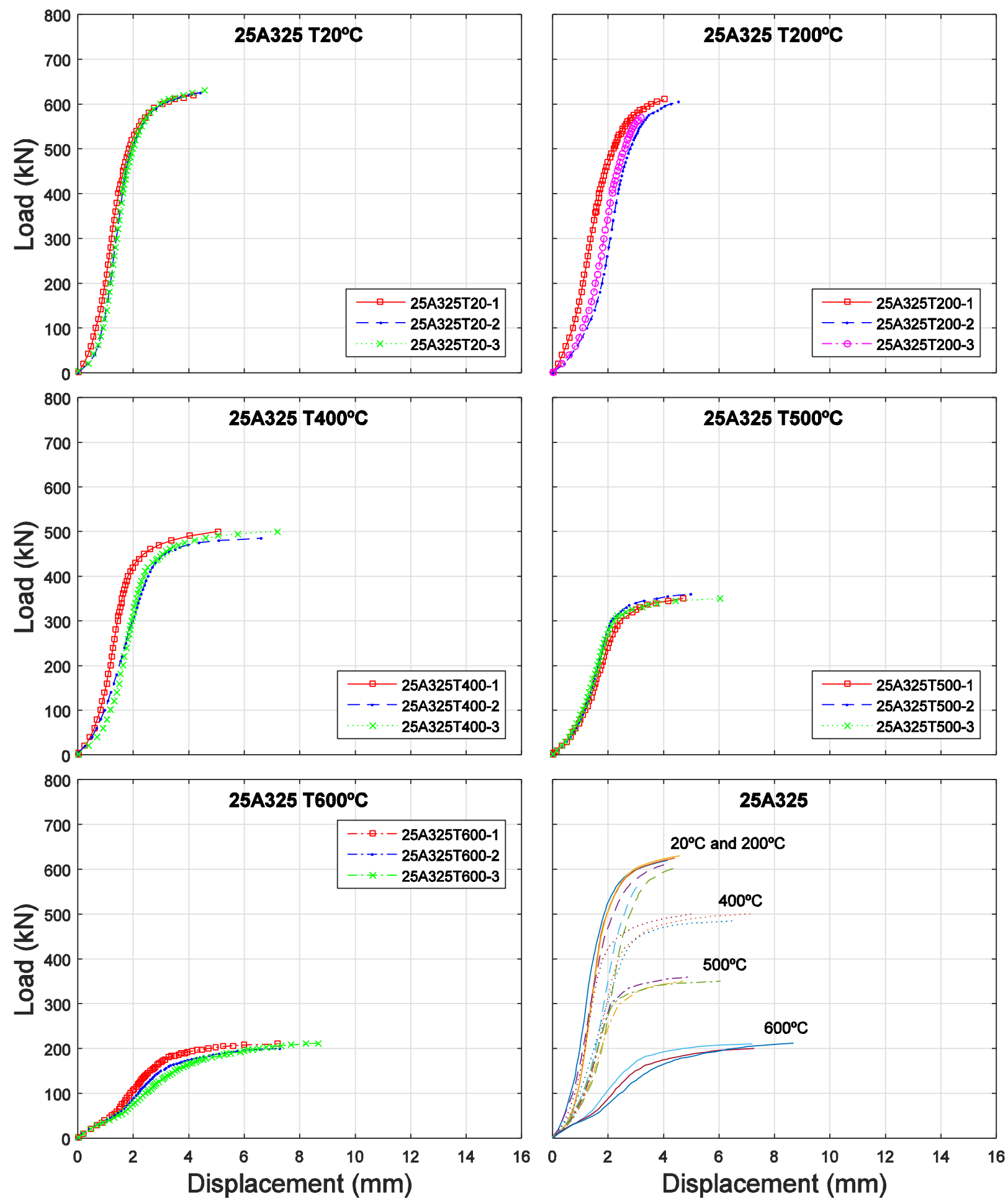

Figure 2-7 Load versus displacement for the 25 mm (1 in) A325 bolts 

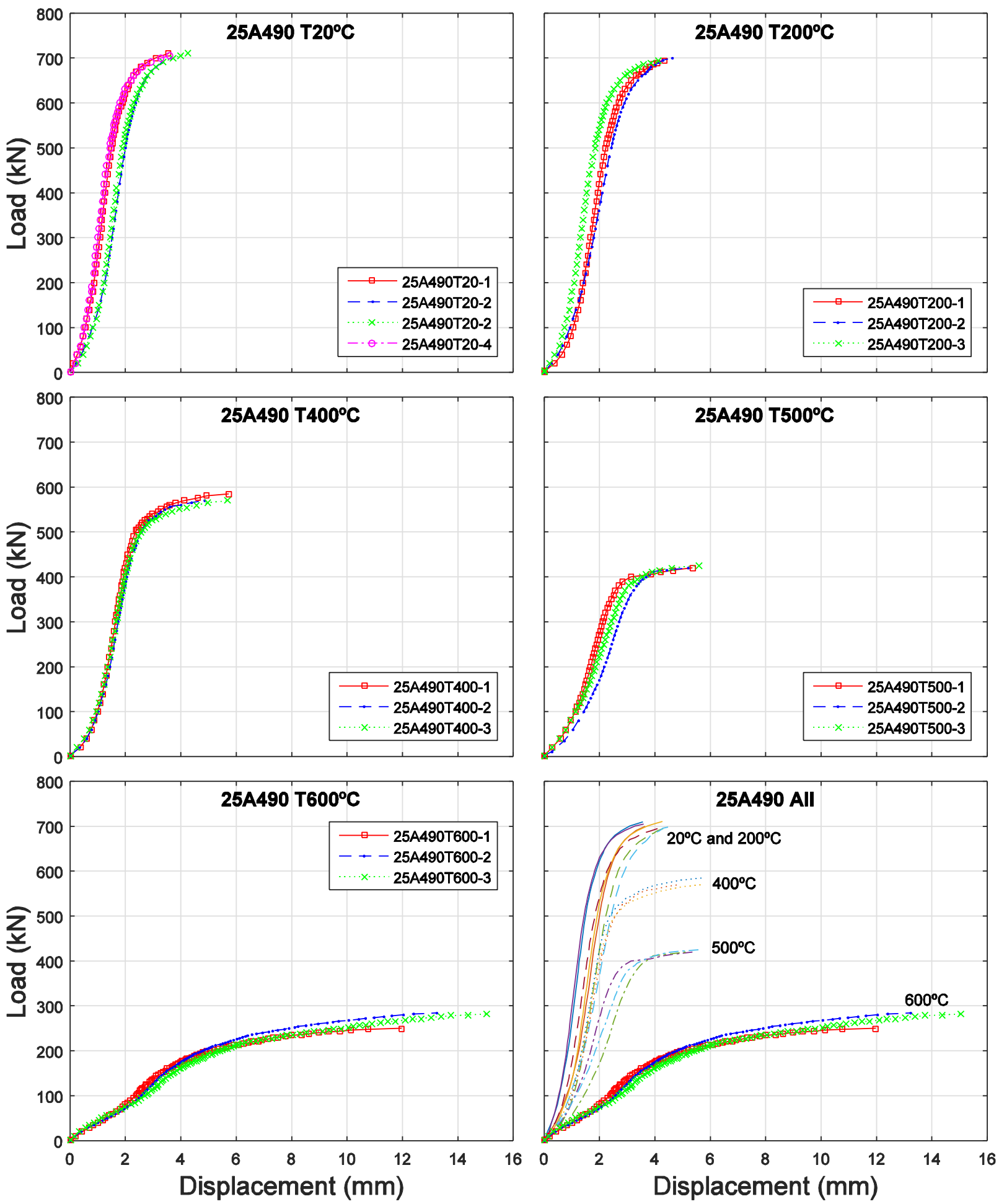

Figure 2-8 Load versus displacement for the 25 mm (1 in) A490 bolts 
Table 2-5 Results for $25 \mathrm{~mm}$ (1 in) bolt diameter experiments

\begin{tabular}{|c|c|c|c|c|}
\hline Specimen Name & Steel & $\begin{array}{l}\text { Temperature } \\
\left({ }^{\circ} \mathrm{C}\right)\end{array}$ & $\begin{array}{l}\text { Failure Load } \\
\text { kN (kip) }\end{array}$ & $\begin{array}{c}\text { Displacement } \\
\text { at Failure } \\
\text { mm (in) }\end{array}$ \\
\hline 25A325T20-1 & \multirow{15}{*}{ A325 } & \multirow{3}{*}{20} & $623.6(140.3)$ & $4.15(0.163)$ \\
\hline 25A325T20-2 & & & $629.2(141.6)$ & $4.41(0.173)$ \\
\hline 25A325T20-3 & & & $631.3(142.0)$ & $4.59(0.180)$ \\
\hline 25A325T200-1 & & \multirow{3}{*}{200} & $612.1(137.7)$ & $4.02(0.158)$ \\
\hline 25A325T200-2 & & & $607.2(136.6)$ & $4.54(0.178)$ \\
\hline 25A325T200-3 & & & $596.5(131.2)$ & $3.17(0.125)$ \\
\hline 25A325T400-1 & & \multirow{3}{*}{400} & $500.6(112.6)$ & 5.05 (0.199) \\
\hline 25A325T400-2 & & & $485.4(109.2)$ & $6.60(0.259)$ \\
\hline 25A325T400-3 & & & $500.6(112.6)$ & $7.18(0.282)$ \\
\hline 25A325T500-1 & & \multirow{3}{*}{500} & 354.9 (79.9) & $4.70(0.185)$ \\
\hline 25A325T500-2 & & & $361.3(81.3)$ & $4.98(0.196)$ \\
\hline 25A325T500-3 & & & $350.1(78.8)$ & $6.06(0.238)$ \\
\hline 25A325T600-1 & & \multirow{3}{*}{600} & $210.7(47.4)$ & $7.20(0.283)$ \\
\hline 25A325T600-2 & & & $200.7(45.2)$ & $7.27(0.286)$ \\
\hline 25A325T600-3 & & & $212.1(47.7)$ & $8.68(0.341)$ \\
\hline 25A490T20-1 & \multirow{16}{*}{ A490 } & \multirow{4}{*}{20} & $710.3(159.8)$ & $3.56(0.140)$ \\
\hline 25A490T20-2 & & & $704.5(158.5)$ & $3.65(0.144)$ \\
\hline 25A490T20-3 & & & $713.6(160.6)$ & $4.27(0.168)$ \\
\hline 25A490T20-4 & & & $707.6(159.2)$ & $3.59(0.141)$ \\
\hline 25A490T200-1 & & \multirow{3}{*}{200} & $696.2(156.6)$ & $4.34(0.170)$ \\
\hline 25A490T200-2 & & & $700.0(157.5)$ & $4.63(0.182)$ \\
\hline 25A490T200-3 & & & $698.4(157.1)$ & $4.13(0.162)$ \\
\hline 25A490T400-1 & & \multirow{3}{*}{400} & $585.4(131.7)$ & $5.73(0.225)$ \\
\hline 25A490T400-2 & & & $573.0(128.9)$ & $4.86(0.191)$ \\
\hline 25A490T400-3 & & & $570.0(128.3)$ & $5.70(0.224)$ \\
\hline 25A490T500-1 & & \multirow{3}{*}{500} & $423.3(95.2)$ & $5.35(0.210)$ \\
\hline 25A490T500-2 & & & $424.4(95.5)$ & $5.20(0.204)$ \\
\hline 25A490T500-3 & & & $425.3(95.7)$ & $5.58(0.219)$ \\
\hline 25A490T600-1 & & \multirow{3}{*}{600} & $251.8(56.7)$ & $11.97(0.470)$ \\
\hline 25A490T600-2 & & & 285.7 (64.6) & $13.23(0.520)$ \\
\hline 25A490T600-3 & & & $283.6(63.8)$ & $15.06(0.592)$ \\
\hline
\end{tabular}




\section{$2.4 \quad$ DISCUSSION}

\subsubsection{Testing Blocks}

As mentioned before, two sets of testing blocks were designed to carry out the experiments; the design aimed to develop blocks that would withstand the loading with minimal deformation compared to the bolt deformation. For the $19 \mathrm{~mm}$ (3/4 in) and $22 \mathrm{~mm}$ (7/8 in) bolt diameter tests, the same set of testing blocks was used and only the hole necessary to pass the bolt was enlarged after all the $19 \mathrm{~mm}(3 / 4 \mathrm{in})$ bolts were tested. For the $25 \mathrm{~mm}$ ( 1 in) bolts diameter tests, a new testing block with same dimensions was manufactured, using a different steel grade: AISI/SAE 8640 thermal treated instead of ASTM A36.

This change of material affected the configuration of the loading versus displacement curve. For the $19 \mathrm{~mm}$ (3/4 in) and $22 \mathrm{~mm}$ (7/8 in) bolt diameter tests, the loading versus displacement curve, after a short first stage, it presents a second stage in which the displacement increases at a greater rate than before; this second stage is nonexistent in all $25 \mathrm{~mm}(1 \mathrm{in})$ bolts' experiments. This second stage is due to localized deformation at the bolt hole, which was confirmed by measurements taken of the bolt-hole diameter throughout the study; for $19 \mathrm{~mm}(3 / 4 \mathrm{in})$ and $22 \mathrm{~mm}$ (7/8 in) bolt diameter the bolt hole slightly increases after each experiment, but for $25 \mathrm{~mm}$ ( 1 in) bolts the bolt hole practically does not change except for the $600{ }^{\circ} \mathrm{C}$. Thus, if these experiments are to be modeled, proper consideration of the incremental change of the bolt-hole diameter after each experiment is essential. It is noted that although the testing block's deformation affects the overall deformation of the $19 \mathrm{~mm}(3 / 4 \mathrm{in})$ and $22 \mathrm{~mm}$ (7/8 in) diameter bolts, it has no effect on their strength (capacity). Their test results provide very reliable data for the purpose of characterizing the degradation in bolts' strength and developing retention (reduction) factors at different temperatures. The unaffected results of the $25 \mathrm{~mm}(1 \mathrm{in})$ diameter bolts will provide further information needed for the development of full models. For a detailed discussion on the different stages of the loading versus displacement curve, refer to Chapter 3 and Chapter 4 of this report in which these relationships are used to develop an empirical component-based model for modelling shear behavior in high-strength bolts at elevated temperatures.

\subsubsection{Shear Strength}

The bolt shear strength is directly proportional to the cross-section area of the bolt shaft. The ratio between the area of a $25 \mathrm{~mm}$ ( $1 \mathrm{in})$ diameter bolt and a $19 \mathrm{~mm}(3 / 4 \mathrm{in})$ is 1.73 , while the ratio between the area of a $22 \mathrm{~mm}(7 / 8 \mathrm{in})$ diameter bolt and a $19 \mathrm{~mm}(3 / 4 \mathrm{in})$ is 1.34 . A comparison between the shear strength of bolts with A325 steel grade is shown in Fig. 2-9, while Fig. 2-10 shows the same comparison for bolts with A490 steel grade. Note that, for any temperature, and both materials, the area ratio is similar to the ratio between failure loads. 
Fig. 2-9 and Fig. 2-10 also show that, for all diameters and materials tested herein, the shear strength was nearly constant up to $200{ }^{\circ} \mathrm{C}$. From $200^{\circ} \mathrm{C}$ to $400^{\circ} \mathrm{C}$ there is a clear shear strength reduction, which increased at an increasing rate from $400{ }^{\circ} \mathrm{C}$ to $600{ }^{\circ} \mathrm{C}$; note that from $400{ }^{\circ} \mathrm{C}$ to $600{ }^{\circ} \mathrm{C}$ the degradation of shear strength is nearly linear.

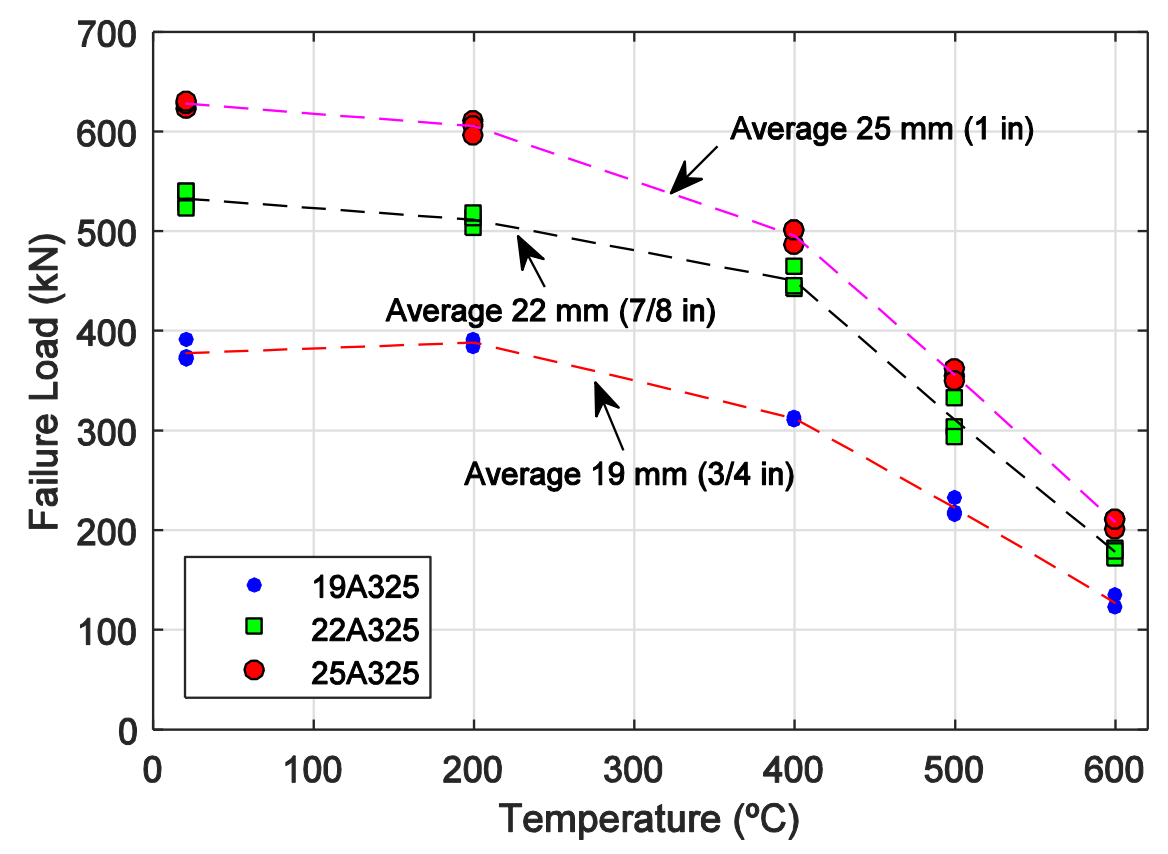

Figure 2-9 Failure load versus temperature for the A325 bolts

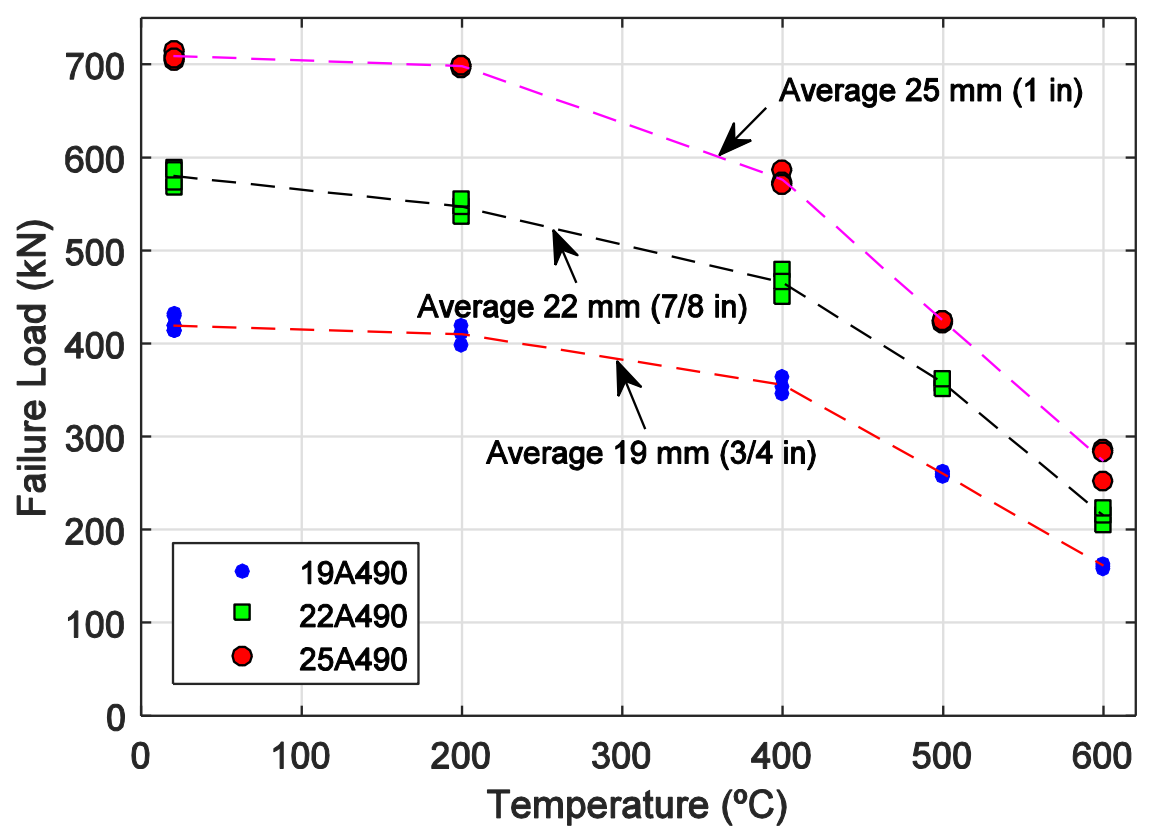

Figure 2-10 Failure load versus temperature for the A490 bolts 
Fig. 2-11 shows the shear strength retention by the ratio of the failure load of a certain experiment by the average shear strength at ambient temperature for the same bolt diameter and material. The shear strength retention consistently changes at similar rate for the two materials and three bolt diameters.

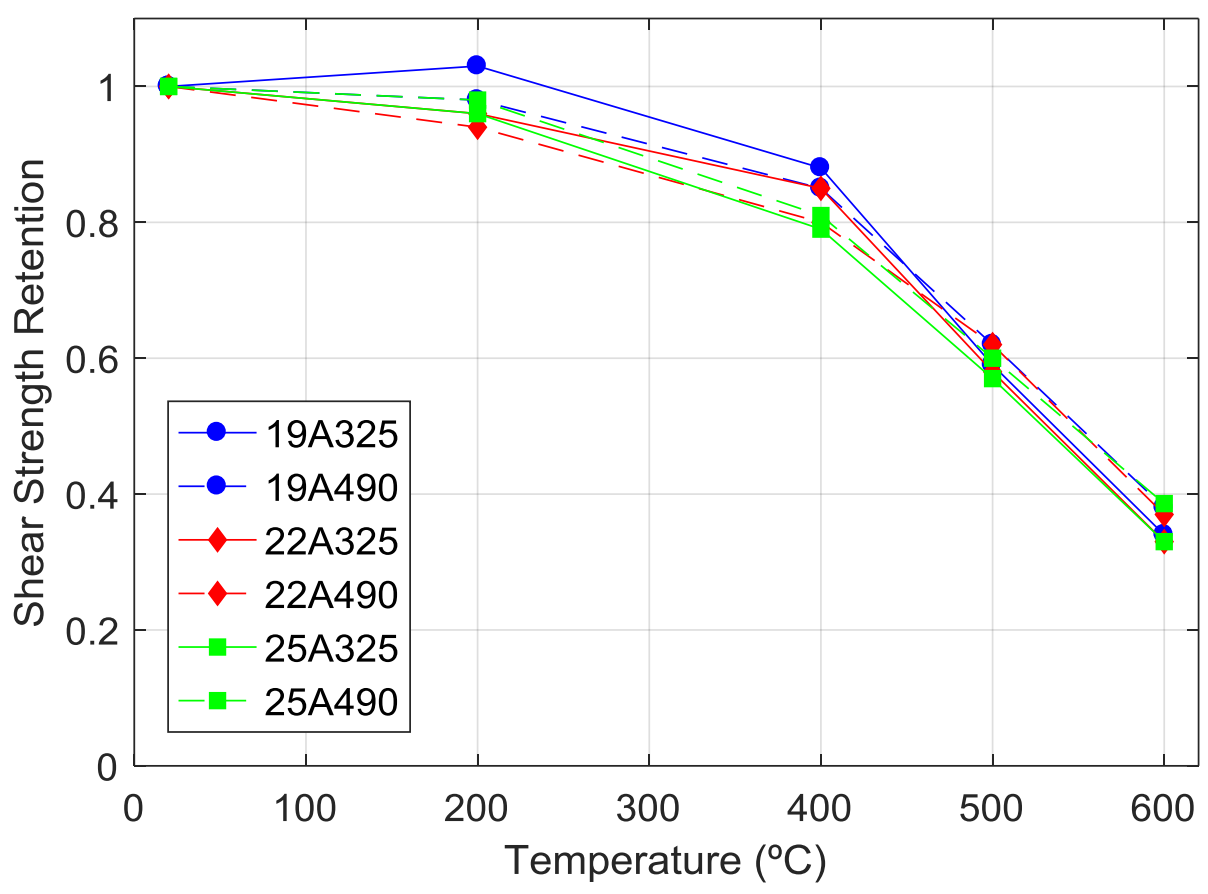

Figure 2-11 Shear strength retention versus temperature.

Fig. 2-12 shows how the double-shear retention factors from the experimental results compare to the to the design retention factors specified in the Eurocode (2005), as well as to the other experimental results found in the literature; particularly from Kodur et al. (2012), and Yu (2006). Per the Eurocode, the fire design resistance of bolts loaded in shear should be determined from:

$$
F_{v, t, R d}=F_{v, R d} k_{b, \theta} \frac{\gamma_{M 2}}{\gamma_{M, f i}}
$$

where $k_{b, \theta}$ is the reduction factor determined at the appropriate temperature (Table D.1 of Eurocode (2005)),

$F_{v, R d}$ is the design shear resistance of the bolt per shear plane (Table 3.4 of Eurocode (2005)),

$\gamma_{M 2}$ is the partial factor at normal temperature, and

$\gamma_{M, f i}$ is the partial factor for fire conditions. 

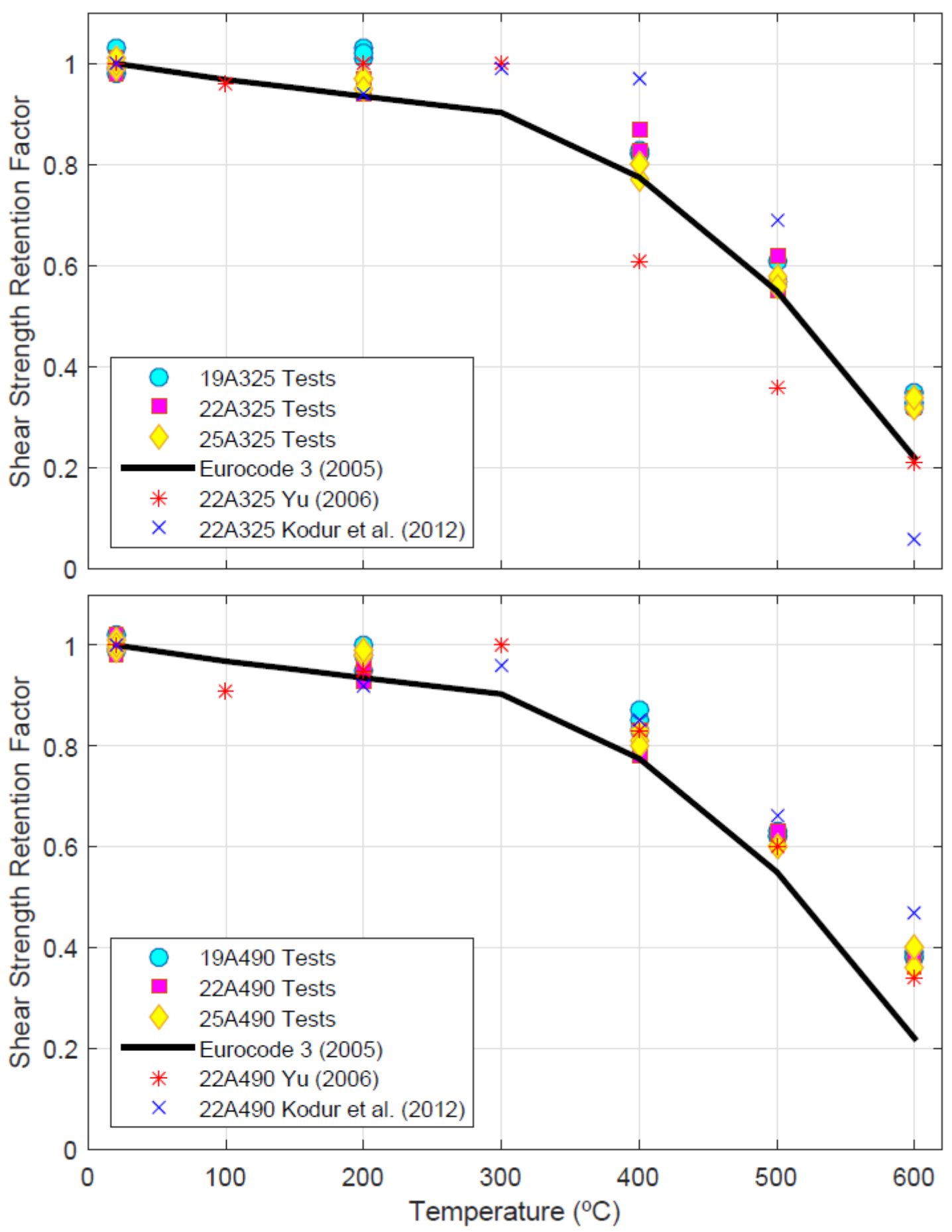

Figure 2-12 Comparison of different shear retention factors for (a) A325 bolts, and (b) A490 bolts.

The retention factors were relatively consistent across all three bolt diameters and for both bolt material grades. For temperatures up to $500{ }^{\circ} \mathrm{C}$, the Eurocode retention factors were $5 \%$ to $10 \%$ more conservative than the experimental data. However, at $600{ }^{\circ} \mathrm{C}$, the Eurocode was about $40 \%$ 
more conservative than the experimental data. It is noted that data from Kodur et al. (2012), as well as from Yu (2006), is limited to one result at each tested temperature, and the studies' scope was limited to one bolt diameter (22 mm (7/8 in)), making any full comparison inconclusive. Finally, it is noted that the AISC (2010) does not specify retention factors values for high-strength bolts at elevated temperatures.

\subsubsection{Displacement at Failure}

The loading blocks used for the $25 \mathrm{~mm}$ (1 in) bolt diameter tests is different than the blocks used for the $19 \mathrm{~mm}$ (3/4 in) and $22 \mathrm{~mm}$ (7/8 in) bolt diameter tests, which is discussed in more detail in the next section; also, deformation at failure load must be always taken in account together with shear strength or steel grade, for example: A490 bolts have consistently presented for experiments at $600{ }^{\circ} \mathrm{C}$ greater deformation at failure load when compared to A325 bolts, but it does not necessarily mean that $\mathrm{A} 490$ bolts are less stiff than $\mathrm{A} 325$ bolts at $600{ }^{\circ} \mathrm{C}$. On the other hand, since the average deformations at failure load from ambient temperature through $500{ }^{\circ} \mathrm{C}$ are similar when comparing different steel grades and same bolt diameter, it is concluded that A490 bolts are stiffer than A325 bolts since it has greater shear strength but similar shear deformation. Finally, Fig. 2-13 shows the displacement at failure at different temperatures for different bolt diameters and bolt grades. 

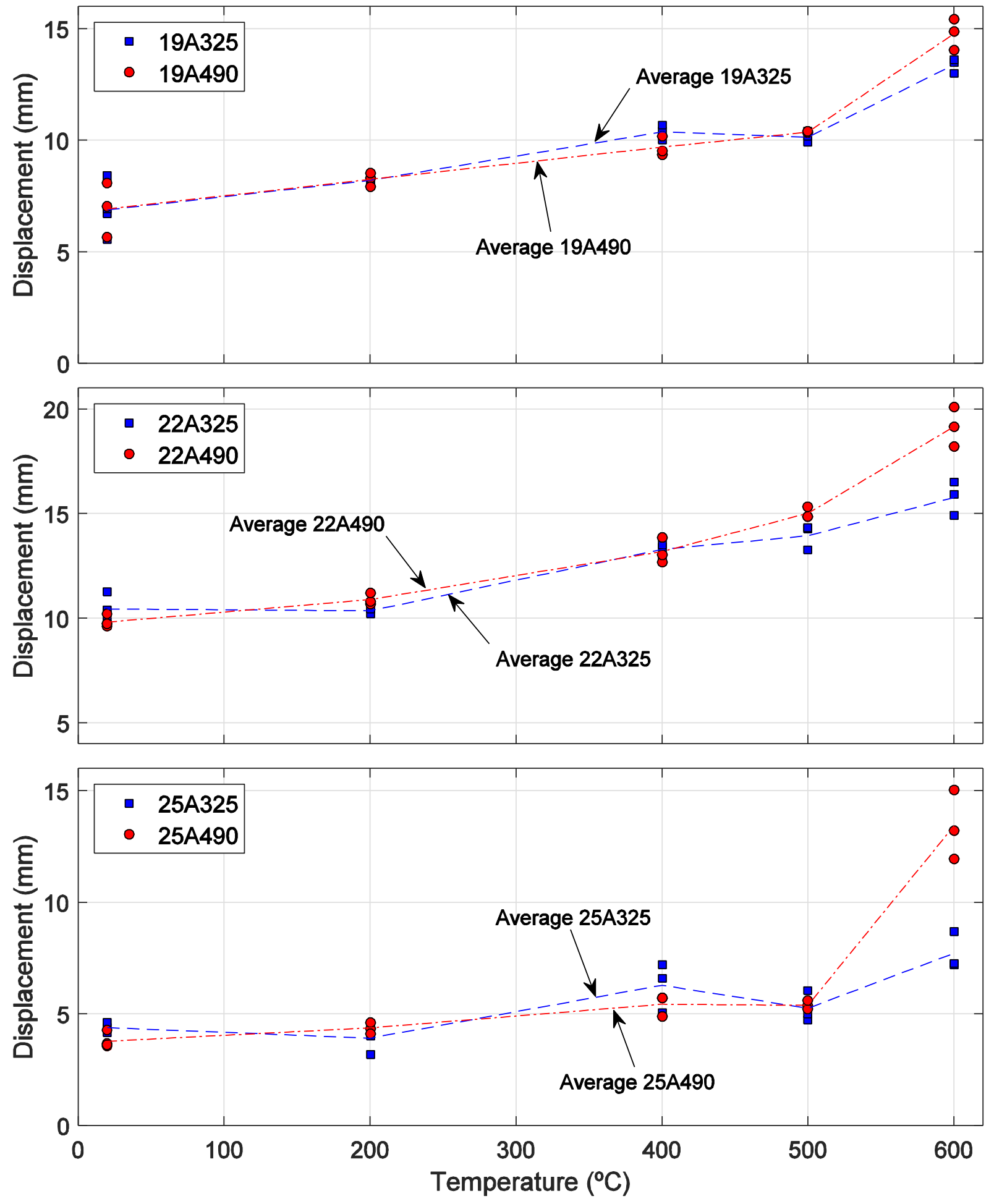

Figure 2-13 Displacement at failure versus temperature for: (a) $19 \mathrm{~mm}(3 / 4 \mathrm{in})$ bolts, (b) $22 \mathrm{~mm}(7 / 8 \mathrm{in})$ bolts, and (c) $25 \mathrm{~mm}(1 \mathrm{in})$ bolts.

$$
(1 \mathrm{in}=24.5 \mathrm{~mm})
$$




\subsubsection{Bolt Curvature after Testing}

Although this paper aims to only study the shear behavior of steel bolts, a small amount of bending is intrinsic in any experiment. To address and document this issue, after each bolt was tested, an image scanning was carried out, measuring the curvature of the bolt centerpiece located between both shear planes, as shown in Fig. 2-14.

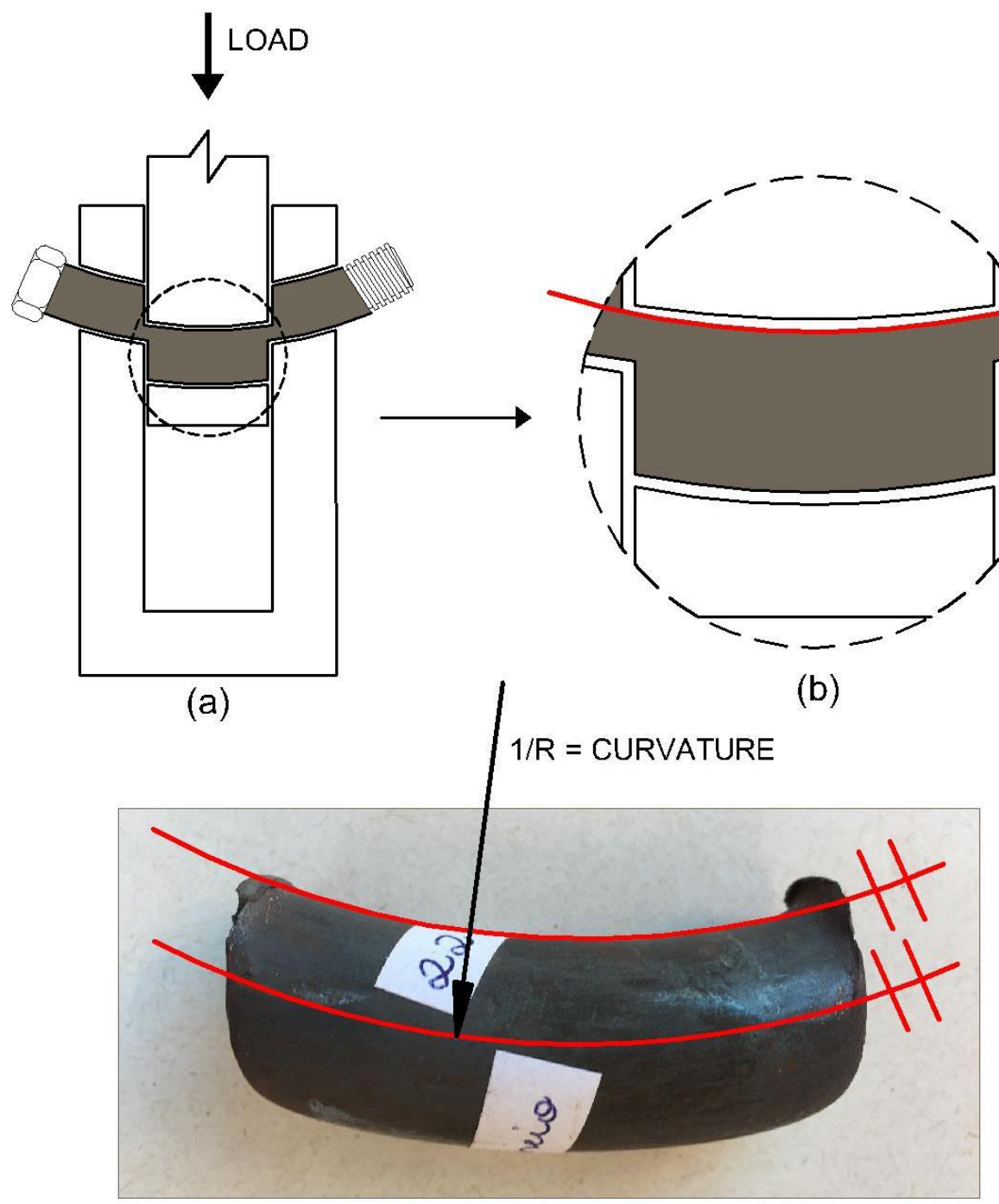

(c)

Figure 2-14 Curvature: (a) amplified deformed shape before complete bolt shear failure, (b) zoom in the bolt, and (c) photo showing bolt's curvature after testing. 


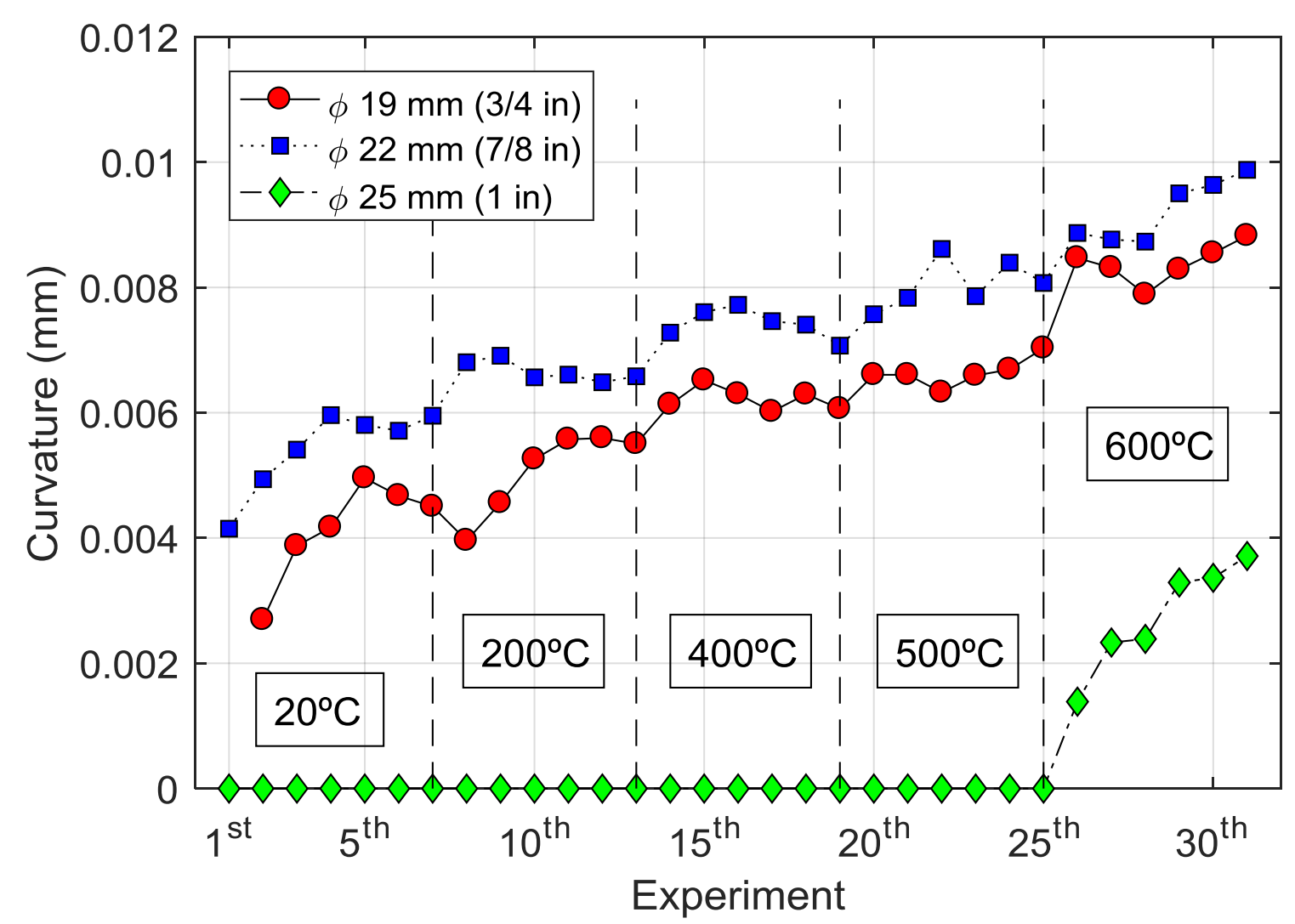

Figure 2-15 Curvature versus order of each experiment in the sequence of experiments.

$(1$ in $=24.5 \mathrm{~mm})$

Fig. 2-15 shows the increase in the final bolt curvature with the progression of the study for the different bolt sizes. The $19 \mathrm{~mm}$ ( $3 / 4 \mathrm{in})$ and $22 \mathrm{~mm}$ (7/8 in) diameter bolts had greater amounts of bending deformation after testing, and greater curvature, when compared to the $25 \mathrm{~mm}$ ( 1 in) diameter bolts; such observation is due to the fact that the testing blocks for the $25 \mathrm{~mm}$ ( 1 in) diameter bolts, which had higher strength and stiffness, allowed less local deformation which led to less bending. Also, the testing sequence due to the incremental bolt-hole deformation and increase in the testing temperature led to increased amounts of bending. Nonetheless, the amount of bending deformation was still small compared to the amount of shear deformation.

\subsubsection{Shear Plane Fracture}

Fig. 2-16 shows, pictures of the shear plane fracture of one bolt sample at each temperature; in this figure becomes clear: (i) the type of failure, varying from a clearer cut surface to a more viscous type of shear failure, and (ii) the change of coloration, varying from a clear silver color, to a blue coloration, and finally to a black coloration. 


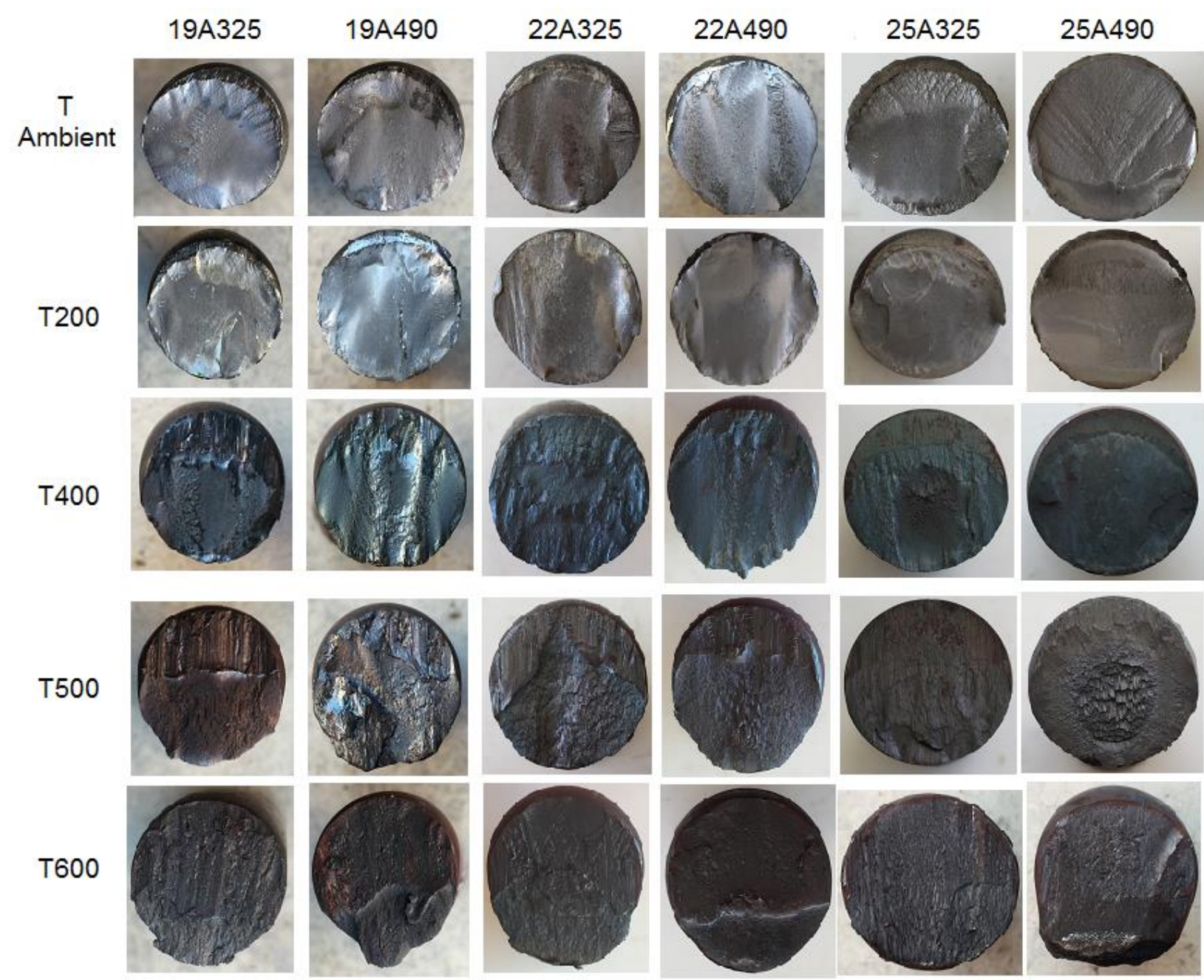

Figure 2-16 Pictures of bolts shear plane

For ambient temperature, the shear plane is brilliant, silver/grey color, smooth but not necessarily flat. Some shear planes present waves/undulations. The shear plane for $200{ }^{\circ} \mathrm{C}$ is very similar to that of the ambient temperature: brilliant, silver/grey color, little less smooth with some groove marks on the bottom. For both ambient temperature and $200{ }^{\circ} \mathrm{C}$, a slight plastic deformation is visible, due to the vertical bolt displacement during the loading.

At $400{ }^{\circ} \mathrm{C}$, the shear surface is rough and with parallel abrasion marks, indicating the increase in steel ductility. Also, the color becomes blue, due to the steel oxidation at this temperature. For $500{ }^{\circ} \mathrm{C}$, the shear plane shows larger parallel abrasions compared to $400{ }^{\circ} \mathrm{C}$. The color is not blue anymore, but it's still rough. At $600^{\circ} \mathrm{C}$, the shear plane shows a red/copper color and the entire 
surface is flat. The parallel abrasion marks are visible, however, they are softer, and a rough part extends along the entire bolt end, as the material starts to enter a major phase change at this temperature.

The shear planes of the $25 \mathrm{~mm}$ ( 1 in) diameter bolts are flatter than those of the $19 \mathrm{~mm}(3 / 4 \mathrm{in})$ and $22 \mathrm{~mm}$ (7/8 in) diameter bolts, though for ambient temperature and $200{ }^{\circ} \mathrm{C}$, the shear plane showed a kink on the surface. This is presumably, due using a different block set: the one used for the $25 \mathrm{~mm}$ ( 1 in) diameter tests did not have bolt hole deformation.

\subsubsection{Uncertainty of Measurements}

The experimental results presented in this report include temperatures, mechanical forces, and displacements. For each measurement, Type A and Type B uncertainties, combined standard uncertainties, and total expanded uncertainties were estimated. As defined in Taylor and Kuyatt (1994), Type A uncertainty was evaluated using statistical methods; Type B uncertainty was estimated by other means such as the information available in manufacturer's specifications or from past experience. The combined standard uncertainty was estimated by combining the individual uncertainties using "root-sum-of-squares" (Taylor and Kuyatt, 1994). The expended uncertainty was then computed by multiplying the combined uncertainty by a coverage factor of 2 corresponding to an approximately $95 \%$ confidence interval.

Table 2-5 summarizes various components of the measurement uncertainty. The zero and calibration elements were derived from instrument specifications. The resistive based sensors used in this test program, i.e. the load cells and the displacement transducers, have a linear calibration factor at ambient temperature (in the range of $20{ }^{\circ} \mathrm{C}$ to $45{ }^{\circ} \mathrm{C}$ ). The estimated calibration uncertainty was less than or approximately equal to $\pm 1 \%$. In this test program, those sensors were protected against excessive radiant heat from a fire or placed in the cool zone where the temperature exceeded no greater than $40{ }^{\circ} \mathrm{C}$. Other components, such as the position of the thermocouples, were estimated based upon past experience and previous data. The random and repeatability elements were statistically determined.

The combined standard uncertainty for steel temperature includes a component related to the position of thermocouples mounted in the steel beam specimen. A thermocouple having the nominal diameter (gauge) of $1.5 \mathrm{~mm}$ was placed through a $3.0 \mathrm{~mm}$ hole drilled in the blocks as shown in Fig. 2-2, until they touch the surface of the tested bolts. After reaching the desired testing temperature, the whole setup was held at that temperature for an additional fifteen minutes in order to ensure that the temperature of the specimen is the same as the surrounding air, and reduce the possibility of having the thermocouple partially exposed to either hot or cool surrounding air temperature. This effect could result a higher or cooler temperature than the reported steel 
temperature. With extra care and quality control checks during the installation process, this uncertainty was estimated to be less than $\pm 1 \%$. The measurements with the thermocouple embedded into the specimen were highly repeatable and resulted an estimate of $\pm 10 \%$ total expanded uncertainty.

The uncertainty in the measurement of mechanical forces, applied using the universal loading machine, was estimated at the manufacturer's specified operating temperature $\left(20{ }^{\circ} \mathrm{C}\right.$ to $\left.40{ }^{\circ} \mathrm{C}\right)$. The point load was measured using the machine's built-in load cell, which remained cool during the test. The force measurement was highly repeatable at ambient temperature and resulted an estimate of $\pm 9 \%$ total expanded uncertainty for the test configuration used in this study.

The displacement of the universal testing machine was monitored using an external linear variable displacement transducer (LVDT), which had an estimated standard uncertainty in the displacement measurements of as $\pm 2 \%$ for a displacement range of $1 \mathrm{~mm}$ to $100 \mathrm{~mm}$. The total expanded uncertainty for the displacement measurements in this study was estimated to be $\pm 11 \%$.

Table 2-6 Uncertainty in the experimental data measurements

\begin{tabular}{|l|c|c|c|c|}
\hline Measurement / Component & $\begin{array}{c}\text { Estimation } \\
\text { Method of } \\
\text { Uncertainty }\end{array}$ & $\begin{array}{c}\text { Component } \\
\text { Standard } \\
\text { Uncertainty }\end{array}$ & $\begin{array}{c}\text { Combined } \\
\text { Standard } \\
\text { Uncertainty }\end{array}$ & $\begin{array}{c}\text { Total } \\
\text { Expanded } \\
\text { Uncertainty }\end{array}$ \\
\hline Steel Temperature & Type B & $\pm 1 \%$ & & \\
Calibration & Type B & $\pm 1 \%$ & $\pm 5 \%$ & $\pm 10 \%$ \\
Installation & Type A & $\pm 1 \%$ & & \\
Random & Type A & $\pm 5 \%$ & & \\
Repeatability & & & & \\
\hline Point load & Type B & $\pm 0.2 \%$ & $\pm 4.5 \%$ & \\
Zero & Type B & $\pm 1 \%$ & \\
Calibration & Type A & $\pm 2 \%$ & \\
Random & Type A & $\pm 4 \%$ & & \\
Repeatability & & & & \\
\hline Displacement (LVTD) & Type B & $\pm 1 \%$ & \\
Zero & Type B & $\pm 0.1 \%$ & $\pm 5.5 \%$ & \\
Calibration & Type A & $\pm 2 \%$ & & \\
Random & Type A & $\pm 5 \%$ & & \\
Repeatability & & & \\
\hline
\end{tabular}

\section{$2.5 \quad$ SUMMARY}

This chapter presented results from recently conducted tests on high-strength structural bolts subject to double-shear loading at elevated temperatures. The parameters varied between tests included the bolt grade, bolt diameter, and temperature. Bolt grades A325 and A490 were tested. For each bolt grade, three different diameters were tested (19 mm (3/4 in), $22 \mathrm{~mm}$ (7/8 in), and $25.4 \mathrm{~mm}(1 \mathrm{in}))$ at five different temperatures $\left(20^{\circ} \mathrm{C}, 200{ }^{\circ} \mathrm{C}, 400{ }^{\circ} \mathrm{C}, 500{ }^{\circ} \mathrm{C}\right.$, and $\left.600{ }^{\circ} \mathrm{C}\right)$. At least 
three tests were conducted for each combination of parameters. Degradations in the mechanical and material properties including stiffness, strength, and deformation at fracture, were characterized and presented herein. The results from these experiments fill a critical knowledge gap currently present in the literature regarding the behavior of high-strength structural bolts under shear loading at elevated temperatures.

Results showed that up to $200^{\circ} \mathrm{C}$, the bolts do not lose their shear strength if compared to ambient temperature, however, the deformation is higher. As the temperature increases, the shear strength gradually decreases. Under $400{ }^{\circ} \mathrm{C}$, the bolts held approximately $82 \%$ of their initial strength. At $500{ }^{\circ} \mathrm{C}$, the $\mathrm{A} 325$ and $\mathrm{A} 490$ bolts both held about $60 \%$ of the initial shear strength. At $600{ }^{\circ} \mathrm{C}$, the bolts were down to about $35 \%$ of their initial resistance. Development of temperature dependent material models for high strength bolts that capture the behavior observed in this study is currently underway. 


\section{Chapter 3 \\ CoRRected DATA}

\section{$3.1 \quad$ INTRODUCTION}

This Chapter presents the procedure used to remove the effects of initial bearing deformation from the bolt double-shear force-deformation data presented in Chapter 2. By removing these initial deformations, the bolt double-shear behavior is uncoupled from the flexure behavior, discussed in Section 2.4.1, caused by the initial bearing deformations of the testing blocks. The initial bearing deformations were especially significant in the data from the $19 \mathrm{~mm}(3 / 4 \mathrm{in})$ and the $22 \mathrm{~mm}$ (7/8 in) diameter bolts).

\subsection{REMOVING INITIAL BEARING DEFORMATIONS}

The bolt double-shear load-deformation data in Chapter 2 had a reduced stiffness at low load levels (e.g., see Fig. 3-1 (a)) due to the initial bearing deformations in the loading and reaction blocks (as discussed in Section 2.4.1). The stiffness increased as full contact was established between the bolt shaft and the faces of the holes in the testing blocks. The initial-deformation portion of the bolt response is identifiable by the upward concavity of the bolt load-deformation response.

The component-based model for the bolt double-shear load-deformation response, presented in Chapter 4, was formulated as if the bolt was in full bearing contact with the faces of the holes in the testing blocks at onset of applied loading. Therefore, the parameters for the component-based model were fitted to a subset of the data, corresponding to the data from Chapter 2 for only the $25 \mathrm{~mm}$ ( 1 in) diameter bolts without the initial reduced-stiffness portions. The portion of the data used in fitting the parameters of the component-based model were selected using the following procedure:

1. Select data from an individual bolt test (Fig. 3-1(a)).

2. Calculate the slope of the bolt load-deformation response (Fig. 3-1 (b)). In this chapter, complex step differentiation was used; however, other numerical differentiation methods such as central-differencing are also acceptable.

3. Calculate the initial stiffness as the slope obtained from linear regression of the bolt loaddeformation data for which the slope exceeds $95 \%$ of the peak slope. Fig. 3-1 (b) indicates the slope values that exceeded $95 \%$ of the peak slope, and the corresponding loaddeformation data points are also indicated in Fig. 3-1 (c). 
4. Select data lying above the linear regression line to be used in fitting the parameters of the component-based model (Fig. 3-1 (c)).

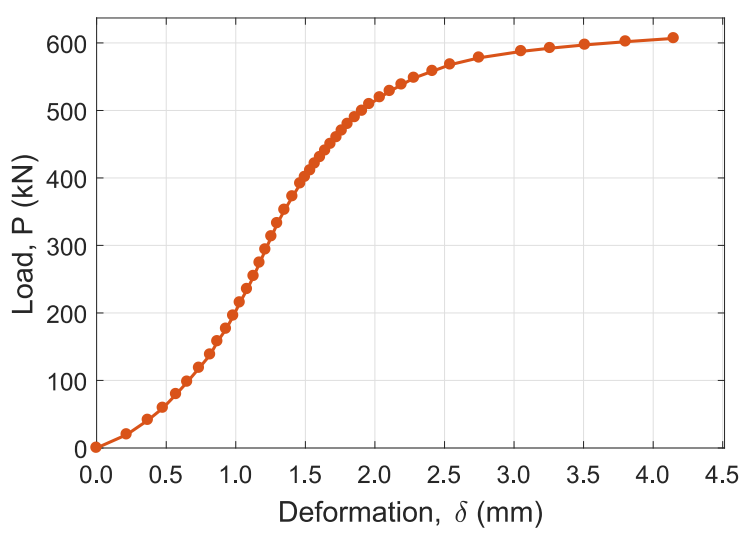

(a)

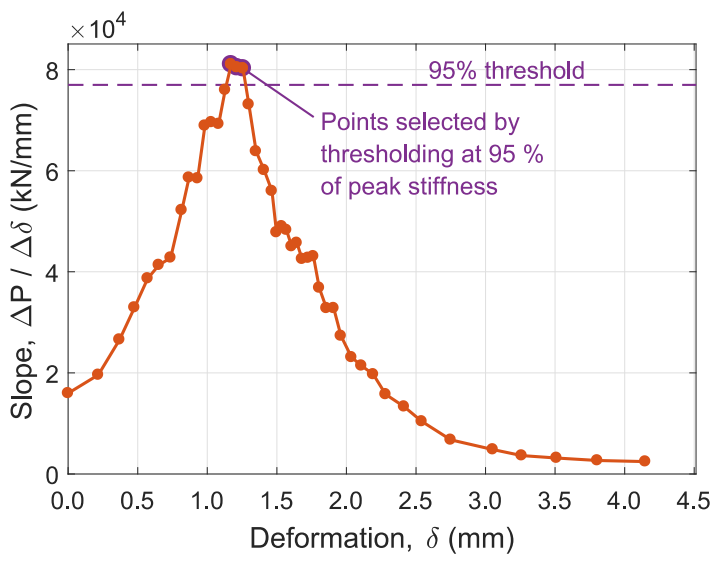

(b)

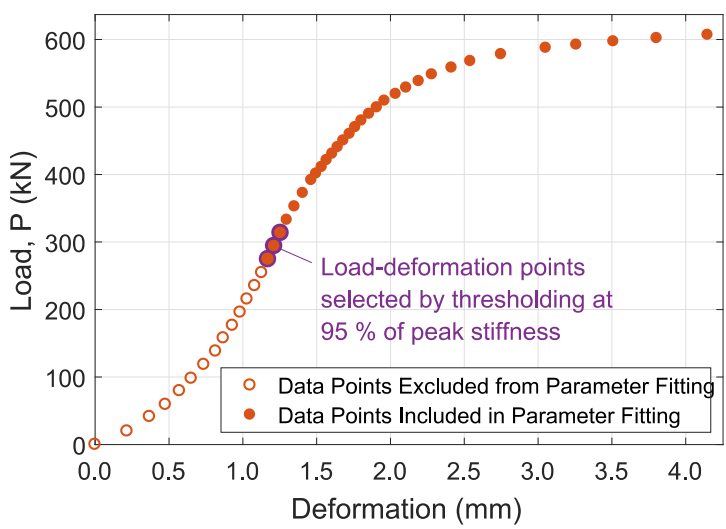

(c)

Figure 3-1: (a) Data from an individual bolt load-deformation response, (b) slope of bolt load-deformation response, and (c) selected data to be used in fitting the parameters of the component-based model.

The procedure to remove the initial deformations was first applied to the $25 \mathrm{~mm}$ (1 in) diameter bolts. Fig. 3-2 shows the data selected to be used in fitting the parameters of the component-based model described in Chapter 4 for each of the $25 \mathrm{~mm}$ (1 in) diameter grade A325 and A490 bolt specimens, respectively. The procedure to exclude the data influenced by the initial bearing deformations was applied uniformly across all of the $25 \mathrm{~mm}$ (1 in) diameter bolt specimens, and did not influence their double-shear capacity. It is noted that only the data from the $25 \mathrm{~mm}$ ( 1 in) diameter bolts was chosen for the formulation of the component-based model described in Chapter 4, as it had the minimal influence from the initial bearing deformations due to using the stronger testing blocks as detailed in Chapter 1. 
The same procedure was also uniformly applied to the data from the $19 \mathrm{~mm} \mathrm{(3/4} \mathrm{in)} \mathrm{and} 22 \mathrm{~mm}$ (7/8 in) diameter bolts, and the data lying above the linear regression line are shown in Figs. 3-3 and 3-4 (as the solid, rather than dashed lines). Figs. 3-5 and 3-6 show the data from the $19 \mathrm{~mm}$ (3/4 in) and $22 \mathrm{~mm}$ (7/8 in) diameter grade A325 and A490 bolts, respectively, with the initial bearing deformations $\delta_{0}$ removed. Data from these smaller-diameter bolts were not used in fitting the parameters of the component-based model described in Chapter 4.

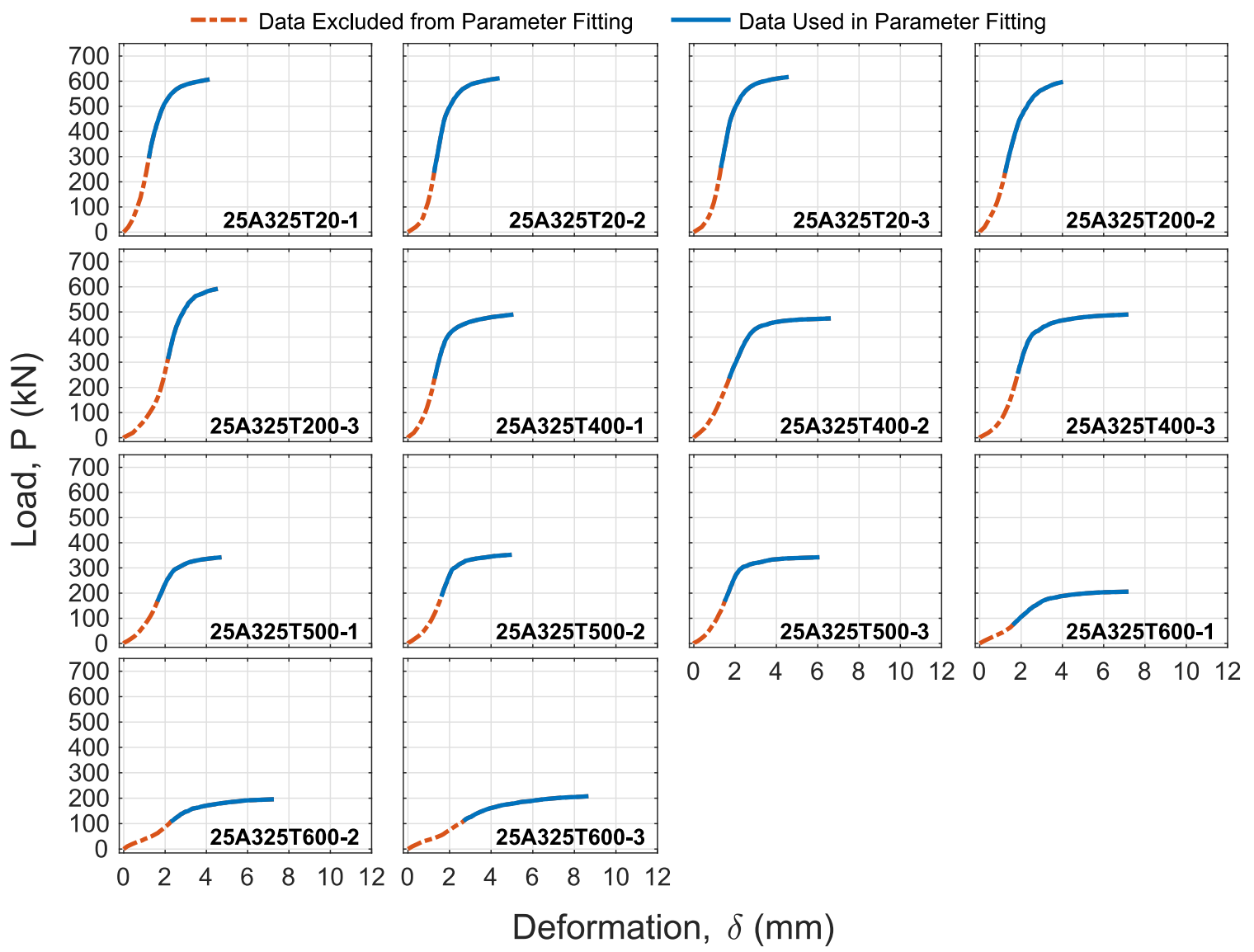

(a) 


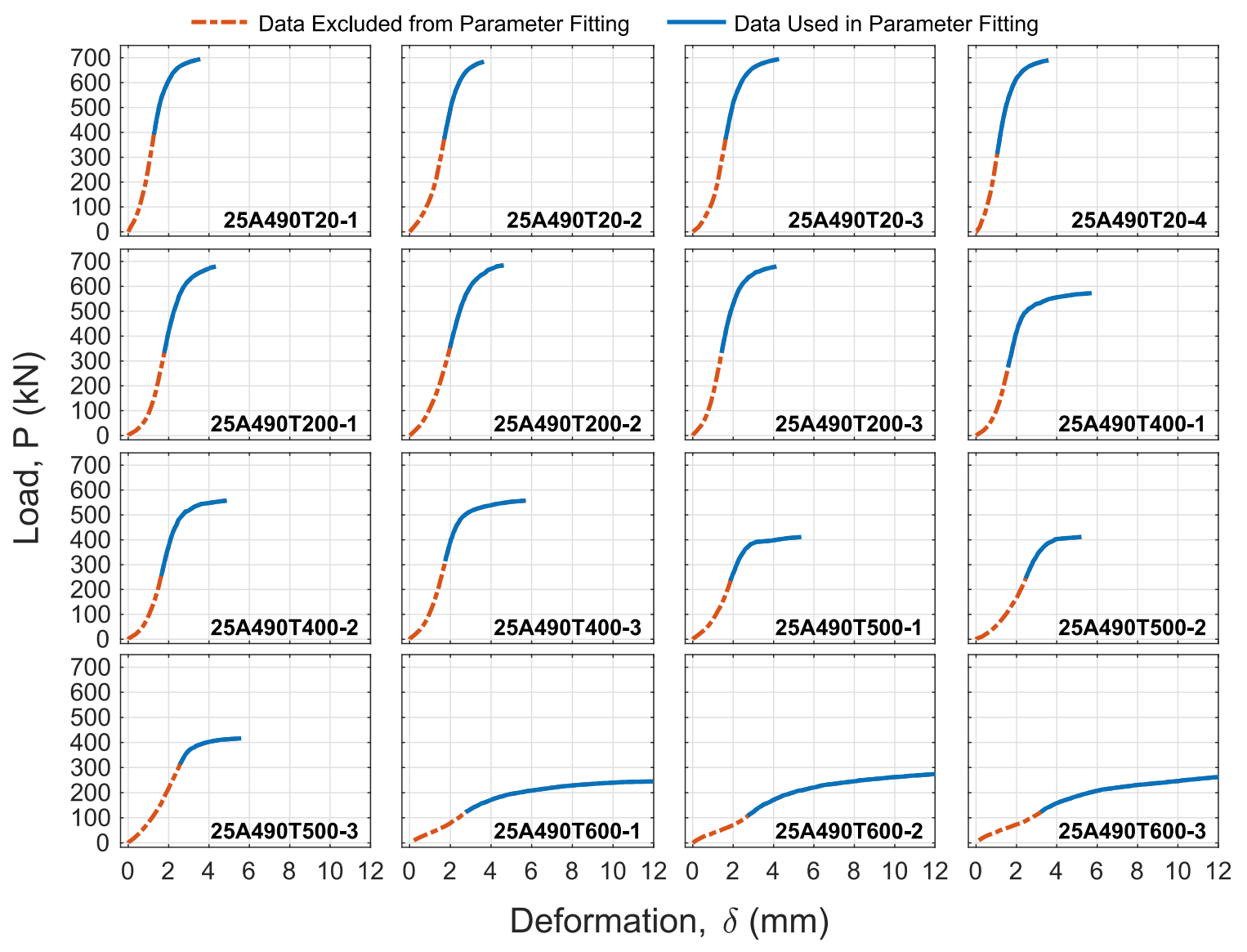

(b)

Figure 3-2: Data used in parameter fitting for 25 mm (1 in) diameter (a) A325 bolt specimens and (b) A490 bolt specimens. 


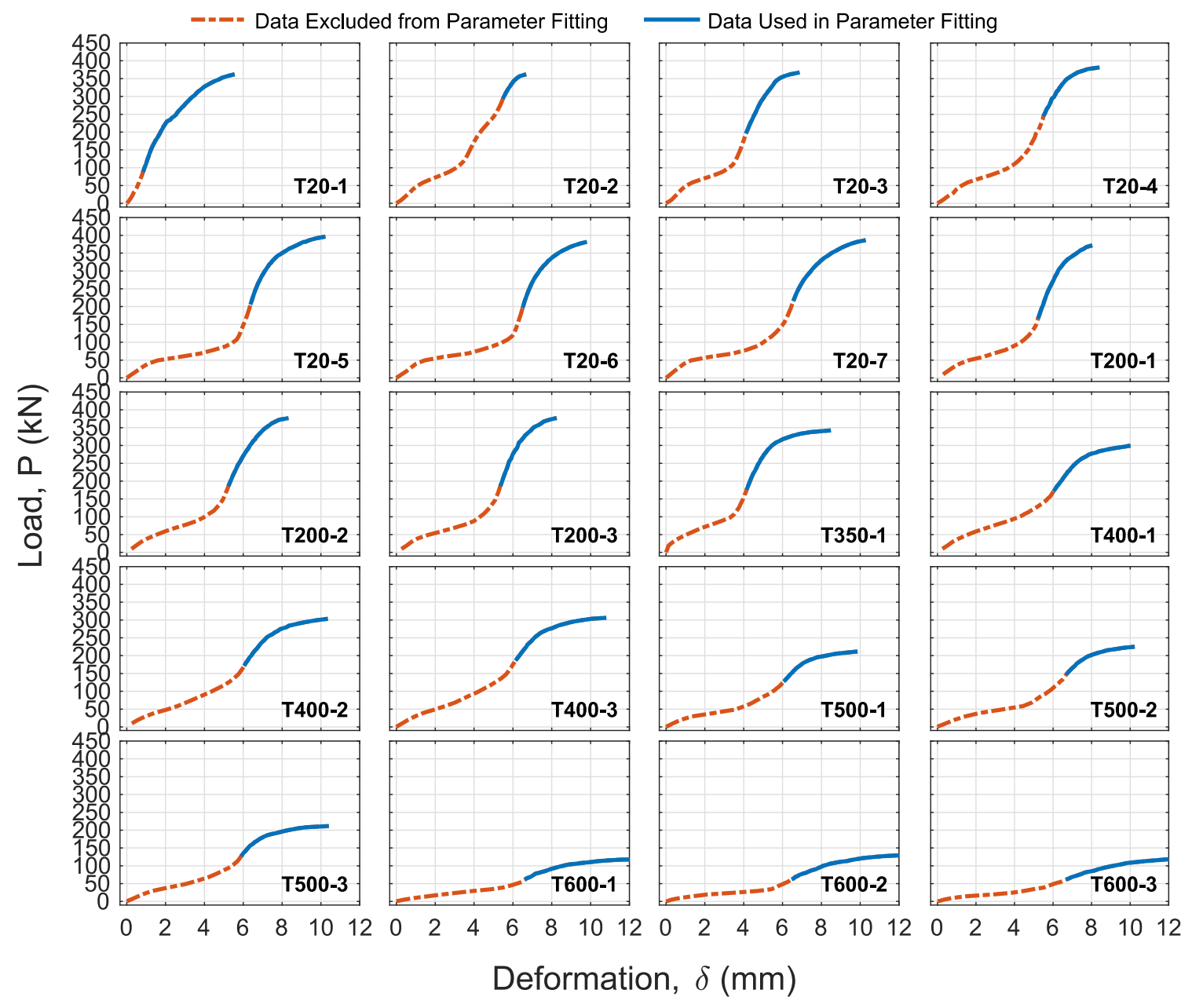

(a) 


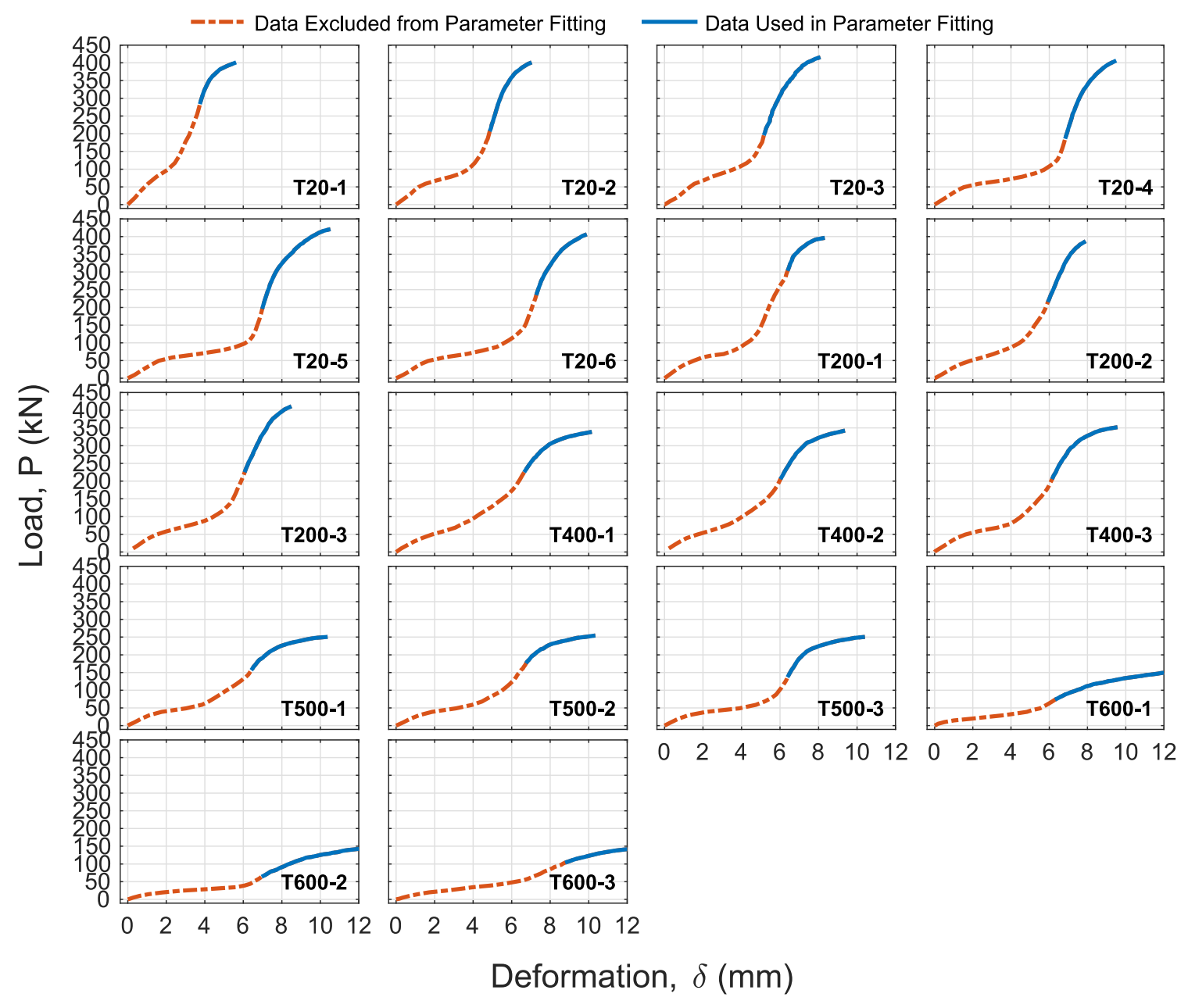

(b)

Figure 3-3: Portion of data lying above the linear regression line for $19 \mathrm{~mm}(3 / 4 \mathrm{in})$ diameter (a) A325 bolt specimens and (b) A490 bolt specimens. 


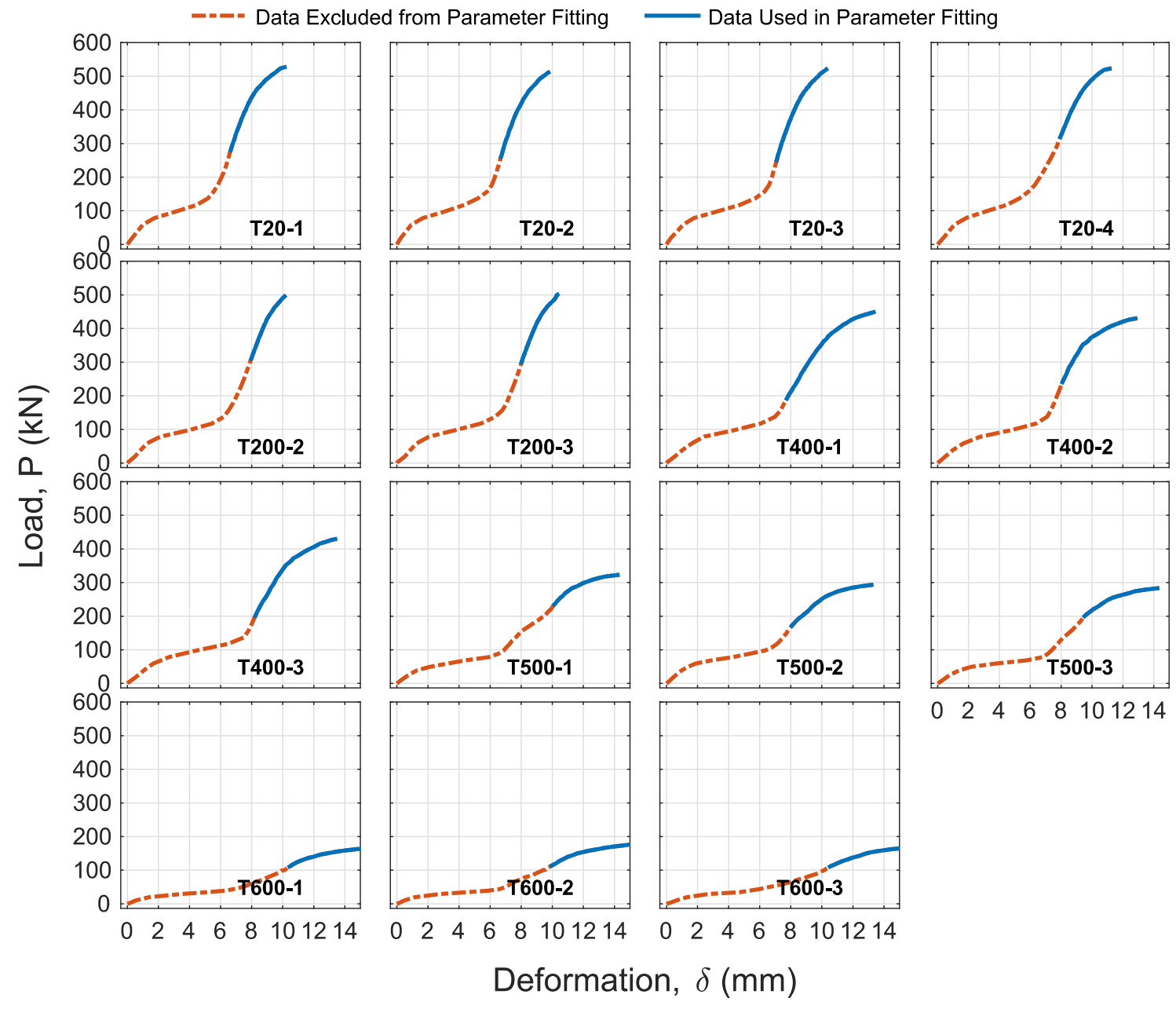

(a) 


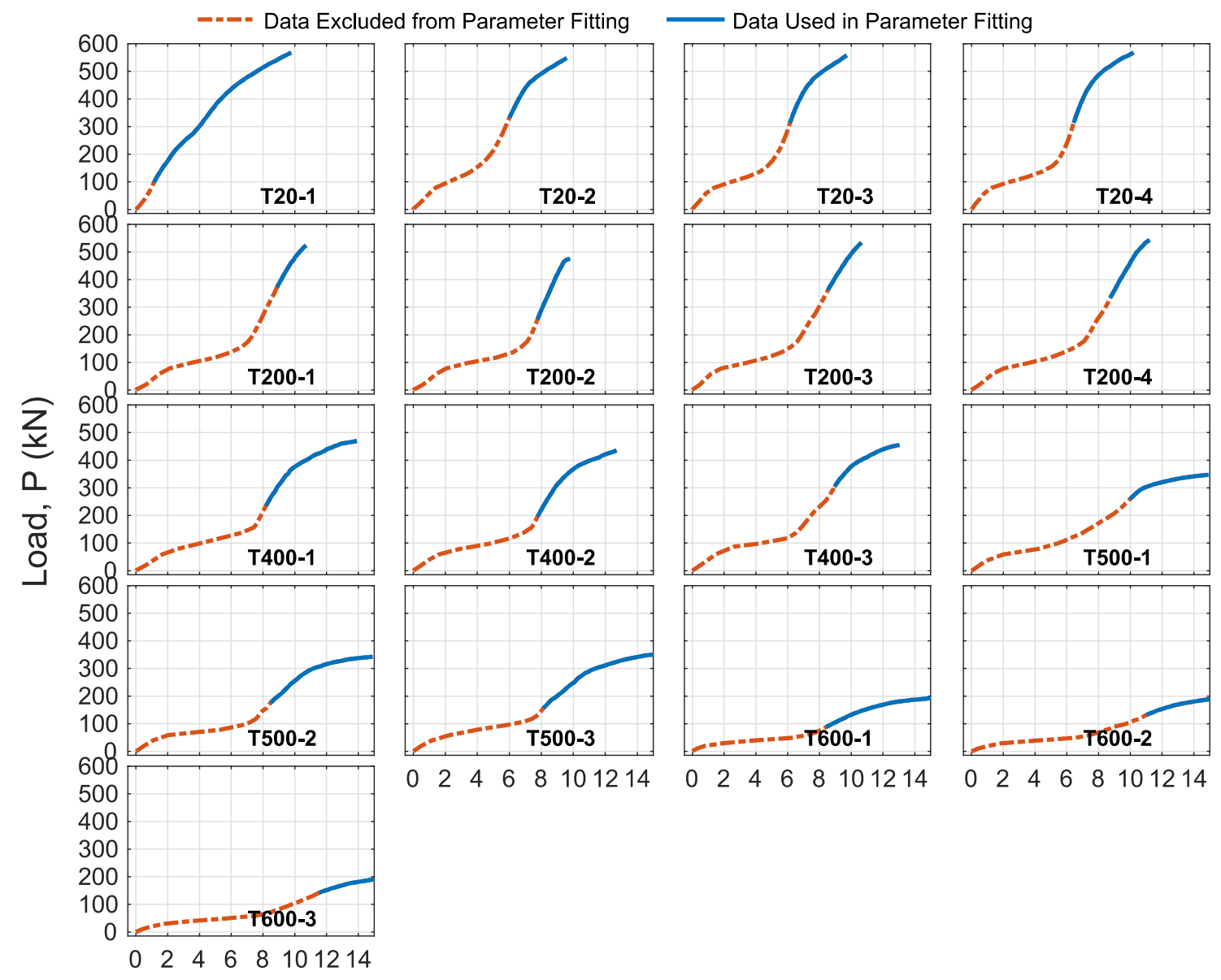

Deformation, $\delta(\mathrm{mm})$

(b)

Figure 3-4: Portion of data lying above the linear regression line for $22 \mathrm{~mm}$ (7/8 in) diameter (a) A325 bolt specimens and (b) A490 bolt specimens. 


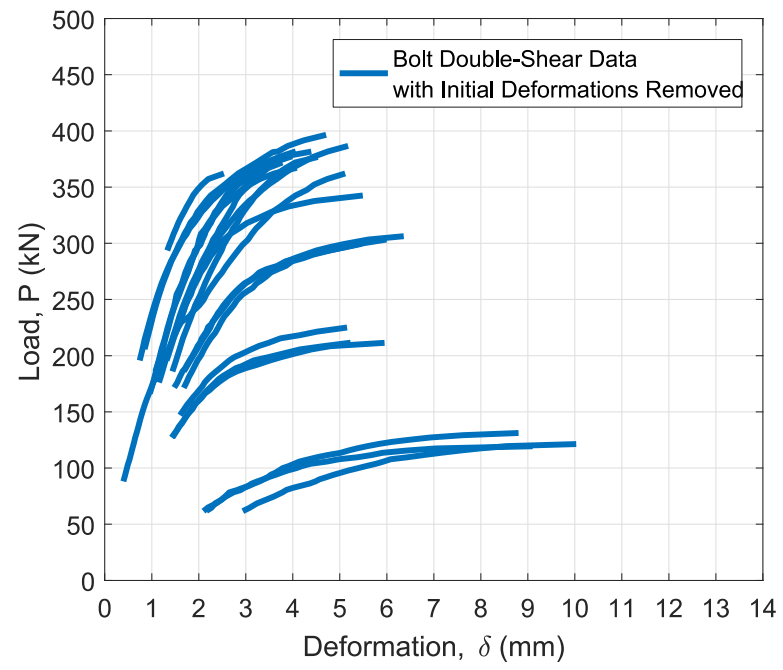

(a)

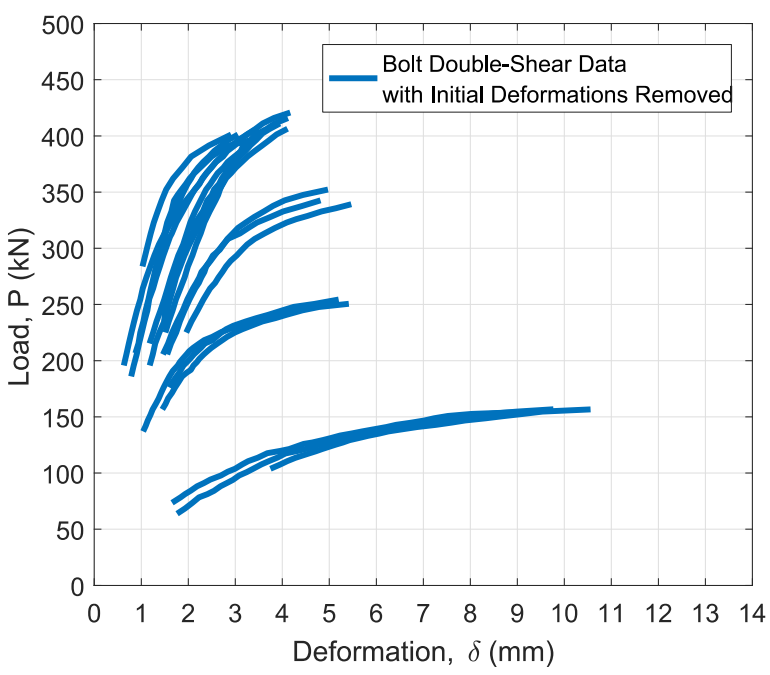

(b)

Figure 3-5: Experimental data (with initial bearing deformations removed) for $19 \mathrm{~mm}$ (3/4 in) diameter (a) A325 bolts and (b) A490 bolts.

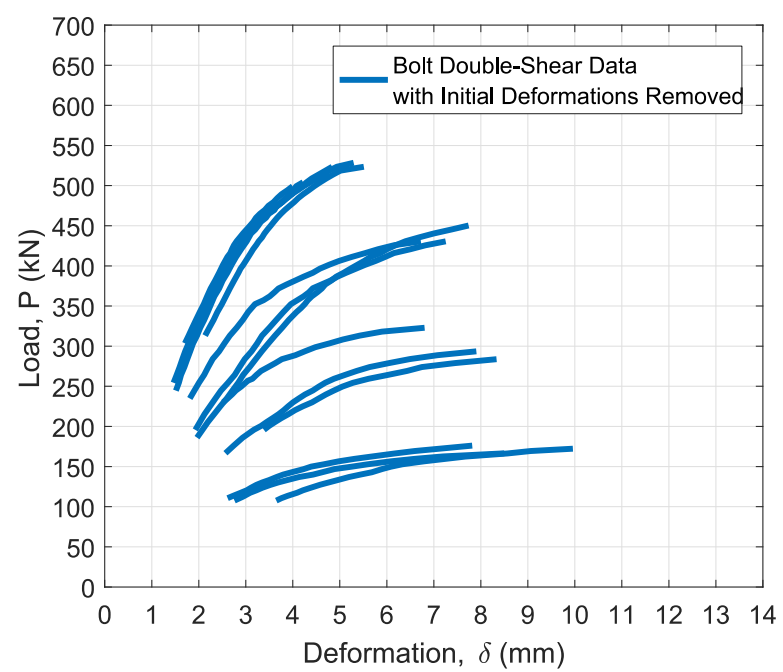

(a)

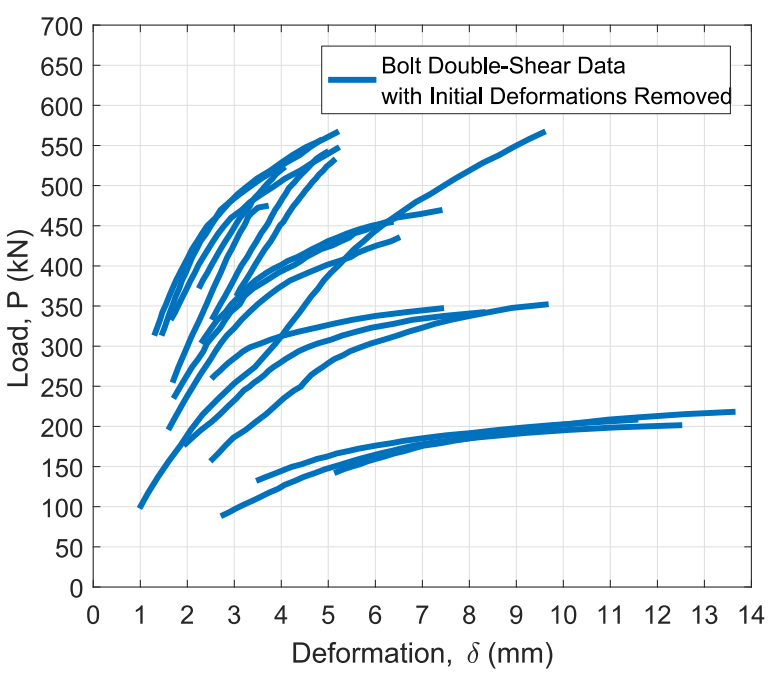

(b)

Figure 3-6: Experimental data (with initial bearing deformations removed) for $22 \mathrm{~mm}$ (7/8 in) diameter (a) A325 bolts and (b) A490 bolts. 


\subsection{SUMMARY, CONCLUSIONS, AND LIMITATIONS}

In this chapter, a procedure was used to remove initial bearing deformations from the bolt doubleshear force-deformation data for $19 \mathrm{~mm}$ ( $3 / 4 \mathrm{in}), 22 \mathrm{~mm}$ (7/8 in), $25 \mathrm{~mm}$ ( 1 in) diameter bolts presented in Chapter 2. These data are critical since the component-based model for the bolt double-shear load-deformation response, which is presented in Chapter 4, was formulated as if the bolt was in full bearing contact with the faces of the holes in the testing blocks at onset of applied loading. The data for the $25 \mathrm{~mm}$ ( 1 in) diameter bolts, with bearing deformations removed, is used to formulate the component-based model in the next chapter. 


\section{Chapter 4 \\ COMPONENT-BASEd MODELLING APPROACH}

\subsection{INTRODUCTION}

While high-fidelity finite element models permit explicit modeling of the bolt and plate geometries, and provide the capabilities to directly capture complex phenomena such as bearing deformations due to contact between the bolt and plate holes and rupture of the bolt in shear, they may be infeasible for modeling of complete structural systems. Phenomenological componentbased models offer considerable advantages in computational efficiency over high-fidelity finite element models, while still providing sufficient resolution to capture the primary characteristics of the response. In component-based models, the individual components of a connection are discretized into component springs, which have fully prescribed strength and stiffness characteristics. In component-based modeling of the double-shear test fixture shown in Fig. 2-2, each half-length of the bolt would be modeled using three components, representing the bolt shaft (deformable in shear) with stiffness $k_{\text {bolt }}$, the loading block with stiffness $k_{\text {loadplt }}$, and the reaction block with stiffness $k_{\text {reactplt }}$ (Fig. 4-1). However, both direct and indirect measurements showed that deformations in the loading and reaction blocks accounted for less than $1 \%$ of the total deformation in the experimental setup. Thus, for simplicity, bearing deformations in the loading and reaction blocks were ignored (i.e., the loading and reaction blocks were modeled as rigid). The constitutive behavior for the bolts in double-shear was formulated based on a previous componentbased model for single-shear behavior in bolts, which was part of a component-based connection model for single-plate shear connections by Weigand (2016). The model in Weigand (2016) was previously validated, at ambient temperatures, against double-shear tests of bolts from Weigand (2014) and additionally tests of single-plate shear connections from Crocker and Chambers (2004) and Weigand and Berman (2014). 


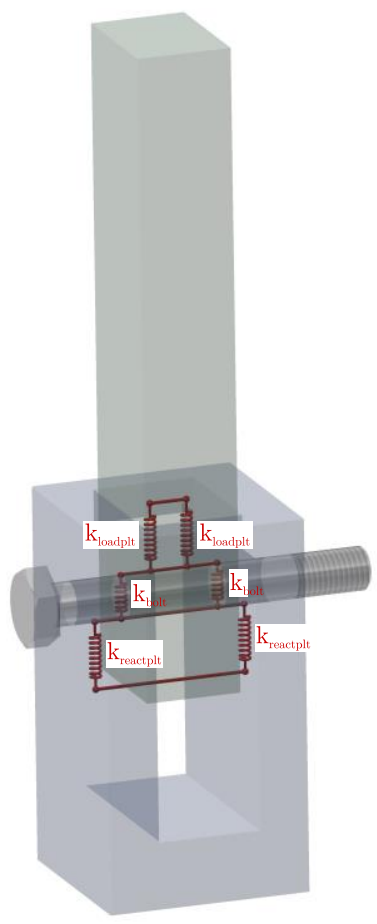

Figure 4-1: Schematic representation of spring assembly used to model bolt double-shear test assembly.

Isolating the bolt component spring behavior from the model in Weigand (2016), the transverse load-deformation behavior of the bolt, including shear and flexural effects, is modeled using the nonlinear four-parameter "Richard Equation", which was formulated by Richard and Abbott (1975):

$$
P(\delta)=\frac{\left(k_{\mathrm{i}}+k_{\mathrm{p}}\right) \delta}{\left(1+\left|\frac{\left(k_{\mathrm{i}}+k_{\mathrm{p}}\right) \delta}{r_{\mathrm{n}}}\right|^{n}\right)^{(1 / n)}}+k_{\mathrm{p}} \delta
$$

where $\delta$ is the bolt shear deformation, $k_{\mathrm{i}}$ and $k_{\mathrm{p}}$ are elastic and plastic stiffnesses of the bolt double-shear load-deformation response, respectively, $n$ is a shape parameter that controls the sharpness of the transition from the elastic stiffness to the plastic stiffness, and $r_{n}$ is a reference load. Eq. (4-1) can be extended to include the effects of elevated temperatures on the bolt shear load-deformation response such that:

$$
P(\delta, T)=\frac{\left(k_{\mathrm{i}}(T)+k_{\mathrm{p}}(T)\right) \delta}{\left(1+\left|\frac{\left(\mathrm{k}_{\mathrm{i}}(T)+k_{\mathrm{p}}(T)\right) \delta}{r_{\mathrm{n}}(T)}\right|^{n(T)}\right)^{(1 / n(T))}}+k_{\mathrm{p}}(T) \delta
$$


where $(T)$ denotes dependence of the stiffness or capacity parameter on temperature. Where possible, temperature-dependence is included by incorporating temperature-dependent bolt steel mechanical properties directly into the equations describing the bolt response.

\subsection{CALCULATION OF EQUATION PARAMETERS}

While fitted values for the parameters in Eq. (4-2) were ultimately determined using structural optimization techniques, close first-order approximations for the parameters (typically within $10 \%-40 \%$ of the globally optimized value, depending on the parameter) can be calculated based on linear least-squares regression of the bolt shear load-deformation data, since the Richard Equation has asymptotic limits of $k_{\mathrm{i}}$ at $\delta=0$ and $k_{\mathrm{p}}$ at $\delta=\delta_{\mathrm{u}}$ (where $\delta_{\mathrm{u}}$ is the ultimate deformation of the bolt). These approximate values are used to initialize the optimization scheme, reducing its computational cost and increasing its likelihood of finding the globally optimized solution.

Fig. 4-2 shows a graphical representation of the calculated first-order approximations for a representative bolt double-shear load-deformation curve. An estimate for the initial stiffness of the bolt double-shear load-deformation response at temperature $T, k_{\mathrm{i}}(T)$, was already previously calculated (in Step 3 of the portion of the data used in fitting the parameters of the componentbased model - see Section 3.2) as the slope of the linear least-squares regression of the bolt loaddeformation data exceeding $95 \%$ of the peak slope. The initial bearing deformation is estimated as the value of the initial stiffness regression line at zero load, or

$$
\boldsymbol{\delta}_{\mathbf{0}} \approx-\frac{\boldsymbol{b}_{\boldsymbol{k}_{\mathbf{i}}}(T)}{\boldsymbol{k}_{\mathrm{i}}(T)}
$$

where $b_{k_{\mathrm{i}}}(T)$ is the constant term of the linear regression. The plastic stiffness $k_{\mathrm{p}}(T)$ is calculated in a similar manner as the initial stiffness, but as the slope of the linear least-squares regression to the last four points of the bolt load-deformation response at the bolts' maximum plastic deformations. The reference load corresponds to the projection of the plastic stiffness at a deformation of $\delta_{0}$, and is thus calculated as

$$
r_{\mathrm{n}}(T) \approx b_{k_{\mathrm{p}}}(T)+k_{\mathrm{p}}(T) \delta_{0}
$$


where $b_{k_{\mathrm{p}}}(T)$ is the constant term of the linear least-squares regression defining the plastic stiffness. The value of the shape parameter was determined using an iterative procedure to minimize the residual between Eq. (4-2) (using the already-fitted values for temperaturedependent initial stiffness $k_{\mathrm{i}}(T)$, plastic stiffness $k_{\mathrm{p}}(T)$, and reference load $r_{\mathrm{n}}(T)$, and the data from each individual bolt double-shear load-deformation curve.

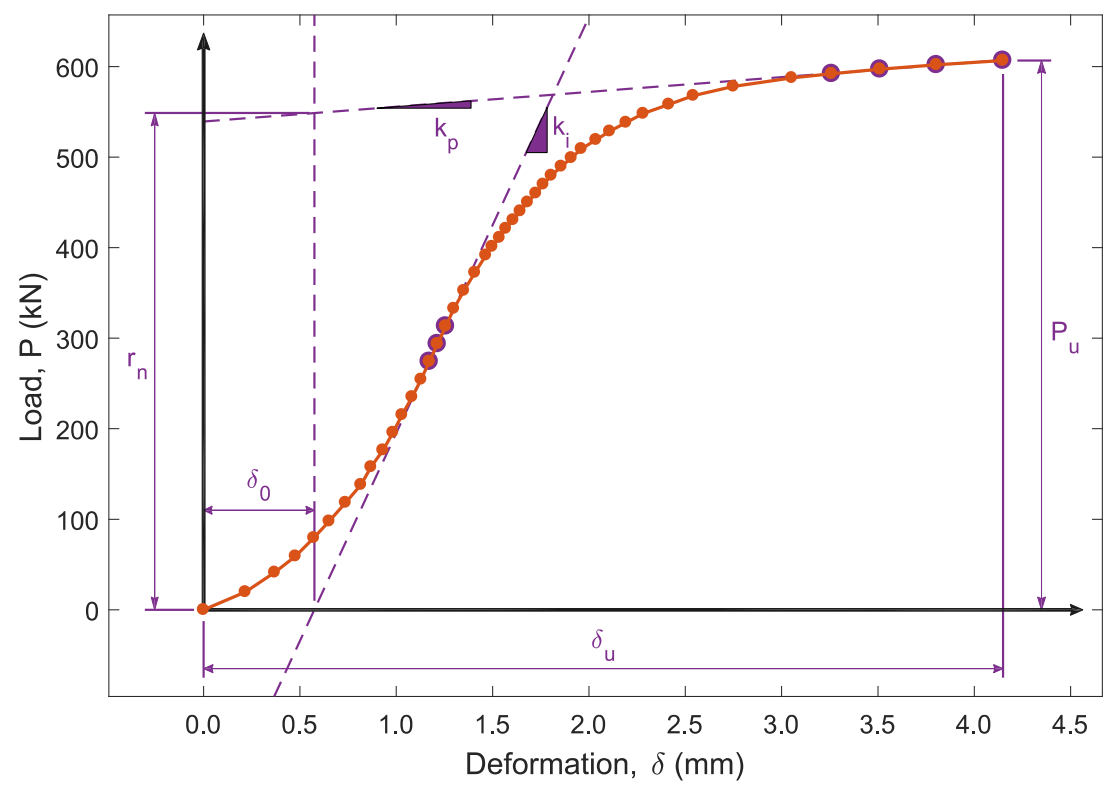

Figure 4-2: First-order approximation of Richard Equation parameters.

The globally optimized values for the parameters of Eq. (4-2) were determined using global optimization (a global search algorithm developed by Ugray et al. (2007) and available in MATLAB's Global Optimization Toolbox (MathWorks, 2016a). This algorithm initially executes gradient-based local optimizations from a large number of starting points from within the parameter space, selecting the local optimization result with the minimum objective function value as the starting point to execute the final global optimization. The global search algorithm was initialized using the first-order approximations for the parameters in Eq. (4-2), which in effect scatters the starting points for the local optimizations in the vicinity of the initial point. Table 4-1 presents a summary of the final fitted parameters for each individual bolt specimen, and the parameter values are also shown graphically in Figs. 4-3 and 4-4 for the $25 \mathrm{~mm}$ (1 in) diameter A325 and A490 bolts, respectively. 
Table 4-1: Summary of measured and fitted curve parameters for bolt shear data.

\begin{tabular}{|c|c|c|c|c|c|c|c|c|}
\hline $\begin{array}{l}\text { Specimen } \\
\text { Name }\end{array}$ & $\begin{array}{l}\mathrm{T} \\
{ }^{\circ} \mathrm{C}\end{array}$ & $\begin{array}{l}k_{\mathrm{i}}(T) \\
\mathrm{kN} / \mathrm{mm} \text { (kip/in) }\end{array}$ & $\begin{array}{l}k_{\mathrm{p}}(T) \\
\mathrm{kN} / \mathrm{mm} \text { (kip/in) }\end{array}$ & $\begin{array}{l}k_{\mathrm{p}}(T) \\
/ k_{\mathrm{i}}(T)\end{array}$ & $\begin{array}{l}r_{\mathrm{n}}(T) \\
\mathrm{kN} \text { (kip) }\end{array}$ & $\begin{array}{l}v_{\mathrm{n}}(T) \\
\mathrm{kN} \text { (kip) }\end{array}$ & $\begin{array}{l}n(T) \\
-\end{array}$ & $\begin{array}{l}\delta_{0}(T) \\
\mathrm{mm} \text { (in) }\end{array}$ \\
\hline $25 \mathrm{~A} 325 \mathrm{~T} 20-1$ & 20 & $406246(2319.7)$ & $9649(55.1)$ & 0.024 & $574.1(129.1)$ & $606.7(136.4)$ & 4.11 & $0.46(0.018)$ \\
\hline $25 \mathrm{~A} 325 \mathrm{~T} 20-2$ & 20 & $563716(3218.9)$ & 9211 (52.6) & 0.016 & $583.7(131.2)$ & 612.4 (137.7) & 3.11 & $0.84(0.033)$ \\
\hline $25 \mathrm{~A} 325 \mathrm{~T} 20-3$ & 20 & $531428(3034.5)$ & 6938 (39.6) & 0.013 & $594.8(133.7)$ & 617.0 (138.7) & 3.2 & $0.83(0.033)$ \\
\hline 25A325T200-1 & 200 & $403817(2305.9)$ & $12959(74.0)$ & 0.032 & $565.7(127.2)$ & $598.7(134.6)$ & 3.21 & $0.64(0.025)$ \\
\hline 25A325T200-2 & 200 & 447788 (2556.9) & $13990(79.9)$ & 0.031 & $557.4(125.3)$ & $594.2(133.6)$ & 3.48 & $1.42(0.056)$ \\
\hline $25 \mathrm{~A} 325 \mathrm{~T} 400-1$ & 400 & 631536 (3606.2) & $7541(43.1)$ & 0.012 & $461.4(103.7)$ & 489.7 (110.1) & 2.37 & $0.89(0.035)$ \\
\hline $25 \mathrm{~A} 325 \mathrm{~T} 400-2$ & 400 & 219143 (1251.3) & 3205 (18.3) & 0.015 & 455.6 (102.4) & 474.6 (106.7) & 5.76 & $0.63(0.025)$ \\
\hline $25 \mathrm{~A} 325 \mathrm{~T} 400-3$ & 400 & $581838(3322.4)$ & $3361(19.2)$ & 0.006 & $475.4(106.9)$ & $491.6(110.5)$ & 2.11 & $1.34(0.053)$ \\
\hline $25 \mathrm{~A} 325 \mathrm{~T} 500-1$ & 500 & 235309 (1343.6) & 7358 (42.0) & 0.031 & $315.8(71.0)$ & $342.6(77.0)$ & 4.05 & $0.92(0.036)$ \\
\hline $25 \mathrm{~A} 325 \mathrm{~T} 500-2$ & 500 & 349763 (1997.2) & 5968 (34.1) & 0.017 & $329.8(74.1)$ & $352.3(79.2)$ & 3.32 & $1.07(0.042)$ \\
\hline 25A325T500-3 & 500 & $317683(1814.0)$ & $2633(15.0)$ & 0.008 & $331.1(74.4)$ & $343.6(77.3)$ & 3.02 & $0.97(0.038)$ \\
\hline $25 \mathrm{~A} 325 \mathrm{~T} 600-1$ & 600 & 90775 (518.3) & $2082(11.9)$ & 0.023 & 194.1 (43.6) & $206.3(46.4)$ & 3.58 & $0.80(0.032)$ \\
\hline $25 \mathrm{~A} 325 \mathrm{~T} 600-2$ & 600 & $162149(925.9)$ & $2658(15.2)$ & 0.016 & $188.4(42.3)$ & $197.2(44.3)$ & 1.73 & $1.45(0.057)$ \\
\hline $25 \mathrm{~A} 325 \mathrm{~T} 600-3$ & 600 & $110453(630.7)$ & 2551 (14.6) & 0.023 & $200.4(45.1)$ & 208.7 (46.9) & 1.72 & $1.41(0.055)$ \\
\hline Average & - & $360832(2060.4)$ & $6436(36.8)$ & 0.019 & 416.3 (93.6) & 438.3 (98.5) & 3.2 & $0.98(0.038)$ \\
\hline 25A325T20-1 & 20 & $475164(2713.3)$ & $15106(86.3)$ & 0.032 & $652.5(146.7)$ & $696.2(156.5)$ & 4.54 & $0.42(0.016)$ \\
\hline 25A325T20-2 & 20 & $523028(2986.6)$ & 19773 (112.9) & 0.038 & 643.1 (144.6) & $687.9(154.6)$ & 3.99 & $0.97(0.038)$ \\
\hline $25 \mathrm{~A} 325 \mathrm{~T} 20-3$ & 20 & $509413(2908.8)$ & $11016(62.9)$ & 0.022 & $664.2(149.3)$ & $696.3(156.5)$ & 3.7 & $0.87(0.034)$ \\
\hline $25 \mathrm{~A} 325 \mathrm{~T} 20-4$ & 20 & $552313(3153.8)$ & $12526(71.5)$ & 0.023 & $657.9(147.9)$ & $691.7(155.5)$ & 3.72 & $0.47(0.019)$ \\
\hline $25 \mathrm{~A} 325 \mathrm{~T} 200-1$ & 200 & 458405 (2617.6) & $16297(93.1)$ & 0.036 & $632.7(142.2)$ & $680.1(152.9)$ & 3.9 & $1.05(0.041)$ \\
\hline $25 \mathrm{~A} 325 \mathrm{~T} 200-2$ & 200 & $389630(2224.8)$ & 20583 (117.5) & 0.053 & $622.3(139.9)$ & $689.6(155.0)$ & 4.23 & $1.06(0.042)$ \\
\hline $25 \mathrm{~A} 325 \mathrm{~T} 200-3$ & 200 & $467048(2666.9)$ & $10292(58.8)$ & 0.022 & $650.3(146.2)$ & $680.2(152.9)$ & 3.84 & $0.70(0.027)$ \\
\hline 25A325T400-1 & 400 & $597447(3411.5)$ & 7078 (40.4) & 0.012 & $544.1(122.3)$ & $574.2(129.1)$ & 2.73 & $1.13(0.044)$ \\
\hline 25A325T400-2 & 400 & $393286(2245.7)$ & $7044(40.2)$ & 0.018 & 532.4 (119.7) & $557.8(125.4)$ & 4.02 & $0.98(0.039)$ \\
\hline $25 \mathrm{~A} 325 \mathrm{~T} 400-3$ & 400 & $456413(2606.2)$ & 9955 (56.8) & 0.022 & $515.3(115.8)$ & $560.8(126.1)$ & 3.57 & $1.04(0.041)$ \\
\hline 25A325T500-1 & 500 & 337725 (1928.5) & $6022(34.4)$ & 0.018 & $386.4(86.9)$ & $411.0(92.4)$ & 3.85 & $1.16(0.046)$ \\
\hline $25 \mathrm{~A} 325 \mathrm{~T} 500-2$ & 500 & $263709(1505.8)$ & $4697(26.8)$ & 0.018 & $398.6(89.6)$ & $413.6(93.0)$ & 4.2 & $1.52(0.060)$ \\
\hline 25A325T500-3 & 500 & $323106(1845.0)$ & $4520(25.8)$ & 0.014 & $400.4(90.0)$ & $417.6(93.9)$ & 3.55 & $1.45(0.057)$ \\
\hline 25A325T600-1 & 600 & $79396(453.4)$ & $1352(7.7)$ & 0.017 & $243.8(54.8)$ & $247.0(55.5)$ & 1.85 & $0.92(0.036)$ \\
\hline 25A325T600-2 & 600 & 96121 (548.9) & 3417 (19.5) & 0.036 & $251.0(56.4)$ & $280.3(63.0)$ & 1.72 & $1.44(0.057)$ \\
\hline $25 \mathrm{~A} 325 \mathrm{~T} 600-3$ & 600 & 89212 (509.4) & 4775 (27.3) & 0.054 & $220.9(49.7)$ & $279.4(62.8)$ & 1.79 & $1.51(0.060)$ \\
\hline Average & - & $375714(2145.4)$ & $9653(55.1)$ & 0.027 & $501.0(112.6)$ & $535.2(120.3)$ & 3.45 & $1.04(0.041)$ \\
\hline
\end{tabular}




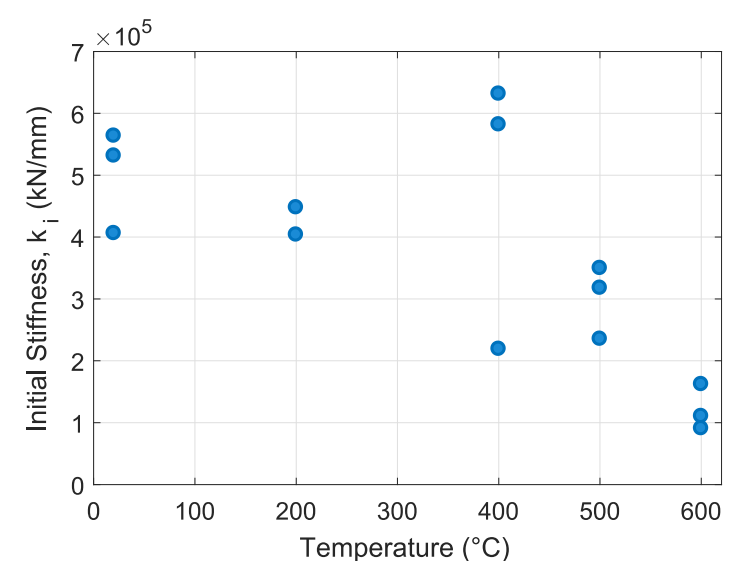

(a)

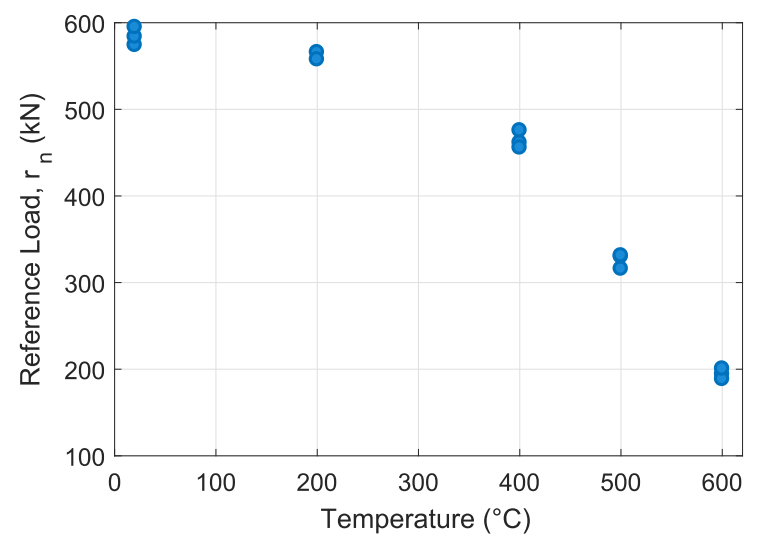

(c)

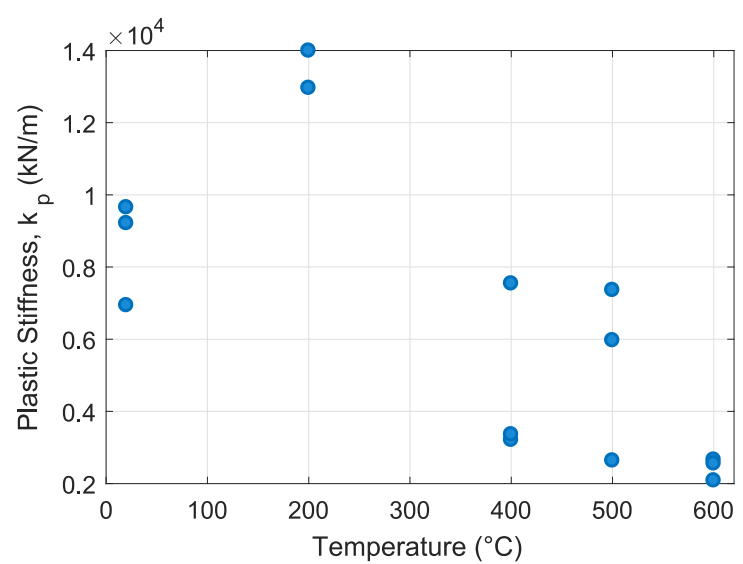

(b)

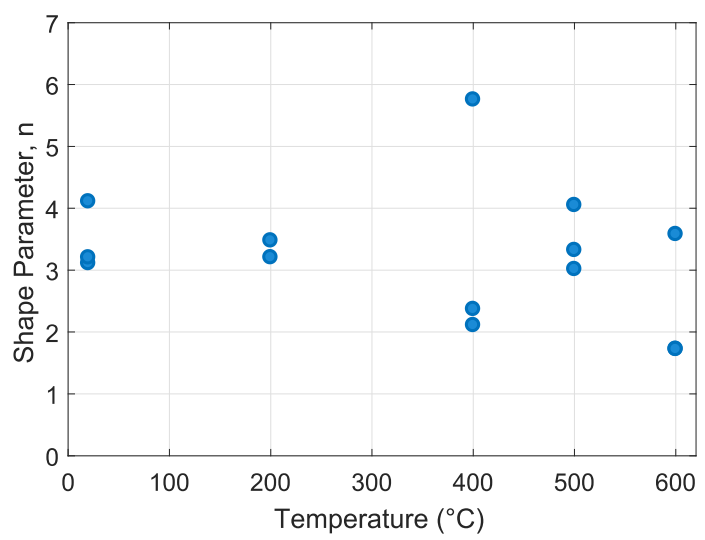

(d)

Figure 4-3: Values of fitted curve parameters for $25 \mathrm{~mm}$ (1 in) diameter A325 bolts as a function of temperature: (a) initial stiffness $k_{\mathrm{i}}(T)$, (b) plastic stiffness $k_{\mathrm{p}}(T)$, (c) reference load $r_{\mathrm{n}}(T)$, and (d) shape parameter $n(T)$ (unitless).

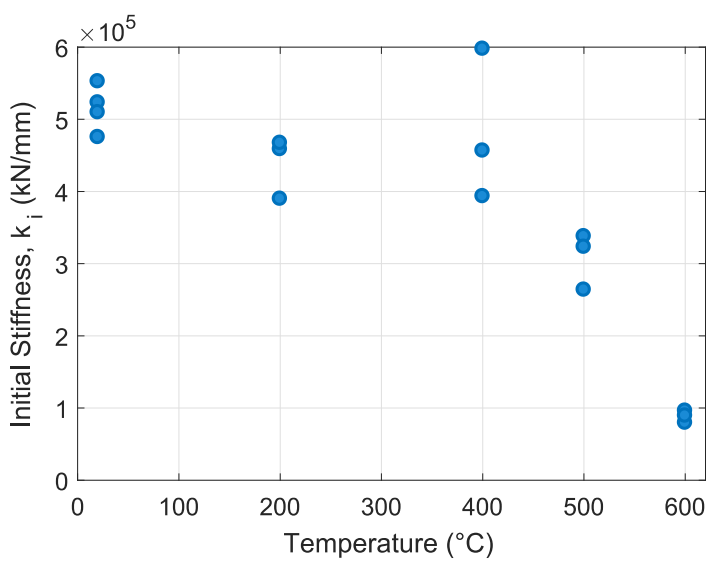

(a)

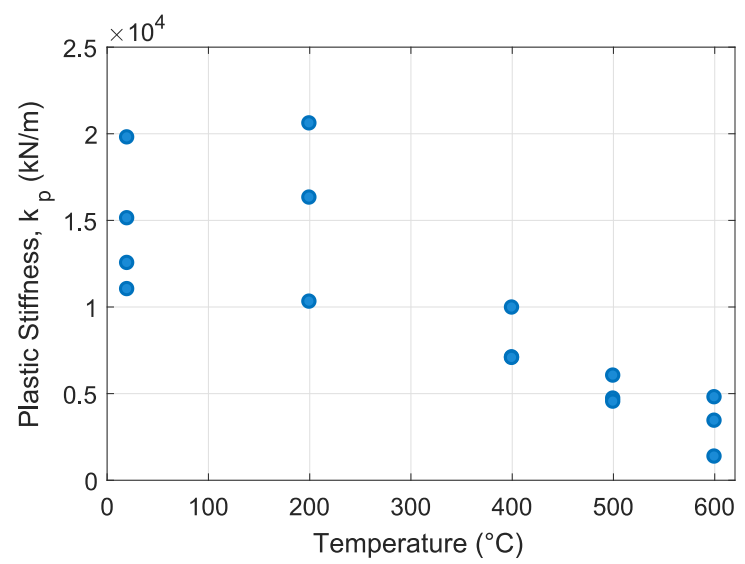

(b) 


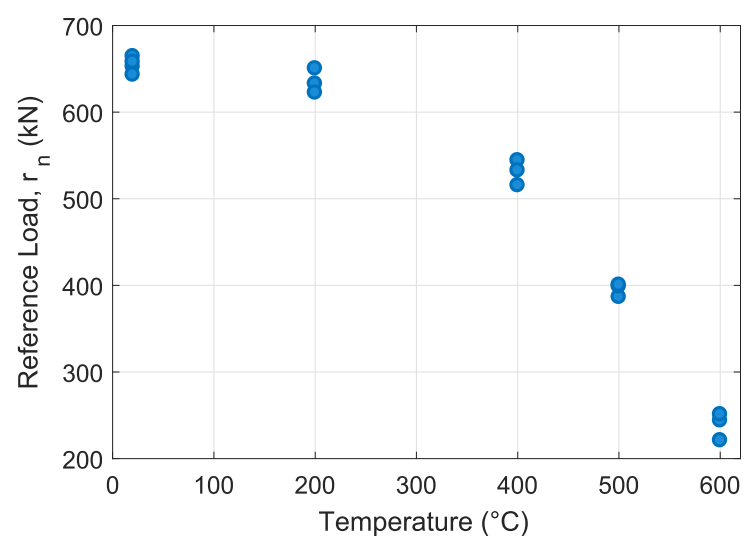

(c)

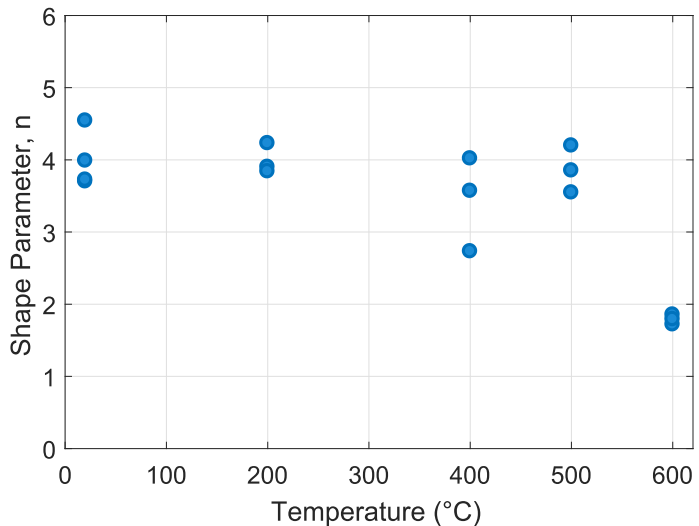

(d)

Figure 4-4: Values of fitted curve parameters for $25 \mathrm{~mm}(1 \mathrm{in})$ diameter $\mathrm{A490}$ bolts as a function of temperature: (a) initial stiffness $k_{\mathrm{i}}(T)$, (b) plastic stiffness $k_{\mathrm{p}}(T)$, (c) reference load $r_{\mathrm{n}}(T)$, and (d) shape parameter $n(T)$ (unitless).

Replicate tests at each temperature level had relatively consistent double-shear capacities $v_{\mathrm{n}}(T)$, within $4.5 \%$ of the mean double-shear capacity value for all specimens. Thus, it follows that at each temperature level, the calculated values for the reference load $r_{\mathrm{n}}(T)$ are closely grouped, having the least scatter of the four calculated curve parameters. For the grade A325 bolts, the reference load degraded only gradually at or below temperatures of $200{ }^{\circ} \mathrm{C}$, after which the rate of degradation increased with increasing temperature. Similarly, the reference load for the A490 bolts degraded only slightly at $200{ }^{\circ} \mathrm{C}$, but had more significant degradation at $400{ }^{\circ} \mathrm{C}$ and above. These trends are consistent with observations by $\mathrm{Yu}$ (2006), who also found that high-strength bolts did not experience significant degradation in strength at temperatures less than $300^{\circ} \mathrm{C}$.

The other three curve parameters had more scatter in their calculated values for a given temperature. In general, both the initial stiffness and the plastic stiffness of the bolt shear loaddeformation curves tended to degrade with increasing temperature. The calculated values for the shape parameter $n$ were usually grouped at a particular temperature; but a systematic trend in their magnitudes with respect to temperature was not observed. For both bolt grades, the value of the shape parameter at all temperatures was between 1.5 and 6.0. The scatter in the calculated values of the initial stiffness $k_{\mathrm{i}}(T)$, plastic stiffness $k_{\mathrm{p}}(T)$, and shape parameter $n$ at each temperature level did not appear to be adversely influenced by increased temperature, with the scatter in the calculated parameter values at ambient temperature often exceeding that at $600{ }^{\circ} \mathrm{C}$. 


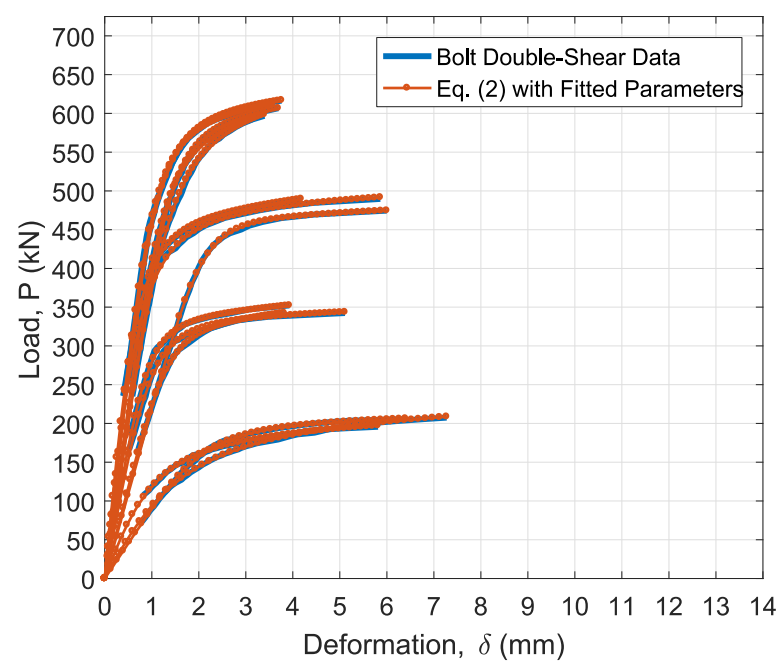

(a)

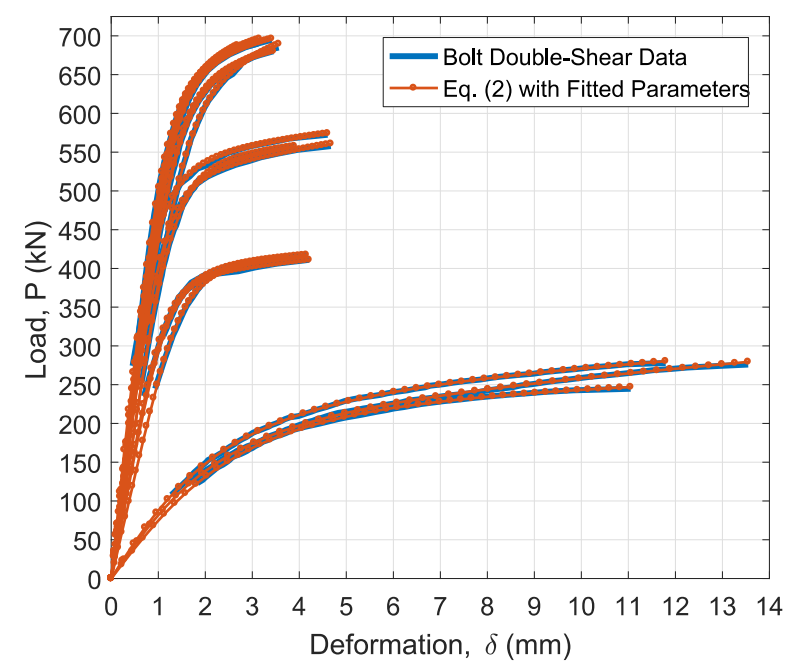

(b)

Figure 4-5: Comparison between Eq. (4-1) using fitted curve parameters and experimental data for 25 mm (1 in) diameter (a) A325 bolts and (b) A490 bolts.

Figs. 4-5(a) and 4-5(b) show a comparison between Eq. (4-2) using the parameters fitted via global optimization with data from the $25 \mathrm{~mm}$ ( 1 in) diameter grade A325 and A490 bolts, respectively, with the initial bearing deformations $\delta_{0}$ removed for each test for clarity. Fig. 4-5 shows that use of Eq. (4-2) with the fitted curve parameters provided in Table (4-1) matches the experimental data within $3 \%$ across all bolt tests.

\subsection{CALCULATION OF SEMI-EMPIRICAL BOLT MECHANICAL PROPERTIES}

To develop an approach that can predict the capacities of the $19 \mathrm{~mm}(3 / 4 \mathrm{in})$ and $22 \mathrm{~mm}(7 / 8 \mathrm{in})$ diameter bolts using the data from the $25 \mathrm{~mm}$ ( 1 in) bolts, the bolt-shear component-based model from Weigand (2016) is used to transform the reference load and initial stiffness data into the ultimate tensile strength and modulus of elasticity, respectively, of the bolt steel. Next, equations are fitted to the data for the ultimate tensile strength and modulus of elasticity, providing the capability to model the bolt double-shear response in terms of the characteristic behavior of the bolt steel mechanical properties, which should be relatively consistent between bolts of different diameters. Piece-wise linear equations are also fitted to the data for the plastic stiffness and shape parameter to facilitate complete double-shear modeling of the bolt response at elevated temperatures.

The ultimate tensile strength of the bolt steels, $F_{\mathrm{u}}(T)$, can be related to the reference load via the equation for the temperature-dependent double-shear capacity of the bolt: $v_{\mathrm{n}}(T)=$ 
$n_{\mathrm{sp}} 0.6 A_{\mathrm{b}} F_{\mathrm{u}}(T)$, where $v_{\mathrm{n}}(T)$ is the double-shear capacity of the bolt, $n_{\mathrm{sp}}=2$ is the number of shear planes through the bolt, $A_{\mathrm{b}}=(\pi / 4) d_{\mathrm{b}}^{2}$ is the bolt cross-sectional area. Writing the bolt steel ultimate tensile strength in terms of the double-shear capacity of the bolt:

$$
F_{\mathrm{u}}(T)=\frac{v_{\mathrm{n}}(T)}{n_{\mathrm{sp}} 0.6 A_{\mathrm{b}}}
$$

The discrete markers in Fig. 4-6 show the values for the ultimate tensile strength calculated using Eq. (4-5).

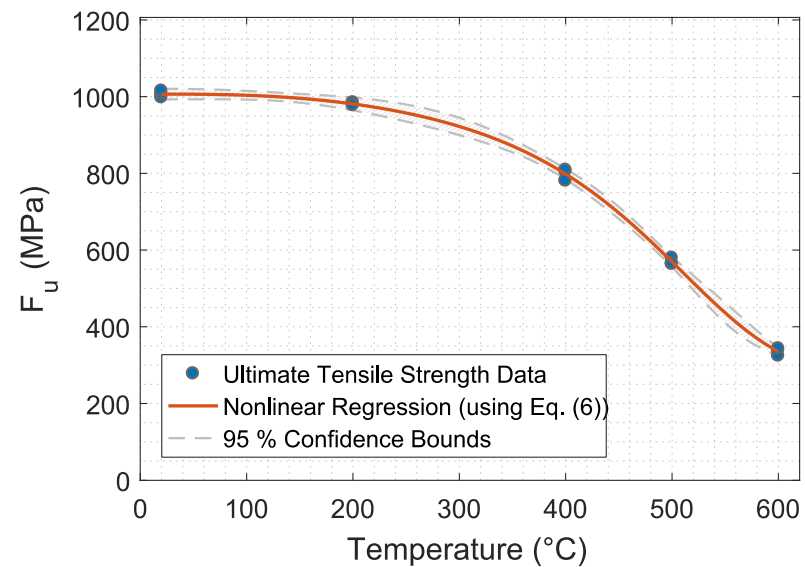

(a)

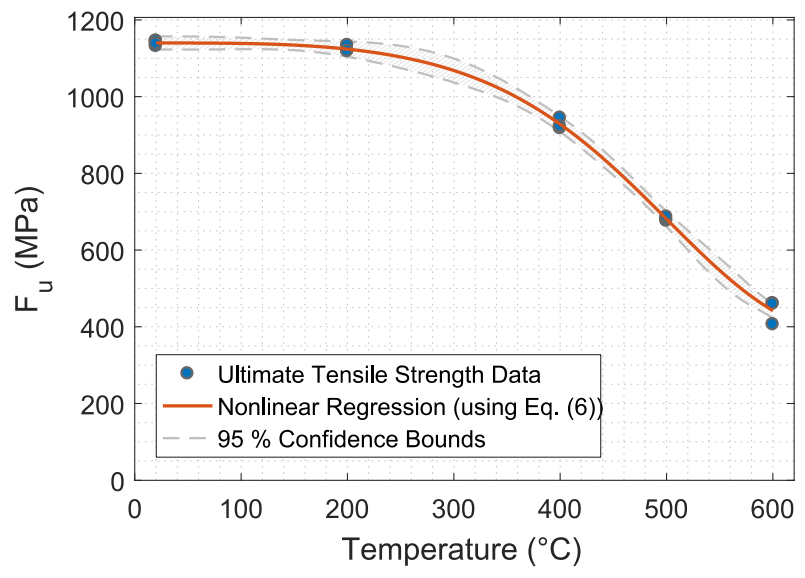

(b)

Figure 4-6: Ultimate tensile strength, fitted using Eq. (4-6), for 25 mm (1 in) diameter (a) A325 bolts and (b) A490 bolts. Hatched area corresponds to $95 \%$ confidence interval.

To characterize the ultimate tensile strength over the full range of temperatures of interest, an exponential function of the form:

$$
F_{\mathrm{u}, \mathrm{fitted}}(T)=a_{1}\left(a_{2}+\left(1-a_{2}\right) \exp \left(-\frac{1}{2}\left(\left(\frac{T-T_{\mathrm{amb}}}{a_{3}}\right)^{a_{4}}+\left(\frac{T-T_{\mathrm{amb}}}{a_{3}}\right)^{a_{5}}\right)\right)\right)
$$

is fitted to the experimental data using nonlinear least-squares regression techniques (Fig. 4-6). The fitted coefficients of Eq. (4-6), $a_{1}$ through $a_{1}$, are shown in Table 4-2 along with their $95 \%$ confidence bounds. The confidence bounds for fitted coefficients are $C=b \pm t \sqrt{S}$ where $b$ are the coefficients produced by the fit, $t$ depends on the confidence interval, and is computed using the Student's $t$ cumulative distribution function, and $S$ is a vector of the diagonal elements from the estimated covariance matrix of the coefficient estimates $\left(X^{T} X\right)^{-1} S^{2}$ (MathWorks, 2016b). In 
a nonlinear least-squares regression $X$ is the Jacobian of the fitted data with respect to the coefficients, and $s^{2}$ is the mean squared error.

The $95 \%$ confidence bounds are also shown on Fig. 4-6 as dashed lines, with the hatched area between the confidence bounds comprising the $95 \%$ confidence interval. A $95 \%$ confidence interval corresponds to a standard uncertainty of $\pm 1.960 \sigma$, where $\sigma$ is the standard deviation (i.e., $\mu_{F_{\mathbf{u}}} \pm k \sigma_{F_{\mathbf{u}}}$ encompasses probability $p=95.0$ percent of the normal distribution for $k=1.960$, where $\mu_{F_{\mathbf{u}}}$ is the expected value of $F_{u}$ determined using $F_{\mathrm{u} \text {,fitted }}(T), \sigma_{F_{\mathbf{u}}}$ is the standard deviation of the $F_{\mathrm{u}}$ data with respect to $F_{\mathrm{u} \text {,fitted }}(T)$, and $k$ is the coverage factor, e.g., see Taylor and Kuyatt (1994)). The $95 \%$ confidence bounds form a narrow band enclosing the respective fits to the ultimate tensile strength data, indicating that the variance in the measured ultimate tensile strengths is relatively small.

Independent tensile bolt-coupon testing of the $25 \mathrm{~mm}$ (1 in) diameter A325 and A490 bolts measured the ambient-temperature ultimate tensile strengths for the A325 and A490 bolts at 950.9 MPa (137.9 ksi) and 1126.7 MPa (163.4 ksi), respectively, which are within $6 \%$ and $1 \%$, of the values calculated using the bolt double-shear data. The close agreement between the calculated values and measured ultimate tensile strengths at ambient temperature provides evidence that Eq. (4-5) is appropriate, and lends credibility to the approach of using the more numerous (in the current study) double-shear strength data to estimate the bolt materials' ultimate tensile strength.

Table 4-2: Summary of fitted curve parameters for bolt mechanical properties.

\begin{tabular}{|c|c|c|c|c|c|}
\hline \multirow[b]{2}{*}{ Fit Type } & \multicolumn{2}{|r|}{ Grade A325 } & \multicolumn{2}{|r|}{ Grade A490 } & \multirow[b]{2}{*}{ units } \\
\hline & Coeff. Value & $\begin{array}{l}95 \% \text { Confidence Bounds } \\
\text { (lower, upper) }\end{array}$ & Coeff. Value & $\begin{array}{l}95 \% \text { Confidence Bounds } \\
\text { (lower, upper) }\end{array}$ & \\
\hline \multirow{5}{*}{$\begin{array}{l}\text { Ultimate } \\
\text { Tensile } \\
\text { Strength } \\
\text { (Eq. (4-6)) }\end{array}$} & $a_{1}=1007(146.0)$ & $(993(144.0), 1020(148.0))$ & $a_{1}=1140(165.3)$ & $(1122(162.8), 1157(167.8))$ & $\mathrm{MPa}(\mathrm{ksi})$ \\
\hline & $a_{2}=0.2758$ & $(0.1591,0.3925)$ & $a_{2}=0.3141$ & $(0.1211,0.5072)$ & ${ }^{\circ} \mathrm{C}$ \\
\hline & $a_{3}=488.7$ & $(456.9,520.5)$ & $a_{3}=492.7$ & $(435.3,550.2)$ & ${ }^{\circ} \mathrm{C}$ \\
\hline & $a_{4}=7.291$ & $(3.924,10.659)$ & $a_{4}=6.251$ & $(0.766,11.736)$ & - \\
\hline & $a_{5}=2.649$ & $(1.767,3.531)$ & $a_{5}=3.207$ & $(1.334,5.079)$ & - \\
\hline \multirow{4}{*}{$\begin{array}{l}\text { Modulus of } \\
\text { Elasticity } \\
\text { (Eq. (14)) }\end{array}$} & $g_{1}=-0.0004083$ & $(-0.0011032,0.0002867)$ & -0.0004835 & $(-0.0007801,-0.0001869)$ & ${ }^{\circ} \mathrm{C}^{-3}$ \\
\hline & $g_{2}=0.2631$ & $(-0.3700,0.8962)$ & 0.3184 & $(-0.0551,0.5818)$ & ${ }^{\circ} \mathrm{C}^{-2}$ \\
\hline & $g_{3}=-48.48$ & $(-197.69,100.73)$ & -59.25 & $(-119.67,1.18)$ & ${ }^{\circ} \mathrm{C}^{-1}$ \\
\hline & $g_{4}=170.1(24675)$ & $(118.92(17248), 221.34(25450))$ & $175.47(25450)$ & $(154.39$ (22392), $196.56(28508))$ & $\mathrm{GPa}(\mathrm{ksi})$ \\
\hline
\end{tabular}

The modulus of elasticity of the bolt steels can be related to the initial stiffness of the bolts using Eq. (20) from Weigand (2016), but adjusted for the two shear planes through the bolt in doubleshear testing, and incorporating temperature-dependence such that: 


$$
k_{\mathrm{i}}(T)=\frac{n_{\mathrm{sp}}}{\frac{1}{k_{\mathrm{br}}(T)}+\frac{1}{k_{\mathrm{v}}(T)}},
$$

with bearing stiffness

$$
k_{\mathrm{br}}(T)=\frac{1}{1+3 \beta_{\mathrm{b}}}\left(\frac{t_{\mathrm{RB}} t_{\mathrm{LB}} E(T)}{2\left(t_{\mathrm{RB}}+t_{L B}\right)}\right)
$$

and shearing stiffness

$$
k_{\mathrm{v}}(T)=\frac{12 E(T) I_{\mathbf{b}}}{L_{\mathbf{b}}^{3}(1+\Phi(T))}
$$

In Eqs. (4-8) and (4-9), $\beta_{\mathrm{b}}$ is a correction factor that accounts for the concentration of bearing forces at the interface between plates $\left(\beta_{\mathrm{b}}=1\right.$ for shear, see Nelson et al. (1983) for more details), $I_{\mathrm{b}}=\left(\pi d_{\mathrm{b}}^{4}\right) / 64$ is the moment of inertia of the bolt shaft cross-section, $L_{\mathrm{b}}=(1 / 2)\left(t_{\mathrm{RB}}+t_{L B}\right)$ is the bolt length at each shear plane where $t_{\mathrm{RB}}=30 \mathrm{~mm}(1.18 \mathrm{in})$ is the thickness of the reaction block, and where $t_{\mathrm{LB}}=56 \mathrm{~mm}$ (2.20 in) is the thickness of the loading block.

$$
\Phi(T)=\frac{12 E(T) I_{\mathbf{b}}}{L_{\mathbf{b}}^{2}}\left(\frac{1}{\kappa G(T) A_{\mathbf{b}}}\right)
$$

is a term in Timoshenko beam theory that characterizes the relative importance of the shear deformations to the bending deformations (e.g., see Thomas et al. (1973)), $G(T)=$ $E(T) /(2(1+v))$ is the bolt shear modulus, $v=0.29$ (assumed over all temperatures) is Poisson's ratio, and $\kappa$ is the shear coefficient for a circular cross-section, defined as:

$$
\kappa=\frac{1}{\frac{7}{6}+\frac{1}{6}\left(\frac{v}{1+v}\right)}
$$

The modulus of elasticity of the bolt steel is determined by solving Eq. (4-7) for $E(T)$ such that:

$$
E(T)=\gamma k_{\mathbf{i}}(T)
$$

where

$$
\gamma=\frac{2\left(t_{\mathrm{RB}}+t_{L B}\right)\left(3\left(1+3 \beta_{\mathrm{b}}\right) \pi d_{\mathrm{b}}^{4}(1+v)+d_{\mathrm{b}}^{2}(7+2 v(7+4 v)) t_{\mathrm{RB}} t_{L B}+(1+v) t_{\mathrm{RB}} t_{L B}\left(t_{\mathrm{RB}}+t_{L B}\right)^{2}\right)}{n_{\mathrm{sp}}\left(3 \pi d_{\mathrm{b}}^{4}(1+v) t_{\mathrm{RB}} t_{L B}\right)}
$$


Similar to the approach taken for the ultimate tensile strength, an equation was fitted to the modulus of elasticity data to enable its calculation for all temperatures. For the modulus of elasticity, a third-order polynomial equation of the form:

$$
E_{\text {fitted }}=g_{1}\left(T-T_{\mathrm{amb}}\right)^{3}+g_{2}\left(T-T_{\mathrm{amb}}\right)^{2}+g_{3}\left(T-T_{\mathrm{amb}}\right)+g_{4}
$$

was fitted to the experimental data using least-squares regression techniques. Coefficients $g_{1}$ through $g_{4}$ are shown in Table 4-2. Fitted curves using Eq. (4-14) are shown in Fig. 4-7 as solid lines. As a result of the larger variances in the modulus of elasticity data, the $95 \%$ confidence intervals calculated for the fitted modulus of elasticity curves are significantly wider than those calculated for the ultimate tensile strength.

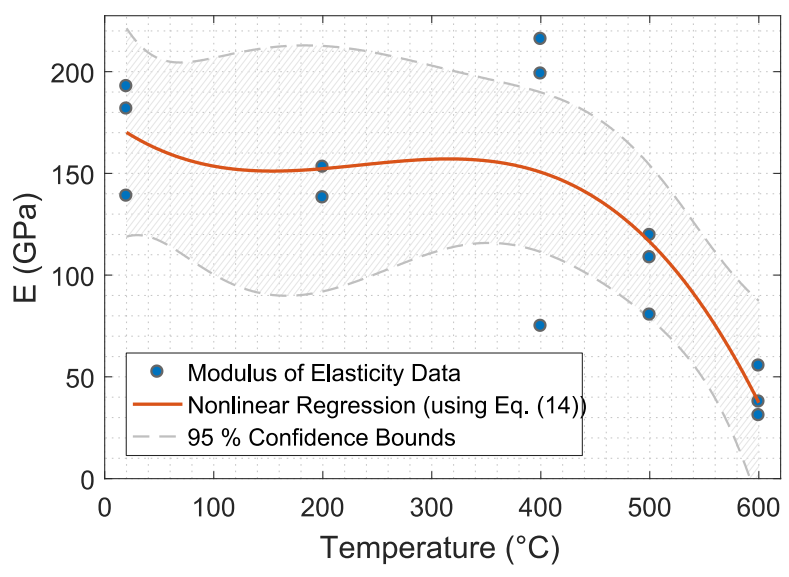

(a)

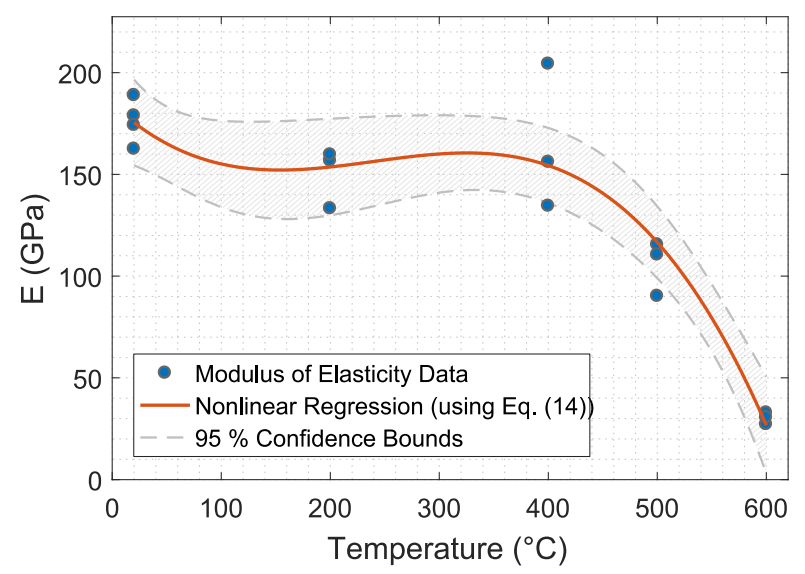

(b)

Figure 4-7: Modulus of elasticity, fitted using Eq. (4-14), for $25 \mathrm{~mm}$ (1 in) diameter (a) A325 bolts and (b) A490 bolts. Hatched area corresponds to $95 \%$ confidence interval.

Due to the significant scatter in the data for the plastic stiffness (see Figs. 4-3(b) and 4-4(b)), a different approach was used to calculate it. The relationship between the plastic stiffness and the elastic stiffness, at a particular temperature, was determined as the average of the $k_{\mathrm{p}}(T) / k_{\mathrm{i}}(T)$ values from Table 4-1 (Fig. 4-8), and the plastic stiffness was calculated as this ratio multiplied by specimen-specific initial stiffness. The shape parameter $n$, while influencing the bolt double-shear response at the transition from elastic to plastic deformations, has relatively little influence on the calculated capacity of the bolts. Thus, the value of $n$ was simply chosen as the average value at each individual temperature. The data from Peixoto et al. (2017) showed no systematic influence 
of bolt diameter of the double-shear deformation at failure, and thus the deformations at failure was similarly chosen as the average value at each temperature. Since the stiffness of the bolt double-shear response had significantly decreased at the ultimate deformations, choosing averaged values for the ultimate deformation capacities had only a minor influence on the calculated bolt reference loads.

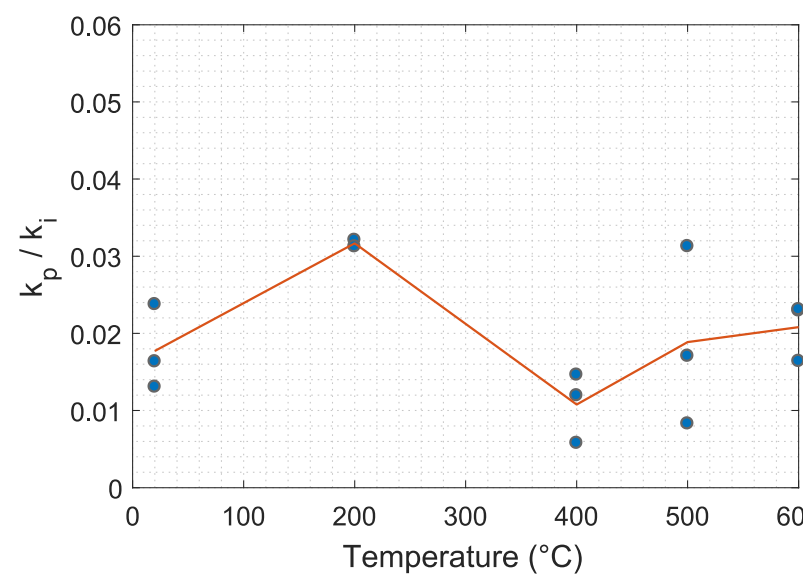

(a)

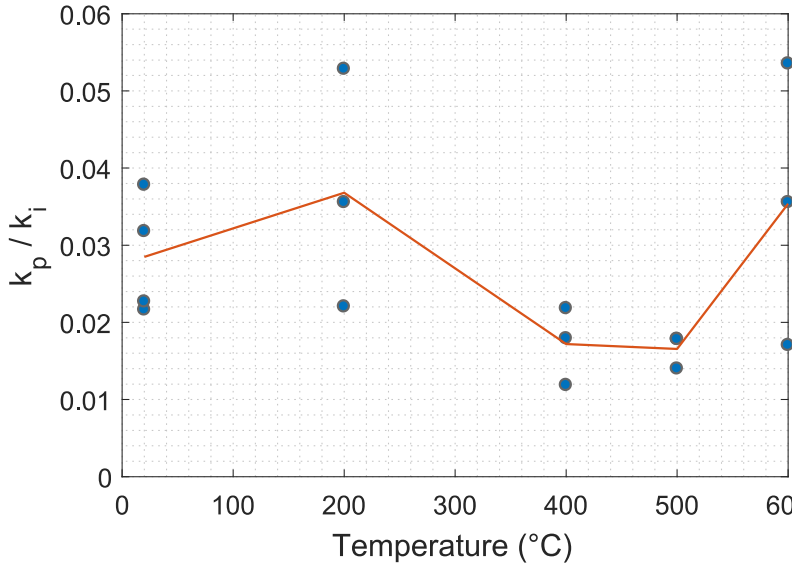

(b)

Figure 4-8: Fitted ratio of plastic stiffness to initial stiffness for $25 \mathrm{~mm}$ (1 in) diameter (a) A325 bolts and (b) A490 bolts. Hatched area corresponds to $95 \%$ confidence interval.

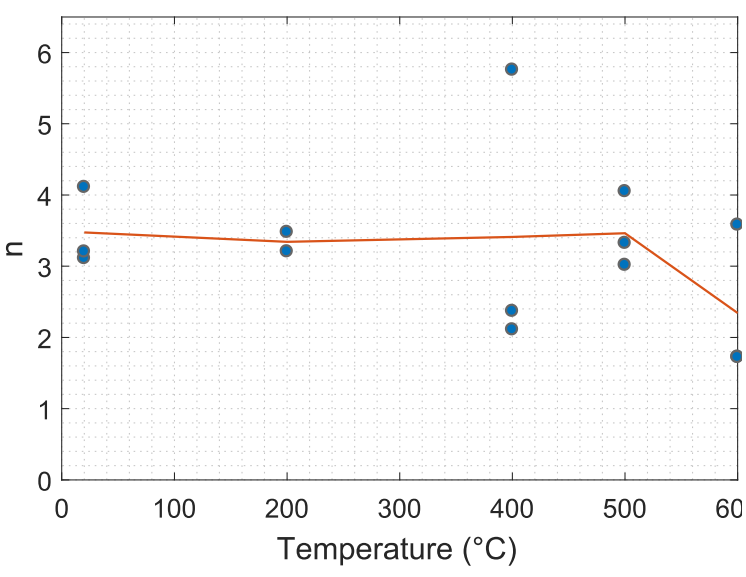

(a)

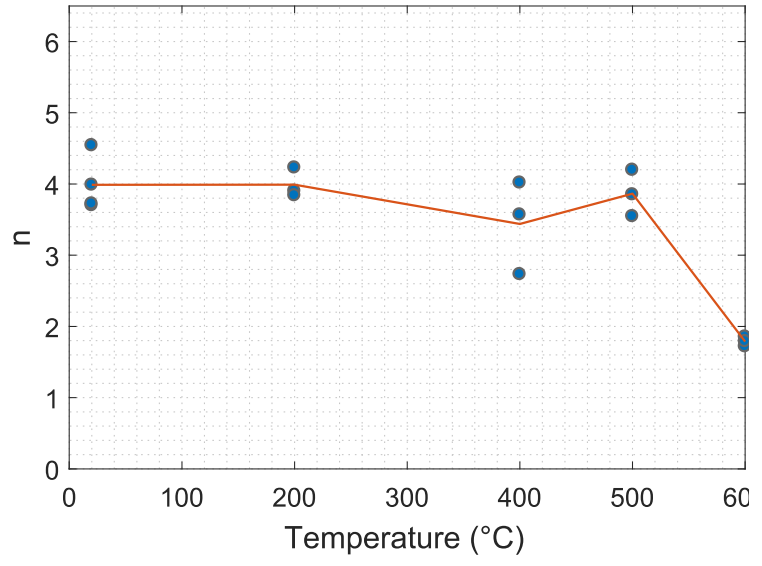

(b)

Figure 4-9: Fitted shape parameter for 25 mm (1 in) diameter (a) A325 bolts and (b) A490 bolts. Hatched area corresponds to $95 \%$ confidence interval.

Figs. 4-10(a) and 4-10(b) and show comparisons of the component-based model, with parameters fitted using Eq. (4-6), Eq. (4-14), and the approaches for calculating $k_{\mathrm{p}}$ and $n$ described above, to the experimental data for the $25 \mathrm{~mm}$ ( 1 in) diameter bolts. 


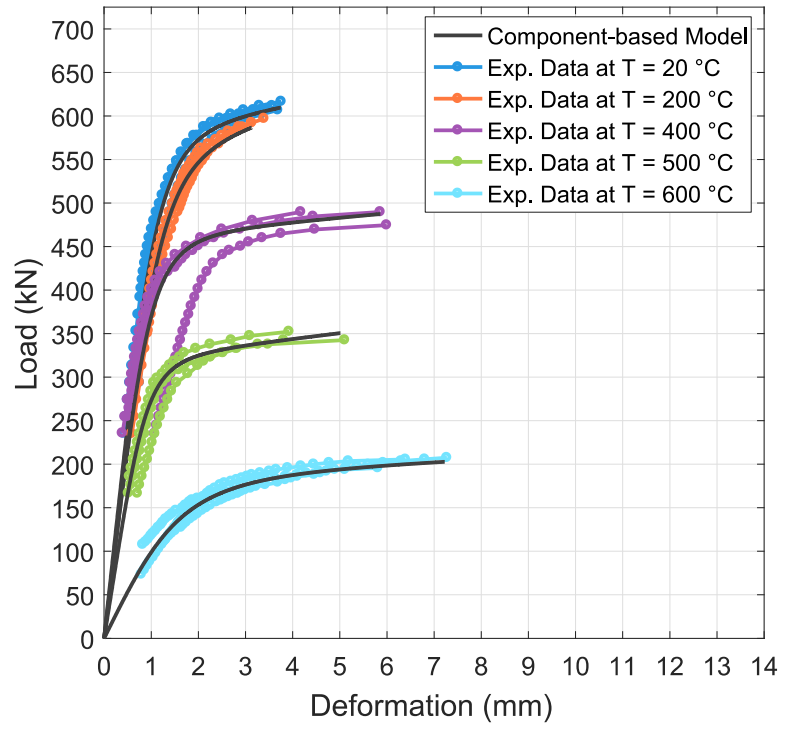

(a)

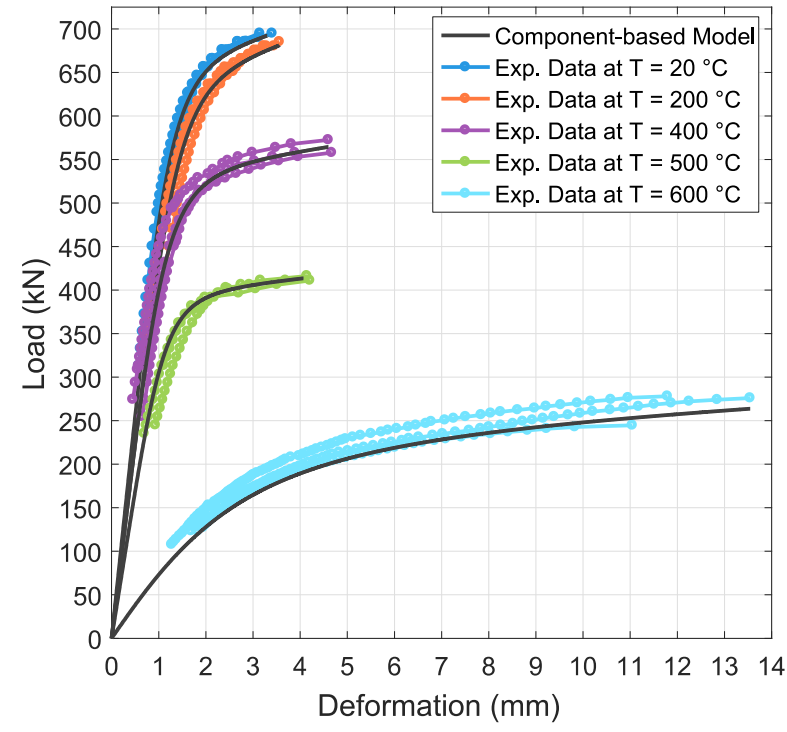

(b)

Figure 4-10: Comparison of the component-based model predicted behavior to the experimental data for $25 \mathrm{~mm}$ (1 in) diameter (a) A325 bolts and (b) A490 bolts.

\subsection{APPLICATION OF MODELING APPROACH TO SMALLER-DIAMETER BOLTS}

The empirical bolt load-deformation modeling approach is based solely on the data from Chapter 2 for the $25 \mathrm{~mm}$ ( 1 in) diameter A325 and A490 bolts, because these data were least-influenced by the initial bearing deformations in the loading and reaction blocks. However, to further validate the component-based modeling approach, its capabilities predicting temperature-dependent bolt double-shear capacities are tested against data from the $19 \mathrm{~mm}(3 / 4 \mathrm{in})$ and $22 \mathrm{~mm}(7 / 8 \mathrm{in})$ diameter bolts in Chapter 2. Fig. 4-11 shows the effect of the accumulated bearing deformations on the first $19 \mathrm{~mm}$ (3/4 in) diameter bolt test (19A325T20-1), in which the virgin loading and reaction blocks were used, and the third $19 \mathrm{~mm}$ (3/4 in) diameter bolt test (19A325T20-3). Since the accumulated bearing deformations had relatively little influence on the bolt double-shear capacity (as demonstrated by Fig. 4-11), the double-shear capacities of the $19 \mathrm{~mm}$ (3/4 in) and $22 \mathrm{~mm}$ (7/8 in) diameter bolts can be objectively compared against the model formulated using the data from the $25 \mathrm{~mm}$ ( 1 in) diameter bolts. 


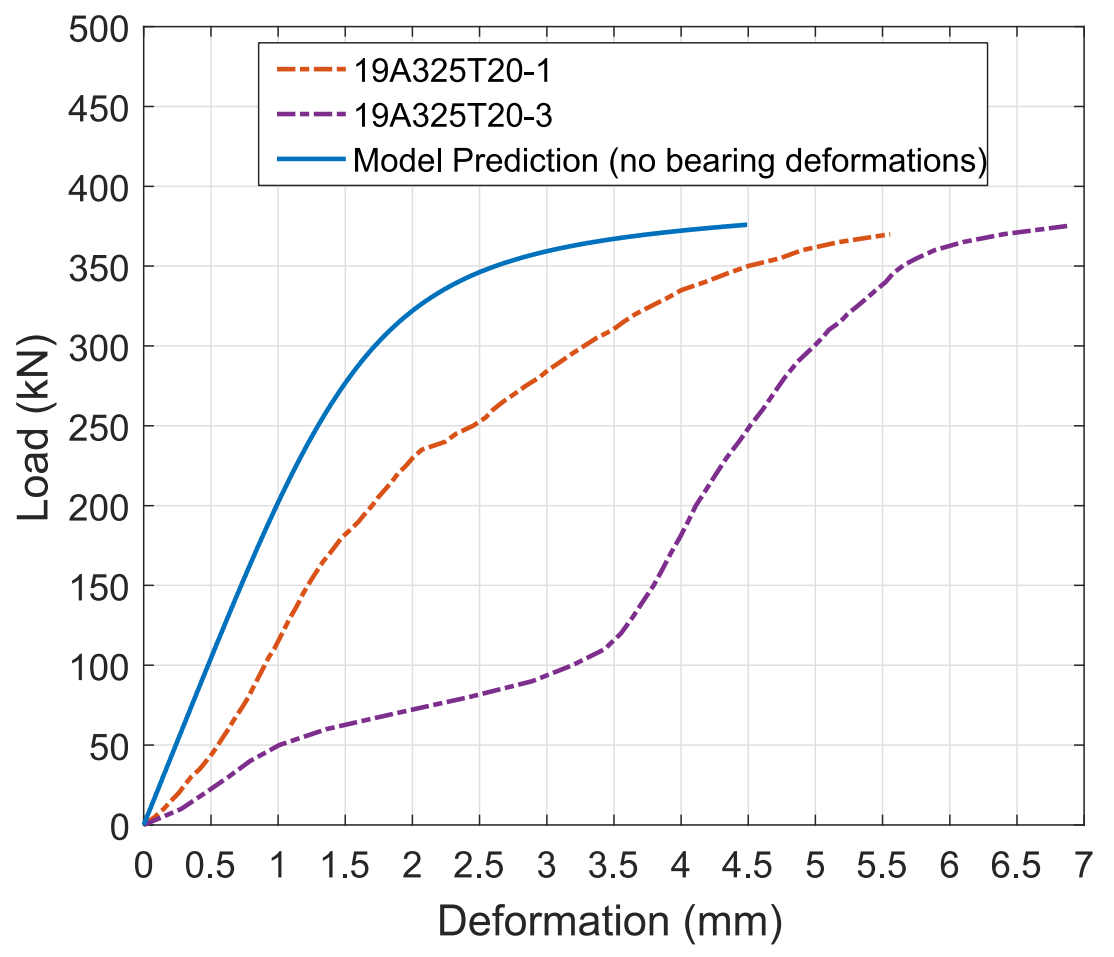

Figure 4-11: Effect of accumulated bearing deformations on $19 \mathrm{~mm}(3 / 4 \mathrm{in})$ diameter bolt tests.

The bolts are modeled using Eq. (4-2), with (i) initial stiffness determined from Eq. (4-7), incorporating temperature-dependence via Eq. (4-14) (Fig. 4-7) for the modulus of elasticity, (ii) plastic stiffness determined as a function of the initial stiffness, using the ratios shown in Fig. 4-8, (iii) shape parameter taken as the average value at each temperature (see Fig. 4-9), and reference load calculated as

$$
r_{\mathrm{n}}=n_{\mathrm{sp}} 0.6 A_{\mathrm{b}} F_{\mathrm{u}}(T)\left(\delta_{\mathrm{u}}-\delta_{0}\right)
$$

using the fitted ultimate tensile strength (Eq. (4-6), Fig. 4-6). The bolt-shear deformation capacities at failure were assumed to be equivalent to the average deformation capacities of the corrected $25 \mathrm{~mm}$ (1 in) diameter bolt data. 
Table 4-3: Summary of measured and predicted double-shear capacities for $19 \mathrm{~mm}(3 / 4 \mathrm{in})$ and $22 \mathrm{~mm}$ (7/8 in) diameter A325 high-strength bolts.

\begin{tabular}{|c|c|c|c|c|}
\hline $\begin{array}{l}\text { Specimen } \\
\text { Name }\end{array}$ & $\begin{array}{l}\mathrm{T} \\
{ }^{\circ} \mathrm{C}\end{array}$ & $\begin{array}{l}\text { Meas. Failure } \\
\text { Load, kN (kip) }\end{array}$ & $\begin{array}{l}\text { Pred. Failure } \\
\text { Load, kN (kip) }\end{array}$ & $\begin{array}{l}\text { Percent } \\
\text { Difference }\end{array}$ \\
\hline 19A325T20-1 & 20 & $372.3(83.7)$ & \multirow[t]{3}{*}{$379.9(85.4)$} & 2.0 \\
\hline 19A325T20-2 & 20 & $375.4(84.4)$ & & 1.2 \\
\hline 19A325T20-3 & 20 & $391.9(88.1)$ & & -3.1 \\
\hline 19A325T200-1 & 200 & $384.3(86.4)$ & \multirow[t]{3}{*}{$370.2(83.2)$} & -3.7 \\
\hline 19A325T200-2 & 200 & $392.3(88.2)$ & & -5.6 \\
\hline 19A325T200-3 & 200 & $388.8(87.4)$ & & -4.8 \\
\hline 19A325T400-1 & 400 & $310.0(69.7)$ & \multirow[t]{3}{*}{$301.2(67.7)$} & -2.8 \\
\hline 19A325T400-2 & 400 & $312.3(70.2)$ & & -3.5 \\
\hline 19A325T400-3 & 400 & $314.5(70.7)$ & & -4.2 \\
\hline 19A325T500-1 & 500 & $218.0(49.0)$ & \multirow[t]{3}{*}{$214.9(48.3)$} & -1.4 \\
\hline 19A325T500-2 & 500 & $232.6(52.3)$ & & -7.6 \\
\hline 19A325T500-3 & 500 & $216.6(48.7)$ & & -0.8 \\
\hline 19A325T600-1 & 600 & $122.3(27.5)$ & \multirow[t]{3}{*}{$126.6(28.5)$} & 3.5 \\
\hline 19A325T600-2 & 600 & $134.8(30.3)$ & & -6.0 \\
\hline 19A325T600-3 & 600 & $124.1(27.9)$ & & 2.0 \\
\hline |Average & - & - & - & 3.5 \\
\hline 22A325T20-1 & 20 & $540.5(121.5)$ & \multirow[t]{4}{*}{$533.1(119.8)$} & -1.4 \\
\hline 22A325T20-2 & 20 & $528.0(118.7)$ & & 1.0 \\
\hline 22A325T20-3 & 20 & $540.5(121.5)$ & & -1.4 \\
\hline 22A325T20-4 & 20 & $523.6(117.7)$ & & 1.8 \\
\hline 22A325T200-1 & 200 & $503.5(113.2)$ & \multirow[t]{3}{*}{$519.5(116.8)$} & 3.2 \\
\hline 22A325T200-2 & 200 & $514.2(115.6)$ & & 1.0 \\
\hline 22A325T200-3 & 200 & $517.8(116.4)$ & & 0.3 \\
\hline 22A325T400-1 & 400 & $464.4(104.4)$ & \multirow[t]{3}{*}{$422.7(95.0)$} & -9.0 \\
\hline 22A325T400-2 & 400 & $443.0(99.6)$ & & -4.6 \\
\hline 22A325T400-3 & 400 & $444.4(99.9)$ & & -4.9 \\
\hline 22A325T500-1 & 500 & $332.7(74.8)$ & \multirow[t]{3}{*}{$301.6(67.8)$} & -9.4 \\
\hline 22A325T500-2 & 500 & $304.3(68.4)$ & & -0.9 \\
\hline 22A325T500-3 & 500 & $294.5(66.2)$ & & 2.4 \\
\hline 22A325T600-1 & 600 & $172.1(38.7)$ & \multirow[t]{3}{*}{$177.7(40.0)$} & 3.2 \\
\hline 22A325T600-2 & 600 & $182.8(41.1)$ & & -2.8 \\
\hline 22A325T600-3 & 600 & $179.3(40.3)$ & & -0.9 \\
\hline |Average| & - & - & - & 3.0 \\
\hline
\end{tabular}


Table 4-4: Summary of measured and predicted double-shear capacities for $19 \mathrm{~mm}(3 / 4 \mathrm{in})$ and $22 \mathrm{~mm}$ (7/8 in) diameter A490 high-strength bolts.

\begin{tabular}{|c|c|c|c|c|}
\hline $\begin{array}{l}\text { Specimen } \\
\text { Name }\end{array}$ & $\begin{array}{l}\mathrm{T} \\
{ }^{\circ} \mathrm{C}\end{array}$ & $\begin{array}{l}\text { Meas. Failure } \\
\text { Load, kN (kip) }\end{array}$ & $\begin{array}{l}\text { Pred. Failure } \\
\text { Load, kN (kip) }\end{array}$ & $\begin{array}{l}\text { Percent } \\
\text { Difference }\end{array}$ \\
\hline 19A490T20-1 & 20 & $414.6(93.2)$ & \multirow[t]{3}{*}{$419.6(94.3)$} & 1.2 \\
\hline 19A490T20-2 & 20 & $415.0(93.3)$ & & 1.1 \\
\hline 19A490T20-3 & 20 & $429.3(96.5)$ & & -2.2 \\
\hline 19A490T200-1 & 200 & $412.4(92.7)$ & \multirow[t]{3}{*}{$413.7(93.0)$} & 0.3 \\
\hline 19A490T200-2 & 200 & $398.6(89.6)$ & & 3.8 \\
\hline 19A490T200-3 & 200 & $420.4(94.5)$ & & -1.6 \\
\hline 19A490T400-1 & 400 & $347.4(78.1)$ & \multirow[t]{3}{*}{$341.7(76.8)$} & -1.7 \\
\hline 19A490T400-2 & 400 & $355.0(79.8)$ & & -3.7 \\
\hline 19A490T400-3 & 400 & $364.8(82.0)$ & & -6.3 \\
\hline 19A490T500-1 & 500 & $258.4(58.1)$ & \multirow[t]{3}{*}{$250.7(56.4)$} & -3.0 \\
\hline 19A490T500-2 & 500 & $262.9(59.1)$ & & -4.6 \\
\hline 19A490T500-3 & 500 & $259.3(58.3)$ & & -3.3 \\
\hline 19A490T600-1 & 600 & $158.4(35.6)$ & \multirow[t]{3}{*}{$162.8(36.6)$} & 2.8 \\
\hline 19A490T600-2 & 600 & $163.7(36.8)$ & & -0.5 \\
\hline 19A490T600-3 & 600 & $161.0(36.2)$ & & 1.1 \\
\hline Average & - & - & - & 2.5 \\
\hline 22A490T20-1 & 20 & $568.5(127.8)$ & \multirow[t]{3}{*}{$533.1(119.8)$} & 1.5 \\
\hline 22A490T20-2 & 20 & $575.2(129.3)$ & & 0.4 \\
\hline 22A490T20-3 & 20 & $588.1(132.2)$ & & -1.8 \\
\hline 22A490T200-1 & 200 & $537.8(120.9)$ & \multirow[t]{3}{*}{$519.5(116.8)$} & 5.8 \\
\hline 22A490T200-2 & 200 & $549.4(123.5)$ & & 3.6 \\
\hline 22A490T200-3 & 200 & $555.6(124.9)$ & & 2.4 \\
\hline 22A490T400-1 & 400 & $480.9(108.1)$ & \multirow[t]{3}{*}{$422.7(95.0)$} & -2.3 \\
\hline 22A490T400-2 & 400 & $450.2(101.2)$ & & 4.4 \\
\hline 22A490T400-3 & 400 & $466.6(104.9)$ & & 0.7 \\
\hline 22A490T500-1 & 500 & $357.2(80.3)$ & \multirow[t]{3}{*}{$301.6(67.8)$} & -3.5 \\
\hline 22A490T500-2 & 500 & $352.7(79.3)$ & & -2.2 \\
\hline 22A490T500-3 & 500 & $363.0(81.6)$ & & -5.0 \\
\hline 22A490T600-1 & 600 & $206.4(46.4)$ & \multirow[t]{3}{*}{$177.7(40.0)$} & 8.5 \\
\hline 22A490T600-2 & 600 & $214.8(48.3)$ & & 4.2 \\
\hline 22A490T600-3 & 600 & $224.2(50.4)$ & & -0.1 \\
\hline Average & - & - & - & 3.1 \\
\hline
\end{tabular}

Tables 4-3 and 4-4 show that the empirically-fitted modeling approach predicts the capacity of the $19 \mathrm{~mm}(3 / 4 \mathrm{in})$ and $22 \mathrm{~mm}$ (7/8 in) bolts within an average difference of less than $3.5 \%$. A negative value for the percent error indicates that the predicted double-shear capacity is larger than the experimentally measured double-shear capacity, while a positive value for the percent error indicates that the predicted double-shear capacity is smaller than the experimentally measured 
double-shear capacity. The reported averages in Tables 4-3 and 4-4 correspond to the average of the absolute value of the percent differences across the full range of test temperatures.

Tables 4-3 and 4-4 also show that the percent difference between the predicted bolt double-shear capacity and the measured bolt double-shear capacity tends to increase with increasing temperature, with the predicted capacities at $500{ }^{\circ} \mathrm{C}$ and $600{ }^{\circ} \mathrm{C}$ on average having the largest percent differences. This trend could be rationally expected, due to contributions from the combined uncertainties in the deformation at failure and the plastic stiffness in the measured data at these temperatures.

\subsection{CONSOLIDATION AND SIMPLIFICATION OF COMPONENT-BASED MODEL}

With only a minor loss of accuracy relative to the separately fitted models for the grade A325 and A490 high-strength bolt materials presented in Section 4.3, the component-based model can be consolidated to include both high-strength bolt materials. Fig. 4-12(a) shows a comparison between the retained ultimate tensile strengths for the grade A325 and A490 bolt materials. The retained mechanical properties of the bolt materials are calculated simply as the values of the mechanical properties at elevated temperatures normalized by their mean value at ambient temperature, $\mu_{F_{\mathrm{u}, \mathrm{amb}}}$. Both material grades exhibit similar trends, having relatively little degradation at $200{ }^{\circ} \mathrm{C}$ after which the rate of degradation increases with increasing temperature. Clearly, the retained ultimate tensile strength of the grade A325 bolt material is less than that of the grade A490 bolt material, indicating that the grade A325 bolt material degraded faster than the grade A490 bolt material with increasing temperature. However, the difference in the retained ultimate tensile strengths of the two bolt materials is relatively minor, differing by only $5.5 \%$ at the maximum considered temperature of $600{ }^{\circ} \mathrm{C}$ (the ultimate tensile strength of the grade A325 and A490 bolt materials were on average, $33.3 \%$ and $38.8 \%$, respectively, of their ambienttemperature ultimate tensile strengths). Fig. 4-12(b) shows the consolidated fit to the bolt ultimate tensile strength data results, determined by fitting Eq. (4-6) to the aggregated data for both the grade A325 and A490 bolt materials. The fitted coefficients, $a_{1}$ through $a_{5}$, along with their $95 \%$ confidence bounds, are shown in the textbox embedded in Fig. 4-12(b). 


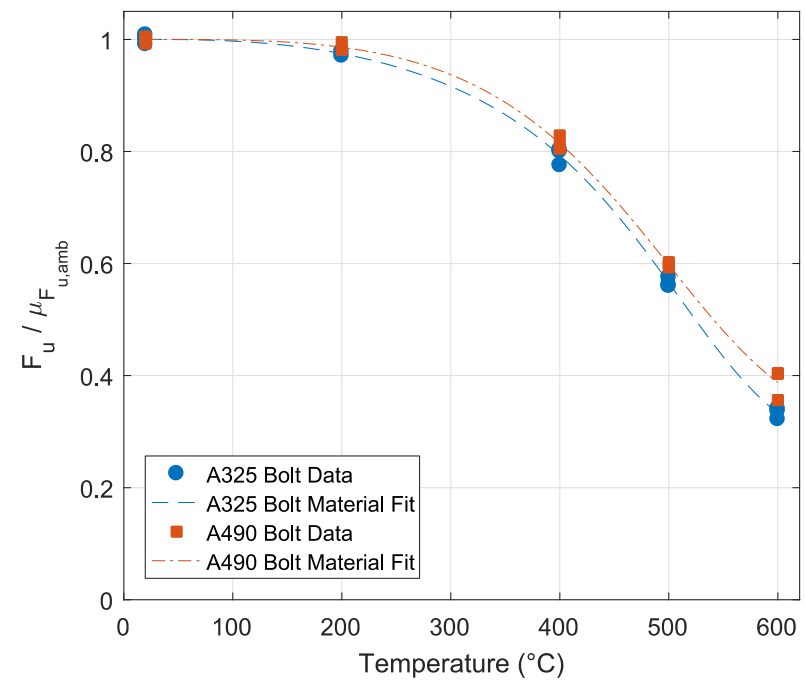

(a)

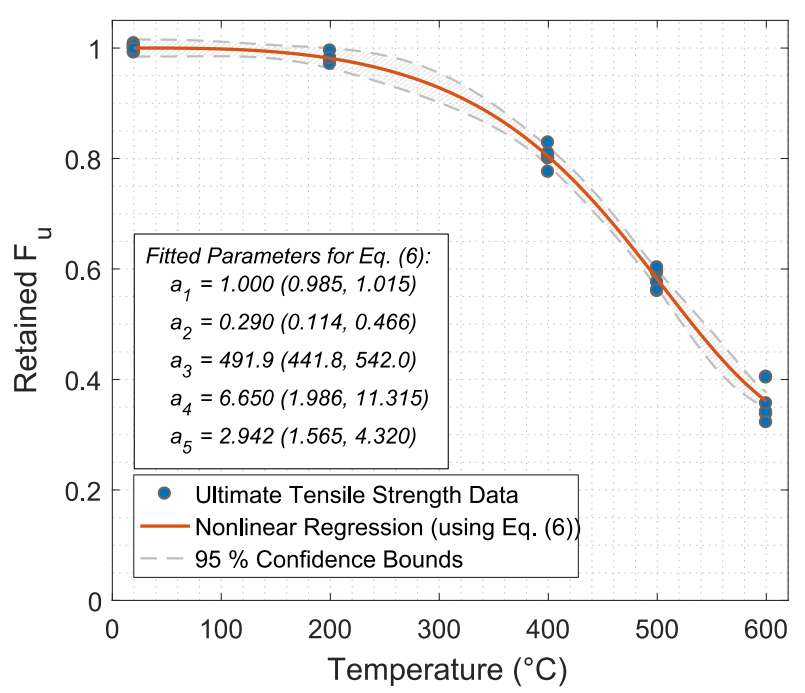

(b)

Figure 4-12: (a) comparison of individually fitted retained ultimate tensile strength curves for $25 \mathrm{~mm}(1 \mathrm{in})$ diameter grade A325 and A490 bolts and (b) aggregated ultimate tensile strength, fitted using Eq. (4-6).

A similar consolidation strategy can be considered for the modulus of elasticity data. Fig. 4-13(a) shows a comparison between the retained modulus of elasticity of the grade A325 and A490 bolt materials. The fitted curves for the modulus of elasticity show that for both bolt materials, the modulus is degraded only slightly at or below $400{ }^{\circ} \mathrm{C}$, but then begins to degrade rapidly at temperatures above $400{ }^{\circ} \mathrm{C}$. At $600{ }^{\circ} \mathrm{C}$, the retained modulus of elasticity of the grade A325 and A490 bolt materials were on average, $24.3 \%$ and $17.2 \%$, respectively, of their ambienttemperature values. Despite the obvious scatter in the modulus of elasticity data, particularly for the tests at $400{ }^{\circ} \mathrm{C}$, both the fitted retained modulus of elasticity curves for two bolt materials are barely distinguishable from one another. The close proximity of these two curves indicates that the bolt grade does not significantly influence the modulus of elasticity, even at elevated temperatures. Fig. 4-13(b) shows the fit of Eq. (4-13) to the aggregated bolt modulus of elasticity data for both the grade A325 and A490 bolt materials, with the fitted coefficients and their $95 \%$ confidence bounds shown in the textbox. 


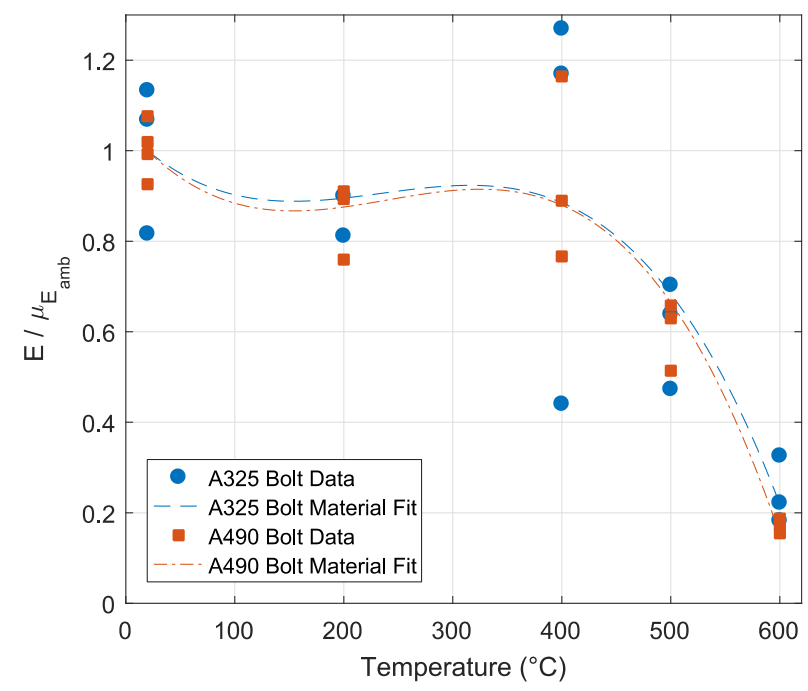

(a)

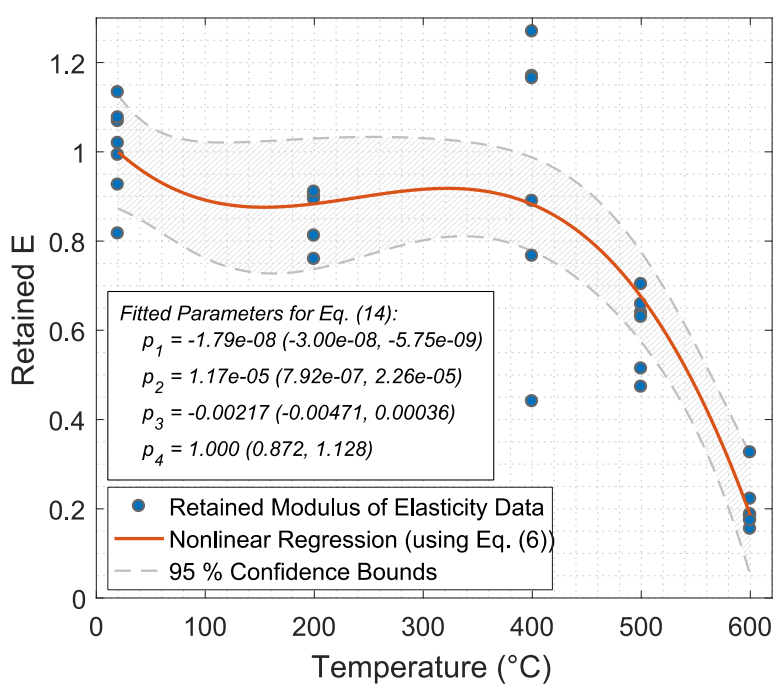

(b)

Figure 4-13: (a) comparison of individually fitted retained modulus of elasticity curves for 25 mm (1 in) diameter grade A325 and A490 bolts and (b) aggregated modulus of elasticity, fitted using Eq. (4-14).

It was previously noted that the shape parameter $n$ had relatively little influence on the calculated capacity of the bolts. The shape parameter likewise has relatively little influence on the initial response of the bolt load-deformation behavior, before appreciable plastic deformations have occurred. To simplify the formulation of the consolidated component-based model, the shape parameter is approximated as a constant value over all temperatures, and is calculated as the average of the consolidated shape parameter data from both the grade A325 and A490 bolts (Fig. 414(a)). A similar strategy is adopted for the ratio of the plastic stiffness to the initial stiffness (Fig. 4-14(b)). Use of average values for the shape parameter and stiffness ratio reduces the dependence of the component-based model on temperature. The consolidated simplified component-based model depends only the temperature-dependent retained ultimate tensile strength and the temperature-dependent retained modulus of elasticity. 


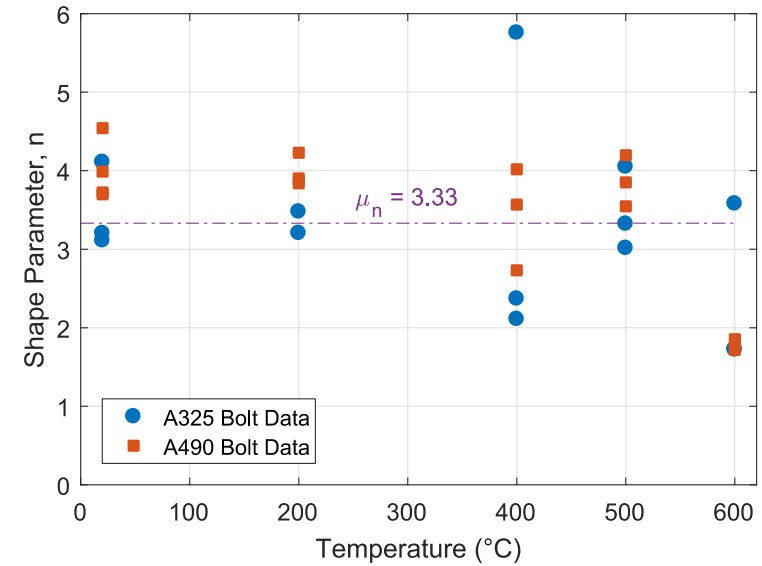

(a)

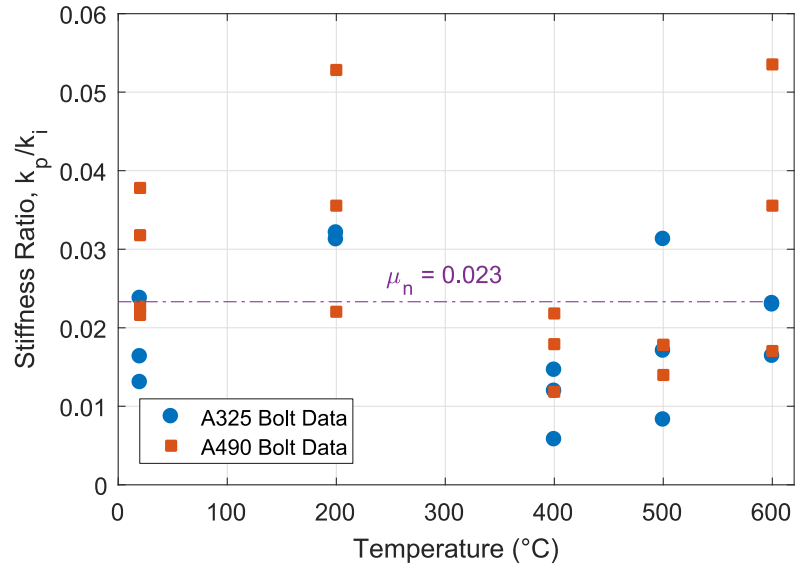

(b)

Figure 4-14: Aggregated 25 mm (1 in) diameter grade A325 and A490 bolt data for (a) shape parameter, and (b) ratio of plastic stiffness to initial stiffness.

Fig. 4-15 shows the predicted bolt double-shear load-deformation behavior from the consolidated component-based model, using the fitted curves to the retained ultimate tensile strength (Fig. 412(b)), retained modulus of elasticity (Fig. 4-13(b)), average shape parameter (Fig. 4-14(a)), and average stiffness ratio (Fig. 4-14(b)). Comparison of Fig. 4-10 using the individually fitted parameters for grade A325 and A490 bolt steels and Fig. 4-15 using the consolidated ultimate tensile strength and modulus of elasticity data, and average values for the shape parameter results in only a slight loss of accuracy with respected to the measured bolt double-shear load-deformation responses. Even when using the simplified component-based model, the predicted response is still typically within the area bounded by the responses of the nominally identical tests. Where the simplified component-based model does predict loads outside the variation between nominal identical tests is typically only at the peak bolt deformation, where the predicted response differs from the nearest experimental response by a maximum of $6.5 \%$ for the grade A325 bolts and $8.4 \%$ for the grade A490 bolts. 


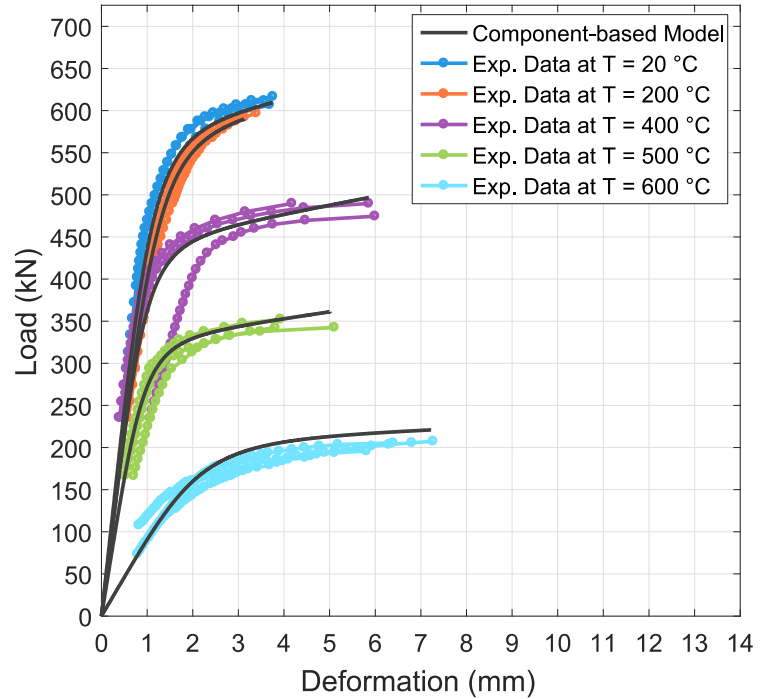

(a)

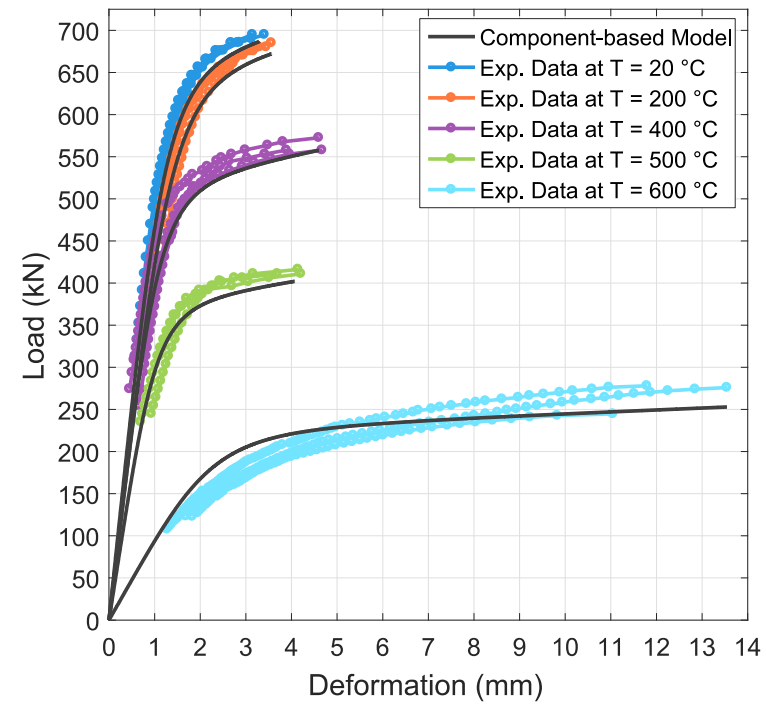

(b)

Figure 4-15: Fitted shape parameter for $25 \mathrm{~mm}$ (1 in) diameter (a) A325 bolts and (b) A490 bolts. Hatched area corresponds to $95 \%$ confidence interval.

\subsection{ASSUMPTIONS AND LIMITATIONS}

The component-based modeling approach presented in this chapter assumed that the deformations in the loading and reaction blocks are sufficiently small to be neglected, and that deformations are concentrated in the bolt in the vicinity of the lapped joints. Since only a small portion (less than $1 \%$ up to the $600{ }^{\circ} \mathrm{C}$ tests) of the deformations went into the loading block and reaction blocks, the approximation of using rigid blocks is reasonable for modeling the $25 \mathrm{~mm}$ ( 1 in) diameter bolt tests reported in Chapter 2. However, this assumption would almost certainly not be valid for modeling realistic configurations of e.g., steel single-plate shear connections, which have plates that are not heat-treated and thicknesses typically on the order of one-half of the bolt diameter. To accurately model connection behavior at elevated temperatures, the model for temperaturedependent bolt behavior of the bolt presented in this paper would need to interact with additional temperature-dependent plate component springs that capture the temperature-dependent frictionslip and bearing behaviors. The presented modeling approach also implicitly assumes, by using the same deformation capacities for the three bolt diameters, that the deformation capacities of the bolts are relatively insensitive to their diameter, at least within the tested range of diameters between $19 \mathrm{~mm}$ (3/4 in) to $25 \mathrm{~mm}(1 \mathrm{in})$. 


\subsection{SUMMARY}

This paper has described the development of a semi-empirical component-based modeling approach for the shear behavior of high-strength bolts at elevated temperatures developed based on the behavior observed in the experimental results. The component-based model separately covers both ASTM A325 and ASTM A490 high-strength bolt materials, and is capable of capturing temperature-induced degradation in both the bolt shear strength and stiffness. A more simplified, consolidated version of the component-based modeling approach was also presented, which predicted the bolt double-shear load deformation response using only the bolt materials' retained ultimate tensile strength and modulus of elasticity. The more simplified model was shown to predict the double-shear load of the bolt within $8.4 \%$ over the full range of tested temperatures from $20^{\circ} \mathrm{C}$ to $600{ }^{\circ} \mathrm{C}$.

The degradation in the ultimate tensile strength of the bolt materials with increasing temperature was characterized using the degradation in the bolt double-shear strength. The estimated values for the bolt steel ultimate tensile strength at ambient temperature, based on the bolt double-shear capacities, were shown to be within $6 \%$ and $1 \%$ of the measured ultimate tensile strengths for the A325 and A490 bolts measured using tensile bolt-coupon testing. The other aspects of the bolt double-shear response were characterized by fitting a four-parameter nonlinear equation to the experimental shear load-displacement data for each bolt-test. Results showed that the developed model accurately captures the temperature-induced degradation in bolt shear strength and stiffness of the high-strength bolts at elevated temperatures under shear loading. In comparison to the $25 \mathrm{~mm}$ ( 1 in) diameter bolt data, the accuracy of the model was within the experimental uncertainty between replicate tests.

While the formulation for the bolt load-deformation response was developed based solely on the data from the $25 \mathrm{~mm}$ ( $1 \mathrm{in}$ ) diameter bolts, application of the modeling approach to data from the $19 \mathrm{~mm}$ (3/4 in) and $19 \mathrm{~mm}$ (3/4 in) diameter bolts from Peixoto et al. (2017) demonstrated the model's predictive capabilities. Results showed that the model predicted the double-shear capacities of the $19 \mathrm{~mm}(3 / 4 \mathrm{in})$ and $22 \mathrm{~mm}$ (7/8 in) bolts within $10 \%$ for each tested bolt, and within an average percent difference of less than $4 \%$ across the full range of tested temperatures for each combination of bolt diameter and grade. Results also showed that the percent difference between the predicted bolt double-shear capacity and the measured bolt double-shear capacity tended to increase with increasing temperature. 
This page intentionally left blank. 


\section{Chapter 5 \\ SUMMARY AND FUTURE WORK}

\section{$5.1 \quad$ INTRODUCTION}

This report presented the behavior of high-strength structural bolts at elevated temperatures. It presented the experimental results of bolts with different strengths, and different diameters, tested at different elevated temperatures. It also showed how the experimental results were used to develop component-based reduced-order computationally-efficient models that are capable capturing the bolts behavior. Summaries of the main aspects of this work, along with the key conclusions are presented herein:

\section{$5.2 \quad$ SUMMARY}

\subsubsection{Experimental Study}

Results were presented from tests conducted on high-strength structural bolts subject to doubleshear loading at elevated temperatures. The parameters varied between tests included the bolt grade, bolt diameter, and temperature. Bolt grades A325 and A490 were tested. For each bolt grade, three different diameters were tested (19 mm (3/4 in), $22 \mathrm{~mm}$ (7/8 in), and $25.4 \mathrm{~mm}$ (1 in)) at five different temperatures $\left(20^{\circ} \mathrm{C}, 200^{\circ} \mathrm{C}, 400{ }^{\circ} \mathrm{C}, 500^{\circ} \mathrm{C}\right.$, and $\left.600{ }^{\circ} \mathrm{C}\right)$. At least three tests were conducted for each combination of parameters. Degradations in the mechanical and material properties including stiffness, strength, and deformation at fracture, were characterized and presented. The results facilitated a more complete understanding of the behavior of high-strength structural bolts under shear loading at elevated temperatures, thus filled a critical gap in the literature.

Results showed that up to $200^{\circ} \mathrm{C}$, the bolts do not lose their shear strength if compared to ambient temperature, however, the deformation is higher. As the temperature increases, the shear strength gradually decreases. Under $400{ }^{\circ} \mathrm{C}$, the bolts held approximately $82 \%$ of their initial strength. At $500{ }^{\circ} \mathrm{C}$, the $\mathrm{A} 325$ and $\mathrm{A} 490$ bolts both held about $60 \%$ of the initial shear strength. At $600{ }^{\circ} \mathrm{C}$, the bolts were down to about $35 \%$ of their initial resistance. 


\subsubsection{Corrected Data}

A procedure was developed and used to remove the effects of initial bearing deformation from the bolt double-shear force-deformation data. By removing these initial deformations, the bolt doubleshear behavior is uncoupled from the flexure behavior, caused by the initial bearing deformations of the testing blocks. The initial bearing deformations were especially significant in the data from the $19 \mathrm{~mm}(3 / 4 \mathrm{in})$ and the $22 \mathrm{~mm}$ (7/8 in) diameter bolts).

\subsubsection{Component-Based Modeling Approach}

A semi-empirical component-based modeling approach for the shear behavior of high-strength bolts at elevated temperatures was developed based on the behavior observed in the experimental results. The component-based model separately covers both ASTM A325 and ASTM A490 highstrength bolt materials, and is capable of capturing temperature-induced degradation in both the bolt shear strength and stiffness. A more simplified, consolidated version of the component-based modeling approach was also presented, which predicted the bolt double-shear load deformation response using only the bolt materials' retained ultimate tensile strength and modulus of elasticity. The more simplified model was shown to predict the double-shear load of the bolt within $8.4 \%$ over the full range of tested temperatures from $20^{\circ} \mathrm{C}$ to $600{ }^{\circ} \mathrm{C}$.

The degradation in the ultimate tensile strength of the bolt materials with increasing temperature was characterized using the degradation in the bolt double-shear strength. The estimated values for the bolt steel ultimate tensile strength at ambient temperature, based on the bolt double-shear capacities, were shown to be within $6 \%$ and $1 \%$ of the measured ultimate tensile strengths for the A325 and A490 bolts measured using tensile bolt-coupon testing. The other aspects of the bolt double-shear response were characterized by fitting a four-parameter nonlinear equation to the experimental shear load-displacement data for each bolt-test. Results showed that the developed model accurately captures the temperature-induced degradation in bolt shear strength and stiffness of the high-strength bolts at elevated temperatures under shear loading. In comparison to the $25 \mathrm{~mm}$ ( $1 \mathrm{in}$ ) diameter bolt data, the accuracy of the model was within the experimental uncertainty between replicate tests.

While the formulation for the bolt load-deformation response was developed based solely on the data from the $25 \mathrm{~mm}$ ( $1 \mathrm{in})$ diameter bolts, application of the modeling approach to data from the $19 \mathrm{~mm}$ (3/4 in) and $19 \mathrm{~mm}$ (3/4 in) diameter bolts demonstrated the model's predictive capabilities. Results showed that the model predicted the double-shear capacities of the $19 \mathrm{~mm}$ (3/4 in) and $22 \mathrm{~mm}(7 / 8 \mathrm{in})$ bolts within $10 \%$ for each tested bolt, and within an average percent difference of less than $4 \%$ across the full range of tested temperatures for each combination of bolt diameter and grade. Results also showed that the percent difference between the predicted bolt 
double-shear capacity and the measured bolt double-shear capacity tended to increase with increasing temperature.

\subsection{FUTURE WORK}

It is noted that the development of a new temperature-dependent material model for high-strength bolts at elevated temperatures is currently underway. The model uses the experimental data presented herein to create tensile stress-strain curves that are capable of capturing the behavior observed during the experiments when implemented in high-fidelity finite element analysis. 
This page intentionally left blank. 


\section{REFERENCES}

AISC (2010). "Specification for structural steel buildings," Specification ANSI/AISC 360-10, American Institute of Steel Construction (AISC), One East Wacker Drive, Suite 700, Chicago, IL 60601-1802.

ASTM International (2011a). "Standard specification for structural steel shapes". Standard A992/A992M-11, ASTM International, W. Conshohocken, Pa. doi:10.1520/ A0992_A0992M-11.

ASTM International. (2011b). "Standard Test Methods for Determination of Carbon, Sulfur, Nitrogen, and Oxygen in Steel, Iron, Nickel, and Cobalt Alloys by Various Combustion and Fusion Techniques." ASTM E1019-11, West Conshohocken, PA, DOI: 10.1520/E1019-11

ASTM International. (2013a), "Standard Specification for High-Strength Low-Alloy ColumbiumVanadium Structural Steel." Standard A572/A572M-13a, ASTM International, West Conshohocken, PA. DOI: 10.1520/A0572_A0572M.

ASTM International. (2013b). "Standard Specification for Steel Bars, Alloy, Standard Grades." ASTM A322-13, West Conshohocken, PA. DOI: 10.1520/A0322

ASTM International. (2014a). "Standard Specification for Carbon Structural Steel." ASTM A36/A36M-12, West Conshohocken, PA. DOI: 10.1520/A0036_A0036M-14

ASTM, Standard Specification for High-Strength Steel Bolts, Classes 10.9 and 10.3, for Structural Steel Joints (Metric), American Society for Testing and Materials (ASTM) International, West Conshohocken, PA, 2014b.

ASTM International. (2015). " Standard Specification for High Strength Structural Bolts, Steel and Alloy Steel, Heat Treated, $120 \mathrm{ksi}$ (830 MPa) and $150 \mathrm{ksi}$ (1040 MPa) Minimum Tensile Strength, Inch and Metric Dimensions." ASTM F3125/F3125M-15a, West Conshohocken, PA. DOI: 10.1520/F3125_F3125M-15A.

ASTM International. (2017). "Standard Test Method for Analysis of Carbon and Low-Alloy Steel by Spark Atomic Emission Spectrometry." ASTM E415-17, West Conshohocken, PA, DOI: $10.1520 / \mathrm{E} 0415-17$

Crocker, J. and Chambers, J. (2004), Single plate shear connection response to rotation demands imposed by frames undergoing cyclic lateral displacements, Journal of Structural Engineering 130 (6), pp. 934-941.

European Committee for Standardization (2005). Eurocode 3: Design of Steel Structure, Part 1-2: General Rules - Structural Fire Design. (EN 1993-1-2: 2005) 
Fischer, E. C., Varma, A. H., and Zhu, Q. (2016). "Behavior of Single-Bolted Lap-Splice Joints at Elevated Temperatures." Proceedings of the Eighth International Workshop on Connections in Steel Structures (Connections VIII), Boston, MA, 2016.

Gowda, B. C. (1978). "Tensile properties of SA516, grade 55 steel in the temperature range of $25^{\circ} \mathrm{C}-927^{\circ} \mathrm{C}$ and strain rate range of $10^{-4}$ to $10^{-1} \mathrm{sec}^{-1}$,, 1978 ASME/CSME Montreal Pressure Vessel \& Piping Conference, Montreal, Quebec, Canada.

Hsieh, S. H. and Deierlein, G. G. (1990). "Nonlinear Analysis of Three-Dimensional Steel Frames with Semi-Rigid Connections." Computers \& Structures, 41(5), pp. 995-1009.

Hu, G., Morovat, M. A., Lee, J., Schell, E., and Engelhardt, M. (2009), "Performance of Steel Shear Tab Connections at Elevated Temperatures." Proceedings of the ASCE/SEI Structures Congress, Austin, Texas, pp. 1067-1076.

Kodur, V., Kand, S., and Khaliq, W. (2012). "Effect of Temperature on Thermal and Mechanical Properties of Steel Bolts.” Journal of Materials in Civil Engineering, 24(6), pp. 765-774.

Luecke, W. E., McColskey, J. D., McCowan, C. N., Banovic, S. W., Fields, R. J., Foecke , T., Siewert, T. A., and Gayle, F. W. (2005), "Robustness of Steel Gravity Frame Systems with Single-Plate Shear Connections", NIST Technical Note NIST-TN-1749, National Institute of Standards and Technology, United States Department of Commerce, 2005.

MathWorks (2016a), MATLAB Global Optimization Toolbox User's Guide, Version 3.4.1 (R2016b), The MathWorks, Inc., Natick, Massachusetts, United States, 2016.

MathWorks (2016b), MATLAB Curve Fitting Toolbox User's Guide, Version 3.4.1 (R2016b), The MathWorks, Inc., Natick, Massachusetts, United States, 2016.

Nelson, W. D., Bunin, B. L., and Hart-Smith, L. J. (1983). "Critical Joints in Large Composite Aircraft Structure”, Tech. Rep. NASA Contractor Report 3710, Douglas Aircraft Company, McDonnell Douglas Corporation, 1983.

Peixoto, R. M., Seif, M. S., and Viera, L. C. (2017). "Double-shear tests of high-strength structural bolts at elevated temperatures." Fire Safety Journal. In review.

Richard, R. M., Abbott, B. J. (1975). “Versatile Elastic-Plastic Stress-Strain Formulation”, Journal of the Engineering Mechanics 101, (EM4), pp. 511-515.

Seif, M.S., Main, J.A., McAllister, T.P. (2013) "Performance of Steel Shear Tab Connections at Elevated Temperatures." Proceedings of the Annual Stability Conference, Structural Stability Research Council, St. Louis, Missouri, April 16-20, 2013.

Seif, M., McAllister, T., Main, J., Luecke, W. (2016a). "Modeling of moment connections for structural fire analyses." AISC, Engineering Journal, Quarter 1, Volume 53, Issue 1, January 2016, Pages 47-60. 
Seif, M., Main, J., Weigand, J., McAllister, T, Luecke, W. (2016b) "Finite element modeling of structural steel component failure at elevated temperatures." Elsevier, Structures, Volume 6, March 2016, pages 134-145. (dx.doi.org/10.1016/j.istruc.2016.03.002)

Seif, M., Choe, L., Main, J.A., Zhang, C., Weigand, J., Gross, J., Sadek, F., McColskey, D., and Luecke, W. (2016c). "Temperature-Dependent Material Modeling for Structural Steels: Formulation and Application". NIST Technical Note TN-1907, National Institute of Standards and Technology, Gaithersburg, MD. (dx.doi.org/10.6028/NIST.TN.1907)

Taylor, B. N., and Kuyatt, C. E. (1994). "Guidelines for Evaluating and Expressing the Uncertainty of NIST Measurement Results." NIST Technical Note TN-1297, Gaithersburg, MD.

Thomas, D. L., Wilson, J. M., and Wilson, R. R. (1973). “Timoshenko Beam Finite Elements." Journal of Sound and Vibration, 31(3), pp. 315-330.

Ugray, Z., Lasdon, L., Plummer, J., Glover, F., Kelly, J., and Marti, R. (2007), "Scatter Search and Local NLP Solvers: A Multistart Framework for Global Optimization”, INFORMS Journal on Computing, 19(3), pp. 328-340.

Weigand, J.M. (2016) "Component-Based Model for Single-Plate Shear Connections with Pretension and Pinched Hysteresis", Journal of Structural Engineering, 143(2), pp. 04016178.

Weigand, J. M. (2014). "The Integrity of Steel Gravity Framing System Connections Subjected to Column Removal Loading." Ph.D. Dissertation in Civil Engineering, University of Washington, Seattle, WA, 2014.

Weigand, J. M. and Berman, J. W. (2014), "Integrity of Steel Single Plate Shear Connections Subjected to Simulated Column Removal”, Journal of Structural Engineering, 140(5), pp. 04013114.

Weigand, J. M., Peixoto, R., Vieira, L., Main, J. and Seif, M. (2017) “An Empirical ComponentBased Model for Shear Behavior of High-Strength Bolts at Elevated Temperatures." Journal of Constructional Steel Research. (Submitted).

Yu, L. (2006), "Behavior of Bolted Connections During and After a Fire.", Ph.D. Dissertation in the Department of Civil, Architectural and Environmental Engineering, The University of Texas at Austin, Austin, TX, 2006. 
